NBER WORKING PAPER SERIES

\title{
UNEMPLOYMENT BENEFITS AND UNEMPLOYMENT IN THE GREAT RECESSION: THE ROLE OF MACRO EFFECTS
}

\author{
Marcus Hagedorn \\ Fatih Karahan \\ Iourii Manovskii \\ Kurt Mitman \\ Working Paper 19499 \\ http://www.nber.org/papers/w19499 \\ NATIONAL BUREAU OF ECONOMIC RESEARCH \\ 1050 Massachusetts Avenue \\ Cambridge, MA 02138 \\ October 2013
}

We would like to thank Bob Hall, Sam Schulhofer-Wohl and seminar participants at Census Bureau, Edinburgh, EIEF, USC, Maryland, Penn State, UPenn, Princeton, Pompeu Fabra, Toulouse, UCL, UConn, Wisconsin, CUNY Graduate Center, Greater Stockholm Macro Group, Federal Reserve Banks of Cleveland, New York, and Philadelphia, 2013 conference on Macroeconomics Across Time and Space, 2013 SED, 2013 NBER Summer Institute (EFCE, EFMB, EFRSW groups), 2013 North American Summer Meeting of Econometric Society, 2013 Minnesota Workshop in Macroeconomic Theory, 15th IZA/CEPR European Summer Symposium on Labor Economics, Mannheim conference on IFinancial Frictions and Real Economy," 4th Ifo Conference on "Macroeconomics and Survey Data", 2014 ASSA Meetings, 2014 NBER Public Economics Program Meeting and 2014 Cowles Foundation Summer Conference on IStructural Empirical Microeconomic Models" for their comments. We are especially grateful to June Shelp, at The Conference Board, for her help with the HWOL data. The opinions expressed herein are those of the authors and not necessarily those of the Federal Reserve Bank of New York or the Federal Reserve System. Support from the National Science Foundation Grants No. SES-0922406 and SES-1357903 is gratefully acknowledged. The opinions expressed herein are those of the authors and not necessarily those of the Federal Reserve Bank of New York, the Federal Reserve System, or the National Bureau of Economic Research.

NBER working papers are circulated for discussion and comment purposes. They have not been peer-reviewed or been subject to the review by the NBER Board of Directors that accompanies official NBER publications.

(C) 2013 by Marcus Hagedorn, Fatih Karahan, Iourii Manovskii, and Kurt Mitman. All rights reserved. Short sections of text, not to exceed two paragraphs, may be quoted without explicit permission provided that full credit, including (C) notice, is given to the source. 
Unemployment Benefits and Unemployment in the Great Recession: The Role of Macro Effects Marcus Hagedorn, Fatih Karahan, Iourii Manovskii, and Kurt Mitman

NBER Working Paper No. 19499

October 2013, Revised May 2016

JEL No. E24,J63,J64,J65

\section{ABSTRACT}

Equilibrium labor market theory suggests that unemployment benefit extensions affect unemployment by impacting both job search decisions by the unemployed and job creation decisions by employers. The existing empirical literature focused on the former effect only. We develop a new methodology necessary to incorporate the measurement of the latter effect. Implementing this methodology in the data, we find that benefit extensions raise equilibrium wages and lead to a sharp contraction in vacancy creation, employment, and a rise in unemployment.

Marcus Hagedorn

Department of Economics, University of Oslo,

Box 1095 Blindern, 0317 Oslo, Norway

marcus.hagedorn@econ.uio.no

Fatih Karahan

Federal Reserve Bank of New York

33 Liberty Street

New York, NY 10045

yfkarahan@gmail.com
Iourii Manovskii

Department of Economics

University of Pennsylvania

160 McNeil Building

3718 Locust Walk

Philadelphia, PA 19104

and NBER

manovski@econ.upenn.edu

Kurt Mitman

Institute for International Economic Studies

Stockholm University

10691 Stockholm

SWEDEN

kurt.mitman@iies.su.se 


\section{Introduction}

Unemployment in the U.S. rose dramatically during the Great Recession and remained at an unusually high level for a long time. The policy response to the initial rise in unemployment during the financial crisis involved an unprecedented extension of unemployment benefits with benefit duration rising from the usual 26 weeks to as long as 99 weeks. The motivation for this policy was to provide "income support for a vulnerable group after they have lost their jobs through no fault of their own" as well as "needed support for the fragile economy." 1

The effectiveness of this policy response was questioned by Barro (2010) and Mulligan (2012), among others. These researchers pointed out that the fact that unemployment benefit extensions represent an implicit tax on market work may offset some of the stimulative effect ascribed to such policies and help explain the persistence of high unemployment even after the end of the Great Recession. Recent careful microeconometric studies have challenged this argument by documenting only small effects of unemployment benefit extensions on labor supply. The methodology underlying the existing empirical research, however, does not allow for a complete evaluation of the effects of unemployment benefit extensions because it excludes the possibility that this policy could also impact labor demand. We develop a novel measurement methodology required to incorporate this effect and attempt to provide a more complete empirical assessment of the labor market implications of this policy response.

The following stylized decomposition helps illustrate the two margins:

$$
\text { Job finding rate } i t=\underbrace{s_{i t}}_{\text {search intensity }} \times \underbrace{f\left(\theta_{t}\right)}_{\text {finding rate per unit of } s}
$$

In other words, the probability that an individual $i$ finds a job at time $t$ depends on how hard that individual searches and how selective he is in his acceptance decisions, which is captured by the "search effort" component $s_{i t}$. It also depends on the aggregate labor market conditions $\theta_{t}$ that determine how easy it is to locate jobs by expending a unit of search effort. To use an extreme example, if there are no job vacancies created by employers, $f\left(\theta_{t}\right)=0$, no amount of search effort by an unemployed worker would yield a positive probability of obtaining a job.

Changes in unemployment benefit policies affect both the search intensity of unemployed workers - the micro effect, and the aggregate job finding rate per unit of search effort through general equilibrium macro effects. Indeed, in the classic equilibrium search framework of Mortensen and Pissarides (1994), the primary analytical device used by economists to study the determination of unemployment, the response of unemployment to changes in benefits is mainly driven by the response of employers' decisions of whether and how many jobs to create

\footnotetext{
1 "Unemployment Insurance Extensions and Reforms in the American Jobs Act," the report by the President's Council of Economic Advisers, the National Economic Council, the Domestic Policy Council, and the Department of Labor, December 2011.
} 
and not by the impact on workers' job search and acceptance decisions. The logic of the model is simple. Everything else equal, extending unemployment benefits exerts an upward pressure on the equilibrium wage. This lowers the profits employers receive from filled jobs, leading to a decline in vacancy creation. Lower vacancies imply a lower job finding rate for workers, which leads to an increase in unemployment.

Starting with the pioneering work of Millard and Mortensen (1997) and Shi and Wen (1999), the evidence on the magnitude of these equilibrium effects is predominantly based on the estimation of structural models based on Mortensen and Pissarides (1994). ${ }^{2}$ For example, a structural analysis based on this model in Krause and Uhlig (2012) reveals a large reduction in unemployment and increase in vacancy creation due to the benefit duration cut (known as Hartz IV reform) in Germany. The firm's vacancy creation decision in this model is based on comparing the cost of creating a job to the profits the firm expects to obtain from hiring the worker. The profit is defined as the difference between a worker's productivity and the wage. Costain and Reiter (2008), Hagedorn and Manovskii (2008) and Ljungqvist and Sargent (2015) have shown that if profits are relatively small, changes in unemployment benefit policies that affect wages can have a large percentage impact on profits, implying a large response of vacancies, and, as a consequence, of unemployment. The key parameter determining the size of profits in the model is the flow utility obtained by unemployed workers. This parameter is notoriously difficult to measure directly but its value is crucial for the magnitude of policy effects delivered by the search model. Our objective in this paper is to directly measure the impact of unemployment benefits on the labor market variables of interest without having to rely on the estimate of the flow utility of the unemployed and without having to fully specify the model. The empirical strategy we develop is, however, consistent with a fully specified model.

Incorporating the measurement of the the macro effect in a policy evaluation requires us to develop a novel empirical methodology. The primary reason is that the macro effect measures the impact of policy on firms' forward looking decisions to create jobs, which, like any investment decisions, are affected not only by the existing policy but also by the expectation of possible future policy changes. As a result, the full expected sequence of future benefit durations in addition to the contemporaneous benefit policy affects current job creation.

The important role of expectations can be seen directly in the data as illustrated in Figures 1 and 2. The key feature of the U.S. unemployment insurance system is that unemployment insurance policies are determined at the state level and apply to all locations within a state. Using our data and sample described below, Panel 1(a) plots the estimated coefficients from a regression of log state unemployment in quarter $t$ on the log of contemporaneous benefit

\footnotetext{
${ }^{2}$ One line of research has studied the effects of unemployment benefits on unemployment using cross-country regressions. While this literature typically finds much larger effects than those implied by the micro studies, these estimates are relatively hard to interpret given the endogeneity problems and heterogeneity across countries that is difficult to control for.
} 


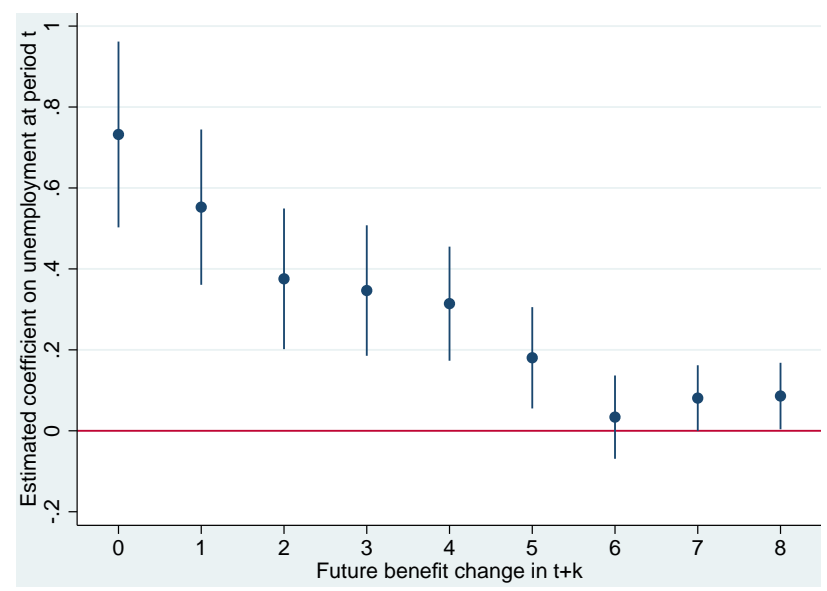

(a) States

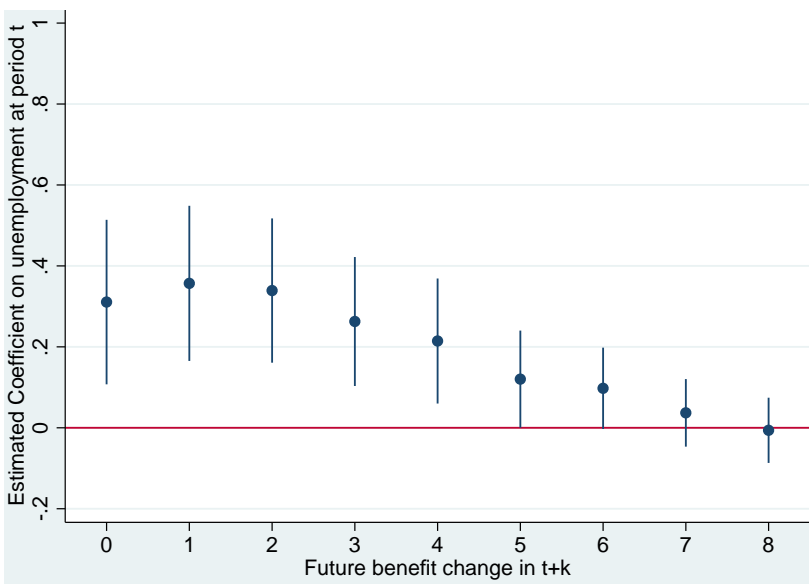

(b) Border counties

Figure 1: The Impact of Future Unemployment Benefit Durations on Current Unemployment.

duration and changes in log benefit duration over the next eight quarters (the regression includes fixed state and time effects). We observe that current unemployment is significantly positively related to future changes in benefit duration. State-level evidence does not isolate the effect of expectations, however, because it also reflects the endogeneity of benefits: benefit duration tends to rise in response to past increases in unemployment at the state level. The same endogeneity problem implies that one cannot infer the effects of benefit extensions by simply relating benefit duration to unemployment in a panel of states.

We show formally below, however, that the endogeneity problem can be overcome by exploiting a policy discontinuity at state borders and comparing the evolution of unemployment in counties that border each other but belong to different states. ${ }^{3}$ Locations separated by a state border share the same geography, climate, access to transportation, agglomeration benefits, access to specialized labor and supplies, etc. Indeed, we provide direct evidence that economic shocks do not stop at the state border but evolve smoothly across borders. The key feature that sets these locations apart is the difference in policies on the two sides of the border. This policy discontinuity allows to identify its labor market implications. ${ }^{4}$

This insight implies that the effects of expectations can be isolated using a similar regression but with all variables differenced between bordering counties (unemployment is now measured at the county level and the regression includes fixed effects for each border county pair). We observe that eliminating the endogeneity problem plaguing the state-level analysis indeed leads to a substantial reduction of estimated coefficients plotted in Panel 1(b) relative to Panel 1(a). Nevertheless, current unemployment at the county level continues to respond significantly to future state-level benefit changes.

\footnotetext{
${ }^{3}$ A Map of U.S. state and county borders can be found in Appendix Figure A-3.

${ }^{4}$ A fundamentally similar identification strategy was used, among others, by Holmes (1998) to identify the impact of right-to-work laws on location of manufacturing industry and by Dube et al. (2010) to identify the effect of minimum wage laws on earnings and employment of low-wage workers.
} 
The presence of significant expectation effects implies an empirical analysis which fails to account for firms' expectations would measure an uninterpretable mixture of the true policy effect and of the unknown effect of labor market participants' expectations of future policies. To address this problem, we derive a quasi-difference estimator of the effect of unemployment insurance policies on variables such as vacancies and unemployment that controls for the effect of expectations (we verify the successful performance of this estimator in data generated by an estimated equilibrium search model in Section 5, validate the methodology using direct evidence in Section 4.2 and by applying it to placebo policy changes in Section 4.3). Having isolated the effect of the current policy, our estimator allows us to generalize our findings and estimate the effect of temporary or permanent changes in unemployment benefit duration.

A simple example might be helpful in illustrating why this methodological advancement is necessary. Consider two otherwise identical states, one which passes a law extending benefits by 20 weeks for one year, and the other which extends benefits by 10 weeks permanently. Our estimates imply that in the state with the temporary extension, unemployment would increase 0.5 percentage points, whereas in the state with the permanent extension unemployment would increase by 0.8 percentage points. The effect is higher in the state with the permanent change because firms expect that profits at all future dates will be lower because of the extension, whereas in the state with the temporary change, firms expect profits to be lower for one year only. A naive difference-in-differences analysis would erroneously suggest a significant negative impact of unemployment benefits on unemployment. Moreover, if employers anticipated these policy changes, say a year in advance, virtually all the adjustment of job creation (and of unemployment in a standard search model) would have occurred prior to the actual change in policy. Indeed, the basic optimality of firms' decisions implies no discrete jumps in vacancy posting at the time that expected policy changes are implemented. Thus, an observer may conclude that unemployment and vacancies are not related to benefits because they change dramatically when benefits do not and do not change when benefits change. It is only by controlling for the movements induced by the changes in expectations that the correct magnitude of the macro effect can be identified. ${ }^{5}$

Using the quasi-difference estimator, we can confirm that significant effects of future policies identified using border county comparisons in Figure 1(b) are indeed due to expectations. Specifically, in Figure 2 we plot estimates from the same regression with the dependent variable being the difference in quasi-differenced unemployment between border counties. Quasi-differencing eliminates the effects of expectations and we observe that indeed, when expectations are controlled for, the difference in current unemployment between border counties is independent of future benefit durations. Note that the flip-side of Figure 2 is that the differences in past quasi-

\footnotetext{
${ }^{5}$ Clearly, the empirical strategy based on comparing border counties requires controlling for expectations of future policy changes not only in the "treated" county but also in the other "control" county.
} 


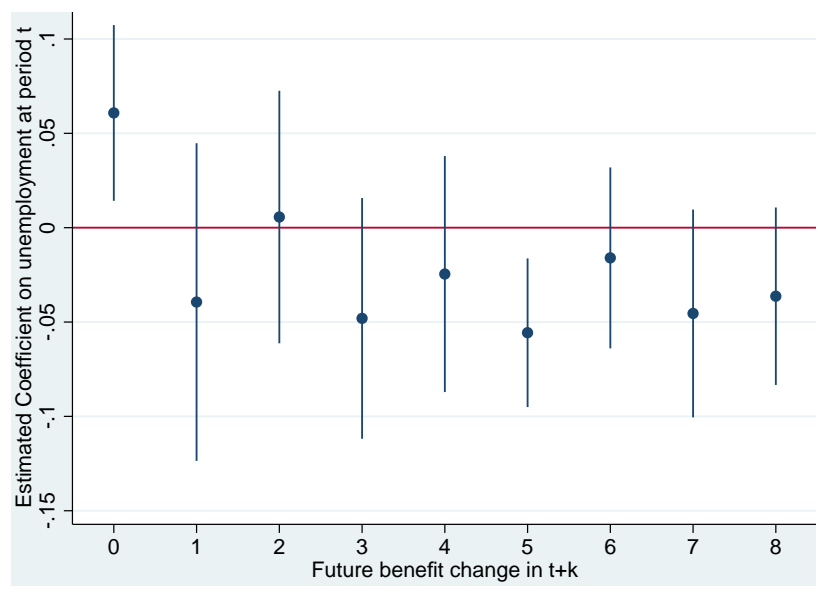

Figure 2: Difference of Quasi-Differenced Unemployment between Border Counties.

differenced unemployment between border counties do not predict changes in current benefit duration, implying the absence of a pre-existing trend. We can therefore be confident that the increase in quasi-differenced unemployment is not the continuation of a pretrend (which at the same time causes the benefit increase) but instead is the causal consequence of the increase in benefits.

As a further validation of our methodology we also use future benefits directly to compute the response of unemployment to changes in unemployment insurance generosity. We find that both the measurement using direct evidence on future policy changes and our quasi-differenced estimator which uses current policy only deliver the same answer, implying first, that future expected policy changes affect current choices and second, that our estimator controls for those expectations very well.

While the paper is motivated by specific empirical questions, it seems worth noting that the methodological advance we propose is applicable much more generally. In particular, a version of a quasi-differenced estimator that we develop can be used in any empirical analysis where expectations of future policies affect current decisions. This applies to virtually all investment decision, including investment in physical capital. As another example, in sticky price New Keynesian models firms' pricing decisions depend on the expected path of current and future marginal costs, potentially affected by future policies. In this environment, Hagedorn et al. (2015a) show that a quasi-differenced inflation can be used to control for expectations and measure the impact of fiscal policies on current marginal costs to reveal their stimulative effect.

Our second methodological innovation provides a more flexible and general model of county level trends that leads to a more precise estimate of the effects of benefit duration relative to a fixed effects regression. This extra flexibility is necessitated by the fact that our estimation is based on a panel of border counties over the period of the Great Recession. Numerous shocks and policy changes have affected the aggregate economy but their impact was likely heterogeneous across county pairs. For example, shocks to and changing regulations of the financial system, 
while aggregate in nature, might have had a particularly strong impact on the counties on the border of New York and New Jersey, while the auto industry bailout likely had a larger impact on counties surrounding the border between Michigan and Indiana or Ohio. Similarly, the aggregate financial crisis potentially had a different impact on states depending on their different foreclosure laws. To obtain consistent estimates of the effect of unemployment benefit extensions despite heterogeneous impacts of the aggregate shocks we follow Bai (2009) and use a flexible interactive effects model. This approach provides a natural way to control for the observed and unobserved spatial heterogeneity and allows for a very flexible model of the county-level trends in variables.

Following the description in Section 3 of our main data sources, we measure the effects of unemployment benefit extensions on unemployment in Section 4. We find that unemployment is significantly higher in the border counties belonging to the states that expanded unemployment benefit duration as compared to the counties just across the state border. The quantitative magnitude of this effect is so large that our estimates attribute a prominent role to benefit extensions in accounting for the persistence of high unemployment following the end of the Great Recession in 2009. It is important to note that our estimates do not imply that the large increase in unemployment at the onset of the Great Recession was due to extensions of unemployment benefits. However, we do find that the extensions of benefits contributed significantly to the slow decline of unemployment thereafter. For example, assuming perfect foresight of future benefits, our estimates imply that unemployment in 2011 would have been 2 percentage points lower had benefits not been extended. While our estimates are undoubtedly large, they are smaller than consensus estimates in the existing empirical literature reviewed below, although we will argue that the interpretation of the existing estimates is unclear.

We continue in Section 4.4 by formally describing how our border-county identification strategy overcomes the potential policy endogeneity problem. At the core of our methodology is the assumption that economic conditions evolve smoothly across state borders while unemployment benefit policies change discontinuously. The state-level benefit policy is affected by shocks to a state's economy, e.g. shocks to state-level productivity or demand. The identifying assumption is then that these shocks affect the counties on the two sides of the state border similarly. We test this assumption by assessing whether the differences in productivities between two neighboring states or differences in state unemployments instrumented with Bartik shocks (Bartik, 1991) help predict (controlling for the difference in benefits) the difference in unemployment between two counties that belong to those states and border each other. We find that they do not and conclude that our empirical methodology overcomes the endogeneity problem because while state unemployment benefit policy is affected by state-level economic conditions, the difference in unemployment between two border counties reflects only the difference in policy and not the difference in state-level economic fundamentals. The fact that the continuity assumption 
is satisfied in the data also implies that the size of the border counties relative to their state's is not a relevant consideration. We show that this test has power by considering an artificial sample of randomly paired up border counties in which the continuity assumption is violated.

This endogeneity test also helps address potential concerns regarding the quality of countylevel unemployment data. It is prohibitively expensive to conduct a representative labor force survey in every county to measure unemployment. The Local Area Unemployment Statistics (LAUS) Program of the Bureau of Labor Statistics (BLS) prepares county-level unemployment estimates using a variety of local data sources. In Section 4.5 we describe the procedure and use the underlying data that BLS released to us to undo the steps where state-level totals may affect the measured county unemployment. We find that doing so does not significantly affect our estimates. This implies that measured county unemployment does not reflect state-level conditions that induce changes in benefits. The endogeneity test described above yielded the same conclusion. Had county unemployment reflected state unemployment driven by shocks to e.g. productivity of the state, the test would have revealed this. Finally, in Section 4.5 we also verify that our results based on LAUS data are fully consistent with those based on the administrative county-level data on the counts of unemployment insurance claims, which are immune to concerns regarding potential contamination with state-level variables.

Of course, unemployment insurance is not the only policy discontinuous at the state border that can have a large impact on unemployment in every county of the state. Taxes, regulations, other benefit policies, etc. may have similar effects. Permanent differences in such policies across states during our sample period are picked up by our interactive effects estimator. The only potential concern is that changes in these policies could be correlated with the changes of unemployment benefit durations, confounding the estimated coefficient. Consequently, we proceed to describe and explicitly control for the effects of numerous other state-level policy changes to ensure that our estimates isolate the effects of unemployment benefit extensions.

In Section 5 we assess whether the mechanisms embedded in the standard equilibrium labor market search model can provide a coherent rationalization of the effect of unemployment benefit extensions on unemployment that we document. Our point of departure is the analysis in Section 4.7 of the effect of the sudden cut in potential benefit duration by 16 weeks in Missouri in April 2011. The reform led to an immediate and very large jump in job vacancy creation, providing direct evidence of an important macro effect. Expanding the scope of this analysis to all benefit duration changes across U.S. states during our sample period, and applying our methodology to control for the effects of expectations, we find that, consistent with implications of the equilibrium search model, relative to the paired border county, wages rise while vacancy rates and employment fall significantly in counties experiencing larger benefit extensions. The estimated magnitudes of these changes are also quantitatively consistent with the model.

An analysis based on a comparison of border counties belonging to states with different 
policy regimes must account for the possibility that residents of both counties may direct their job search efforts to the county with better labor market prospects. In Section 6 we show that these mobility decisions can be measured in the data from observed labor market flows. The estimates reported in that section imply that individuals do not systematically change their location of employment in response to changes in unemployment benefits across states during the Great Recession. This is perhaps not surprising. Residents of the border counties face a trade-off between receiving higher wages with lower job finding probability in a county belonging to the state with higher benefit eligibility and receiving lower wages with higher job finding probability in the state with lower benefits (note that in the U.S. unemployment insurance system benefits depend on the state of employment, and not on the state of residence). Moreover, the difference in the available duration of benefits across border counties is relatively small and may not justify larger commuting expenses. Thus, while we fully control for the response of the location of employment to changes in benefits in Section 6, this modification of the analysis turns out to be inconsequential. This leads us to work with a simpler and more transparent specification that ignores mobility decisions in the early parts of the paper.

While our estimate of the effects of unemployment benefit extensions is based on the difference across border counties, it is also desirable to be able to use the resulting coefficients to predict the effect of a nation-wide extension. A potential concern is that when some states extend benefits more than others, economic activity may reallocate to states with, say, lower benefits. This reallocation would be picked up by our estimates but will be absent when the policy is changed everywhere. Our results in Sections 5 and 6 (and the formal analysis of aggregation in this setting in Hagedorn et al., 2015b) alleviate such concerns. First, we find large negative effect of unemployment benefit extensions on employment in non-tradable sectors which are not subject to reallocation. Second, we find that unemployed workers do not change the strategy of which county to look for work in response to changes in benefits.

In the Appendix destined for on-line publication we describe features of the legal framework underlying the U.S. unemployment insurance system that are relevant for understanding our empirical finding that unemployment benefit extensions lead to higher equilibrium wages of incumbent workers who remain in the same job. In addition, we also briefly consider the implications of our findings for macroeconomic time-series. In particular, we summarize the results in Mitman and Rabinovich (2013), who introduced unemployment benefit extensions into the Mortensen and Pissarides (1994) model calibrated to match the effect of unemployment benefit extensions on unemployment documented in this paper. The model matches nearly perfectly the dynamics of unemployment over the last 60 years. Moreover, the extensions of unemployment benefits generate the apparent shift in the Beveridge curve after the Great Recession that was widely interpreted in the literature as a sign of increased mismatch in the labor market, see Diamond (2013) for a review. 


\section{Empirical Methodology}

\subsection{Identification via Border Counties: Controlling for Expectations}

To estimate the macroeconomic effects of unemployment insurance on a variable $x_{t}$ such as vacancies or unemployment, using the standard labor search model, we first estimate the effect on labor market tightness, $\theta_{t}$, defined as the ratio of vacancies to unemployment, and therefore look at firms' job creation decision. The value of a filled job for the firm is:

$$
J_{t}=\pi_{t}+\beta\left(1-s_{t}\right) E_{t} J_{t+1}
$$

where $\pi_{t}$ is period $t$ profits from the job, $\beta$ is the discount factor, $s_{t}$ is the exogenous probability that the job ends and $E_{t}$ is the expectation operator using information available at time $t$. Free entry into vacancy posting implies that the expected cost of posting a vacancy is equal to the value of a filled job. The job creation decision is then

$$
q\left(\theta_{t}\right) J_{t}=c
$$

where $q\left(\theta_{t}\right)$ is the probability to fill a vacancy and $c$ is the the cost of maintaining a vacancy. This approximately yields

$$
\log \left(\theta_{t}\right)=\tilde{\kappa} \log \left(J_{t}\right)
$$

We now approximate $\log \left(J_{t}\right)$ as a function of $\log \left(\pi_{t}\right), \log \left(J_{t+1}\right)$ and an expectational error $\log \left(\eta_{t}\right)$ around the steady state with a constant $\pi=J(1-\beta(1-s))$, so that the previous equation reads

$$
\log \left(\theta_{t}\right)=\tilde{\kappa} \frac{\pi}{J} \log \left(\pi_{t}\right)+\tilde{\kappa} \beta\left(1-s_{t}\right) \log \left(J_{t+1}\right)+\log \left(\eta_{t}\right)
$$

Using $\pi / J=(1-\beta(1-s))$ and the job creation decision (4) for $t+1$, yields

$$
\log \left(\theta_{t}\right)=\tilde{\kappa}(1-\beta(1-s)) \log \left(\pi_{t}\right)+\beta\left(1-s_{t}\right) \log \left(\theta_{t+1}\right)+\log \left(\eta_{t}\right) .
$$

In quarterly data variables such as unemployment are well approximated by a linear function of $\log (\theta):^{6}$

$$
\log \left(x_{t}\right)=\lambda_{x} \log \left(\theta_{t}\right)
$$

so that we obtain the quasi-difference

$$
\tilde{x}_{t}:=\log \left(x_{t}\right)-\beta\left(1-s_{t}\right) \log \left(x_{t+1}\right)=\tilde{\kappa} \lambda_{x}(1-\beta(1-s)) \log \left(\pi_{t}\right)+\lambda_{x} \log \left(\eta_{t}\right) .
$$

As in the standard Pissarides (2000) model, firms' period $t$ profits from employing a worker are given by the difference between workers' marginal product and the wage. The wage, in turn,

\footnotetext{
${ }^{6}$ See, e.g., Hall (2005), Shimer (2007). Below we verify that this approximation also performs well in a calibrated equilibrium search model with unemployment benefit extensions.
} 
is affected by the generosity of unemployment benefits available to the worker. ${ }^{7}$ Thus, up to a log-linear approximation with respect to the two state variables of the model, firms' profits from employing a worker are given by:

$$
\log \left(\pi_{t}\right)=\gamma_{z} \log \left(z_{t}\right)-\gamma_{b} \log \left(b_{t}\right),
$$

where $z_{t}$ is workers' productivity, $b_{t}$ are unemployment benefits, and $\gamma_{z}$ and $\gamma_{b}$ are unknown coefficients which the standard theory implies should both be positive, although we do not impose such a restriction. As we discussed in Footnote 7, the two state variables $z_{t}$ and $b_{t}$ affect firm's profits through their impact on a number of variables in the model and Equation (9) refers to their relevant total effect.

Finally, denote by $p$ the border-county pair. Then, substituting Equation (9) into Equation (8) and differencing between border counties within a pair yields:

$$
\Delta \tilde{x}_{p, t}=\alpha \Delta b_{p, t}+\Delta \epsilon_{p, t},
$$

where $\Delta$ the difference operator over counties in the same pair. More specifically, if counties $i$ and $j$ are in the same border-county pair $p$, then $\Delta \tilde{x}_{p, t}=\tilde{x}_{p, i, t}-\tilde{x}_{p, j, t}$, and, with a slight abuse of notation, $\Delta b_{p, t}=\log \left(b_{p, i, t}\right)-\log \left(b_{p, j, t}\right)$.

After we describe the structure of the error term $\Delta \epsilon_{p, t}$ in Section 2.2, Equation (10) can be estimated in the data to recover the coefficient of interest $\alpha$, which equals, using equations (9) and (8),

$$
-\gamma_{b} \lambda_{x} \tilde{\kappa}(1-\beta(1-s)) .
$$

Dividing this coefficient by the measurable factor $(1-\beta(1-s))$ yields the permanent percentage change of a variable $x$ in response to a permanent one percentage change in the policy variable $b,-\gamma_{b} \lambda_{x} \tilde{\kappa}$. More generally, the effect of increasing benefit duration from $\omega_{1}$ to $\omega_{2}$ weeks for $n$ time periods is given by

$$
\hat{\alpha} \times \frac{1-(\beta(1-s))^{n}}{1-\beta(1-s)} \times\left(\log \left(\omega_{2}\right)-\log \left(\omega_{1}\right)\right) .
$$

Equation (10), which will form the basis of our empirical strategy, differs from the standard specification in the literature in that the left-hand-side variable is the quasi-difference $\tilde{x}_{p, t}$ as opposed to simply $x_{p, t}$. This is essential in our application because vacancy posting decisions by employers are forward looking and are affected by the expectations of future changes in benefits. Moreover, the expectations of the future path of benefits might depend on the benefit level today. For example, suppose raising benefit levels leads to a rise in unemployment. If the benefit level and the duration are increasing in state unemployment, an increase in benefits

\footnotetext{
7 Note that this is the equilibrium wage response to a change in benefits, combining the direct effect of benefits on wages and various indirect effects which in our empirical analysis we can be deliberately agnostic about. For the response of vacancy creation it is this equilibrium wage response that matters and consequently this what we estimate (equation (29)) in Section 5.3.
} 
today makes it then more likely that benefits would be increased further in the future. Since vacancy creation and, consequently, unemployment respond to this change in expectations, it is clear that the coefficient $\alpha$ in a regression with $x_{p, t}$ on the left-hand side will be a biased estimator of the effect of the current benefit structure on the current variable of interest, such as unemployment.

To clarify how our estimation strategy controls for expectations, recall that our quasidifference is defined as $\tilde{x}_{t}:=\log \left(x_{t}\right)-\beta\left(1-s_{t}\right) \log \left(x_{t+1}\right)$. This works because market tightness in period $t, \theta_{t}$, depends on expected profits $J_{t}$ and thus on the whole expected sequence of future benefit levels in $t, t+1, t+2, \ldots$ Shifting by one period, market tightness $\theta_{t+1}$ depends on expected profits in period $t+1, J_{t+1}$, and thus on the expected sequence of benefit levels in $t+1, t+2, \ldots$ Since profits in periods $t$ and $t+1$ are related by the simple accounting identity, $J_{t}=\pi_{t}+\beta\left(1-s_{t}\right) E_{t} J_{t+1}$, market tightness $\theta_{t}$ depends on current profits $\pi_{t}$ (affected by $b_{t}$ ) and on market tightness $\theta_{t+1}$ which is linearly related to $E_{t} J_{t+1}$ and depends on the sequence of benefits $\left(b_{t+1}, b_{t+2}, \ldots\right)$. As a result, a change in current benefits $b_{t}$ affects current profits, current vacancy creation and thus the quasi-differenced market tightness. In contrast, changes in future benefits, say $b_{t+1}$, affect both $\theta_{t}$ and $\theta_{t+1}$. The effect of $b_{t+1}$ on $\theta_{t}$ is discounted by $\beta\left(1-s_{t}\right)$. The effect of $b_{t+1}$ on $\theta_{t+1}$ is not discounted, but is multiplied by $\beta\left(1-s_{t}\right)$ when constructing the quasi-difference. Thus, the effect of a change in $b_{t+1}$ cancels out in the quasi-difference. By the same logic, the quasi-difference eliminates the effect of a change in $b_{t+2}, b_{t+3}, \ldots$ Thus, our specification allows us to obtain an unbiased estimate of the coefficient $\alpha$ - the effect of a current change in benefits on current profits and current market tightness - despite a forward looking nature of the job creation decision. In order to ascertain the accuracy of our specification, In Section 5.4 we will compare the predicted permanent effect estimated using the proposed method to the actual permanent effect in a calibrated Mortensen and Pissarides (1994) model. We find that our empirical specification is very accurate in model generated data.

\section{$2.2 \quad$ Interactive Effects}

The term $\Delta \epsilon_{p, t}$ in Equation (10) contains the expectation error and the permanent differences in $\tilde{x}$ across border counties caused by, e.g., permanent differences in tax policies across states they belong to. Moreover, as we mentioned in the Introduction, various shocks have affected the aggregate economy during the Great Recession. But the same aggregate shocks are likely to have a heterogeneous impact on different border county pairs. In this case, estimating the panel regression in Equation (10), perhaps with a set of county pair and time fixed effects, is problematic for inference. ${ }^{8}$ Fortunately, Bai (2009) has shown that consistency and proper

\footnotetext{
${ }^{8}$ See Andrews (2005) for the discussion of this problem in a cross-sectional regression. Gobillon and Magnac (2015) establish that the difference-in-differences estimator is generically biased in the panel data context. They also establish the superior performance of the interactive effects estimator that we use relative to alternatives
} 
inference can be obtained in a panel data context, such as ours, through the use of an interactive effects estimator. In particular, we decompose the error term in Equation (10) as

$$
\Delta \epsilon_{p, t}=\lambda_{p}^{\prime} F_{t}+\nu_{p, t}
$$

where $\lambda_{p}(r \times 1)$ is a vector of pair-specific factor loadings and $F_{t}(r \times 1)$ is a vector of timespecific common factors. Our baseline specification can then be written as

$$
\Delta \tilde{x}_{p, t}=\alpha \Delta b_{p, t}+\lambda_{p}^{\prime} F_{t}+\nu_{p, t}
$$

As is shown in Bai (2009), this model incorporates additive time and county pair fixed effects as special cases. It is, however, much more general and allows for a very flexible model of the heterogeneous time trends at the county pair level. The key to estimating $\alpha$ consistently is to treat the unobserved factors and factor loadings as parameters to be estimated. Our implementation is based on an iterative two-stage estimator described in Appendix I.

\subsubsection{Estimating the Number of Factors}

To implement this estimator, we need to specify the number of factors. Bai and Ng (2002) have shown that the number of factors in pure factor models can be consistently estimated based on the information criterion approach. Bai (2009) shows that their argument can be adapted to panel data models with interactive fixed effects. Thus, we define our criterion $C P$ as a function of the number of factors $k$ as:

$$
C P(k)=\hat{\sigma}^{2}(k)+\hat{\sigma}^{2}(\bar{k})\left[k(N+T)-k^{2}\right] \frac{\log (N T)}{N T},
$$

where $\bar{k} \geq r$ is the maximum number of factors, $N$ is the number of pairs, $T$ is the number of time observations, $\hat{\sigma}^{2}(k)$ is the mean squared error, defined as

$$
\hat{\sigma}^{2}(k)=\frac{1}{N T} \sum_{i=1}^{N} \sum_{t=1}^{T}\left(\Delta \tilde{x}_{p, t}-a \Delta b_{p, t}-\lambda_{i}^{\prime}(k) F_{t}(k)\right)^{2},
$$

and $F_{t}(k)$ and $\lambda_{i}^{\prime}(k)$ are the estimated factors and their loadings, respectively, when $k$ factors are estimated. To avoid collinearity, we set $\bar{k}$ to the minimum of seven and $T-1$, one less than the total number of time observations. Our estimator for the number of factors is then given by

$$
\hat{k}=\arg \min _{k \leq \bar{k}} C P(k)
$$

\subsubsection{Standard Errors}

To properly compute standard errors, we need to take into account potential correlation in the residuals across counties and over time. There are two possible sources of correlation. First, the outcomes that we are interested in (unemployment, vacancies, wages, etc.) are highly methods used in the literature. 
serially correlated. This aspect of the data may cause serial correlation in the errors. Second, the fact that some counties appear in multiple county-pairs results in an almost mechanical correlation across county pairs. To account for these sources of correlation in the residuals, we follow Bertrand et al. (2004) and use the block-bootstrap on state border segments to compute standard errors.

\section{Data}

The paper relies on numerous sources of data that are described when they are used. In this Section we only mention the data sets that play the most significant role in the analysis.

Data on unemployment among the residents in each county are from the Local Area Unemployment Statistics (LAUS) provided by the Bureau of Labor Statistics. ${ }^{9}$ We supplement these data with the corresponding local-level administrative data on unemployment insurance claims and final payments from the state unemployment insurance system.

County-level data on private sector employment (the number of jobs located in a county) and wages are from the Quarterly Workforce Indicators (QWI). ${ }^{10}$ QWI is derived from the Local Employment Dynamics, which is a partnership between state labor market information agencies and the Census Bureau. QWI supplies data for all counties except those in Massachusetts. Data availability varies substantially across states until 2004 Q4. Thus, for our main empirical analysis we will restrict attention to quarters beginning with 2005 Q1.

For completeness, we also use county-level employment (the number of jobs located in a county) data from the Quarterly Census of Employment and Wages (QCEW) provided by the BLS. QCEW and QWI datasets are similar but not identical. QWI is better at tracking the precise location of each establishment, which is important for our county-based analysis. If an error in assigning the location of an establishment is discovered, all historical records are updated for that establishment by QWI. QCEW, in contrast, updates the location of an establishment upon discovering an error but does not correct the error in the data for preceding quarters. A disadvantage of QWI is that, to protect confidentially, noise is infused into QWI estimates resulting in some instances in significantly distorted data. ${ }^{11}$ Having to exclude any observations that are flagged as significantly distorted from the analysis, leads to slightly smaller QWI samples as compared to QCEW.

We obtain county-level vacancy data from the Help Wanted OnLine (HWOL) dataset provided by The Conference Board (TCB). This dataset is a monthly series that covers the universe of unique vacancies advertised on around 16,000 online job boards and online newspaper editions (with duplicate ads identified and removed by TCB). The HWOL database started in

\footnotetext{
${ }^{9} \mathrm{ftp}: / / \mathrm{ftp}$. bls.gov/pub/time.series/la/

${ }^{10}$ http://lehd.ces.census.gov/datatools/qwiapp.html

${ }^{11}$ See ftp://ftp2.census.gov/ces/tp/tp-2006-02.pdf.
} 
May 2005 and replaced the Help-Wanted Advertising Index of print advertising also collected by TCB. ${ }^{12}$ For a more detailed description of the data, some of the measurement issues, and a comparison with the well-known JOLTS data, see Sahin et al. (2014). Importantly, our analysis is based only on approximately $93 \%$ of all online vacancies that are uniquely matched by TCB to a county of prospective employment. In other words, we do not use approximately $5 \%$ of HWOL vacancies that are coded as "statewide" and $2 \%$ that are coded as "nationwide."

To identify the role of unemployment benefit extensions on labor market outcomes, we focus our analysis on a sample of county pairs that are in different states and share a border. ${ }^{13}$ There are 1,107 such pairs for which we have complete data.

Data on unemployment benefit durations in each state is based on trigger reports provided by the Department of Labor. These reports contain detailed information for each of the states regarding the eligibility and adoption of the two unemployment insurance programs over our primary sample period: Extended Benefits program (EB) and Emergency Unemployment Compensation (EUC08). ${ }^{14}$

The EB program allows for 13 or 20 weeks of extra benefits in states with elevated unemployment rates. The EB program is a joint state and federal program. The federal government pays for half of the cost, and determines a set of "triggers" related to the insured and total unemployment state rates that the states can adopt to qualify for extended benefits. At the onset of the recession, many states chose to opt out of the program or only adopt high triggers. The American Recovery and Reinvestment Act of February 2009 turned this into a federally funded program. Following this, many states joined the program and several states adopted lower triggers to qualify for the program. ${ }^{15}$

The EUC08 program enacted in June 2008, on the other hand, has been a federal program since its onset. The program started by allowing for an extra 13 weeks of benefits to all states and was gradually expanded to have 4 tiers, providing potentially 53 weeks of federally financed additional benefits. The availability of each tier is dependent on state unemployment rates. The trigger reports contain the specifics of when each state was eligible and activated the EB program and different tiers of the EUC08 program. We have constructed the data through December 2012.

Prior to the end of 2012, the duration of benefits in a given state varied over time but the

\footnotetext{
${ }^{12}$ For detailed information on survey methodology, coverage, and concepts see the Technical Notes at http://www.conference-board.org/data/helpwantedonline.cfm.

${ }^{13}$ Data on county pairs are from Dube et al. (2010).

${ }^{14}$ See http://ows.doleta.gov/unemploy/trigger/ for trigger reports on the EB program and http://ows.doleta.gov/unemploy/euc_trigger/ for reports on the EUC08 program.

${ }^{15}$ Outside of the extensions induced by the Great Recession, the EB program was triggered on in Louisiana in the aftermath of hurricane Katrina. It provided 13 extra weeks of benefits to those whose regular 26 weeks of benefits ran out between October 30, 2005 and February 26, 2006. Excluding this extension form our analysis leaves our conclusions unaffected.
} 
level of benefits remained constant. In 2013, however, just before the expiration of EB and EUC08 programs in December of that year, the system went through considerable upheaval due to the sequestration of the federal budget. The sequester mandated a $10.7 \%$ reduction on spending on EB and EUC08 benefits. However, the implementation of these cuts varied widely across states with some implementing across the board cuts, others implementing much larger cuts for new entrants into the programs (and in some cases for individuals starting new EUC tiers), yet others reducing the number of weeks of benefits available under various EUC tiers but leaving the benefit levels unchanged. While these 2013 changes provide a source of significant variation that might help idenify the labor market effect of unemployment benefit levels, we do not attempt to exploit it in this paper given our focus on the effects of benefit duration.

There is a substantial heterogeneity in the actual unemployment benefit durations across time and across the U.S. states. Appendix Figure A-4 presents some snapshots that illustrate the extent of this variation. Among 1,107 border county pairs used in our analysis, 1,079 have different benefits for at least one quarter. The median county pair has different benefit durations for 11 quarters during 2008-2012. The difference in available benefit duration within a countypair ranges from 0 to 17 quarters.

Some of the data series used in the analysis are available at a monthly frequency while others are quarterly. Therefore, we aggregate all monthly data to obtain quarterly frequency. Logs are taken after aggregation. When constructing the quasi-differences at the quarterly frequency, we set $\beta=0.99$ and use the separation rate from JOLTS data. ${ }^{16}$

\section{Unemployment Benefit Extensions and Unemploy- ment}

\subsection{Baseline Empirical Results}

Column (1) of Table 1 contains the results of the estimation of the effect of unemployment benefit duration on unemployment using the baseline specification in Equation (14). We find that changes in unemployment benefits have large and statistically significant short-run effect on unemployment: a $1 \%$ rise in benefit duration for only one quarter increases unemployment rate by $0.049 \log$ points. Equation (12) helps us extrapolate these effects and estimate the effect of a permanent unanticipated increase in benefit durations. Using the average quarterly separation rate of $10 \%$ in JOLTS data, we find that the effect of permanently $(n=\infty)$ increasing benefits from $\omega_{1}=26$ to $\omega_{2}=99$ weeks is quite sizable: The effect on unemployment is $80 \%$, meaning that such a permanent increase would increase the long-run average unemployment rate from $5 \%$ to $9.13 \%$.

\footnotetext{
${ }^{16} \mathrm{http}: / /$ www.bls.gov/jlt/
} 
Table 1: Unemployment Benefit Extensions and Unemployment

\begin{tabular}{|c|c|c|c|c|c|c|c|c|c|c|}
\hline VAR. & (1) & $(2)$ & $(3)$ & $(4)$ & (5) & (6) & (7) & (8) & (9) & (10) \\
\hline $\begin{array}{l}\text { Weeks of } \\
\text { Benefits }\end{array}$ & $\begin{array}{c}\mathbf{0 . 0 4 9} \\
(0.000)\end{array}$ & $\begin{array}{c}\mathbf{0 . 0 4 9} \\
(0.000)\end{array}$ & $\begin{array}{c}\mathbf{0 . 1 0 2} \\
(0.000)\end{array}$ & $\begin{array}{c}\mathbf{0 . 0 9 6} \\
(0.000)\end{array}$ & $\begin{array}{c}\mathbf{0 . 0 4 7} \\
(0.000)\end{array}$ & $\begin{array}{c}\mathbf{0 . 0 4 3} \\
(0.000)\end{array}$ & $\begin{array}{c}\mathbf{0 . 0 5 3} \\
(0.000)\end{array}$ & $\begin{array}{c}\mathbf{0 . 0 4 7} \\
(0.000)\end{array}$ & $\begin{array}{c}\mathbf{0 . 0 4 8} \\
(0.000)\end{array}$ & $\begin{array}{c}\mathbf{0 . 0 5 1} \\
(0.000)\end{array}$ \\
\hline $\begin{array}{l}\text { State GDP } \\
\text { per Worker }\end{array}$ & & $\begin{array}{c}0.009 \\
(0.430)\end{array}$ & & $\begin{array}{c}\mathbf{- 0 . 0 7 5} \\
(0.000)\end{array}$ & & & & & & \\
\hline N. factors & 2 & 2 & 3 & 3 & 2 & 2 & 2 & 2 & 2 & 2 \\
\hline Obs. & 37,177 & 37,177 & 37,177 & 37,177 & 31,712 & 37,177 & 18,588 & 16,966 & 26,024 & 37,177 \\
\hline R-squared & 0.458 & 0.459 & 0.633 & 0.634 & 0.419 & 0.478 & 0.432 & 0.419 & 0.465 & 0.447 \\
\hline \multicolumn{11}{|c|}{$\begin{array}{l}\text { Note - p-values (in parentheses) calculated via bootstrap. Bold indicates } p<0.01 . \\
\text { Column (1) - Baseline sample, } \\
\text { Column (2) - Baseline sample controlling for State GDP per worker, } \\
\text { Column (3) - Scrambled border county pairs sample, } \\
\text { Column (4) - Scrambled border county pairs sample controlling for State GDP per worker, } \\
\text { Column (5) - Sample of border counties with }<15 \% \text { share of state's employment, } \\
\text { Column (6) - Baseline sample with LAUS additivity factors removed, } \\
\text { Column (7) - Sample of border counties with similar industrial composition, } \\
\text { Column (8) - Sample of border counties with population centers }<30 \text { miles apart, } \\
\text { Column (9) - Sample of border counties within the same Core Based Statistical Areas, } \\
\text { Column (10) - Baseline sample with perfect foresight measure of available benefits. }\end{array}$} \\
\hline
\end{tabular}

As we have stresses several times by now, the strength of the effect of unemployment benefit extensions on labor demand depends on the full expected sequence of future benefit durations (see the direct evidence in Section 4.2 below). In particular, a permanent increase in benefit durations has the strongest negative impact on labor demand as firms expect to bargain with workers entitled to high benefits at all future dates. The benefit extensions enacted following the onset of the Great Recession, however, were not designed to be permanent and benefit durations varied over time. Assuming perfect foresight of future benefits, our estimate of 0.049 implies that if standard durations of unemployment benefits (26 weeks) had prevailed following the Great Recession, the unemployment rate in 2010 and 2011 would have been 2.7 and 2 percentage points lower, respectively. Although the duration of benefits was fairly similar in 2010 and 2011, the implied effect on unemployment was substantially larger in 2010. This is because firms creating jobs in 2011 expected benefit duration to decline in the following year (lowering the expected wage bill and making it easier to cover the costs of vacancy creation). In contrast, firms considering creating jobs in 2010 were confronted with an additional year, 2011, of high benefit durations, which discouraged vacancy creation. This example illustrates an important general property of the effects of unemployment benefits on unemployment. To the extent that employers anticipate future changes in benefits, unemployment evolves smoothly over time and fully responds to future changes in benefits before those changes actually occur. Thus, unless 


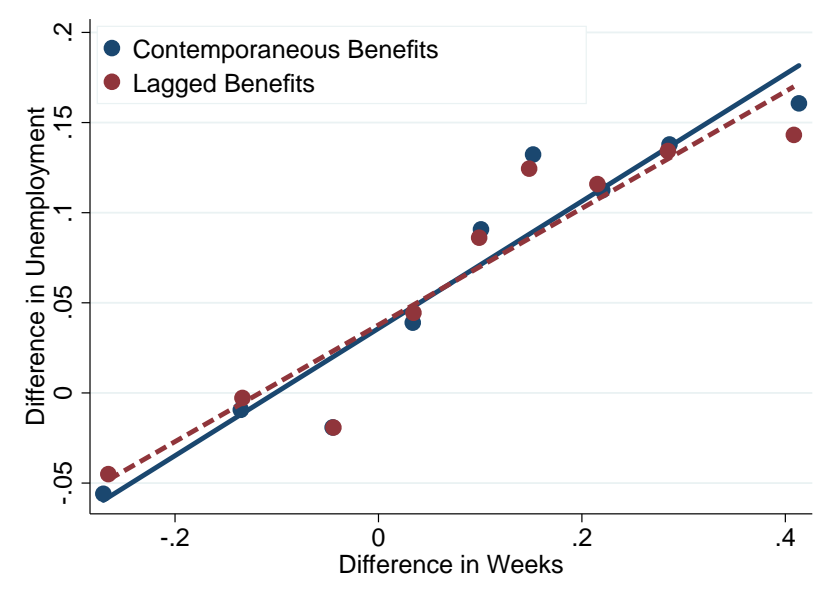

(a) Current and Lagged Benefits and Unemployment

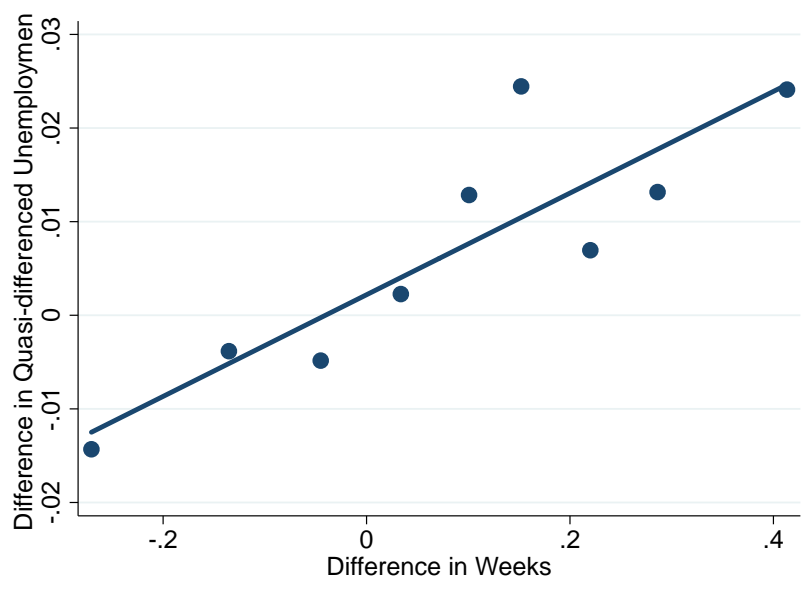

(b) Current Benefits and QD Unemployment

Figure 3: (Quasi-Differenced) Unemployment Differences between Border Counties versus Differences in Benefit Duration.

expectations are known or controlled for, the relationship between contemporaneous changes in benefits and unemployment is uninformative of the true labor market impact of unemployment benefit policies.

When comparing the magnitude of the effect we find to the experience in the data, it is also important to keep in mind that it is based on the difference across pairs of border counties. Thus, the effects of various other shocks or policies that affect these counties symmetrically are differenced out. For example, the $2 \%$ reduction to an employee's share of Social Security payroll taxes implemented in all states in 2011 and 2012 might have had a substantial negative impact on unemployment, counteracting some of the effects of unemployment benefit extensions.

\subsubsection{Under the Hood of the Quasi-Difference}

Our methodology calls for estimating the effect of benefit duration on the quasi-differenced unemployment, i.e., on $\tilde{u}_{t}:=\log \left(u_{t}\right)-\beta\left(1-s_{t}\right) \log \left(u_{t+1}\right)$. It is instructive to consider the effects of benefit duration on the two components of the quasi-difference, i.e., on $\log \left(u_{t}\right)$ and $\log \left(u_{t+1}\right)$. To this end, we regress the difference of these variables between border counties on the difference in the log benefit duration between these counties and fixed effects for each border county pair. We obtain the coefficient of 0.135 (s.e. 0.008) and 0.095 (s.e. 0.008), respectively. Thus, higher benefit duration is associated with higher current and future unemployment, so that both components of the quasi-difference increase in benefit generosity.

To help visualize these results, in Figure 3(a) we provide a binned scatter plot of the difference between border counties in the current or next quarter's unemployment on the difference in current benefits. In Figure 3(b) we provide a similar plot for the difference between border counties in quasi-differenced unemployment. These figures suggest an unambiguous increase in current, future, and quasi-differenced unemployment with benefit duration. 


\subsection{The Impact of Expected Future Policy Changes on Current Un- employment}

Our key methodological contribution is to develop an estimator which controls for the effects of future policies on current decisions, resulting in a specification which includes only current period benefits in the regression. We now extend this methodology to assess more directly the effects of future benefit durations on current unemployment. To do so, we iterate the benchmark equation (10) for the quasi-difference $\tilde{x}_{t}$ forward (through substitution), which yields the $k$ period ahead quasi-difference:

$$
\tilde{x}_{t}^{k}:=\log \left(x_{t}\right)-\left(\prod_{m=1}^{k} \beta\left(1-s_{t+m-1}\right)\right) \log \left(x_{t+k}\right) .
$$

This $k$-period ahead quasi-difference then depends not only on current benefits $b_{t}$ but on the full future sequence of benefits until period $t+k-1$, implying that the effects of current and future benefit policies can be directly estimated through the regression

$$
\Delta \tilde{x}_{p, t}^{k}=\sum_{m=1}^{k} \alpha_{m} \Delta b_{p, t+m-1}+\lambda_{p}^{\prime} F_{t}+\nu_{p, t} .
$$

Our benchmark specification is a special case for $k=1$. The expanded specification in (16) allows us to investigate in the data the expectational channel of policy as it includes the future benefits directly in the regression. Subject to the available panel duration, this specification can be estimated for an arbitrary $k$, that is it allows to assess the impact of benefits at an arbitrary future date on current unemployment. Only benefits after period $t+k$ are not included in the regression but instead are controlled for by using the $k$-period ahead quasi-difference.

Similar to the benchmark, the extended specification also allows to compute the effect of increasing benefit duration from $\omega_{1}$ to $\omega_{2}$ weeks for $n=k$ time periods (using $s_{t}=s$ ) as

$$
\sum_{m=1}^{k} \alpha_{m} \times\left(\log \left(\omega_{2}\right)-\log \left(\omega_{1}\right)\right)
$$

and for a permanent change in benefit duration from $\omega_{1}$ to $\omega_{2}$ weeks as

$$
\frac{\sum_{m=1}^{k} \alpha_{m}}{1-(\beta(1-s))^{k}} \times\left(\log \left(\omega_{2}\right)-\log \left(\omega_{1}\right)\right) .
$$

Note that the theory implies that the effect of a permanent increase in benefits calculated in (18) using $\hat{\alpha}_{m}$ estimates from (16) should be the same for all $k \geq 1$. The results of performing this experiment in the data are presented in Table 2. We find that the estimated effects of benefit extensions are indeed quite stable across specifications including varying number of leads in benefits. This result is noteworthy for two reasons. First, it confirms the appropriateness of our benchmark specification that includes current benefits only. This indicates that a one- 
Table 2: Estimated Permanent Effects Using $k$-Period ahead Quasi-Difference

\begin{tabular}{ccc}
\hline$k$ & Permanent Effect & Implied Unemployment Rate \\
$(1)$ & $(2)$ & $(3)$ \\
\hline 1 & 0.60 & 9.13 \\
2 & 0.68 & 9.82 \\
3 & 0.72 & 10.32 \\
4 & 0.72 & 10.27 \\
5 & 0.62 & 9.28 \\
6 & 0.89 & 12.12 \\
7 & 0.78 & 10.91 \\
8 & 0.48 & 8.06 \\
\hline Mean & 0.69 & 9.93 \\
\hline
\end{tabular}

Note - Column (2) contains estimated effect of a permanent increase in benefit duration from 26 to 99 weeks calculated via (18) using $\hat{\alpha}_{m}$ estimates from specification in (16) for various values of $k$ in Column (1). Column (3) contains the implied unemployment rate assuming a 5\% equilibrium unemployment when 26 weeks of benefits are available. For example, the entry in Column (3) for $k=1$ is obtained from $\log (0.05)+0.60=$ $\log (9.13)$. The calculation for other values of $k$ is analagous.

period-ahead quasi-difference indeed fully captures the expectations of future policies. Second, it directly shows that current unemployment responds to expected changes in benefits in future periods in a way consistent with the basic theory underlying our empirical methodology. ${ }^{17}$

\subsection{Placebo Test for the Quasi-Difference Estimator}

In the previous section we verified the performance of the quasi-difference estimator in the data and established the importance of expectations of future policy changes by analyzing the results from the $k$-period ahead quasi-difference estimator. We now perform another direct test that verifies the empirical performance of the estimator (we will also verify its performance in the model generated data below). Specifically, we apply the estimator to the data from a time period when there were no benefit extensions with an artificially created placebo measure of weeks of benefits available based on a hypothetical trigger of benefit extensions.

Accordingly, we consider data from 1996-2000 when no extended benefits were available in the US. ${ }^{18}$ In practice, a state triggers on a benefit extension in a given month if the three month average of the state seasonally adjusted unemployment rate exceeds a pre-determined threshold. Consequently, we obtain data on the monthly seasonally adjusted unemployment

\footnotetext{
${ }^{17}$ It also corroborates and extends our finding in Section 4.1.1 that the data reject the hypothesis that quasi-differenced unemployment increase because benefits decrease future unemployment. If this were the case, then, since the future period $t+k$ unemployment rate enters the $k$-period ahead quasi-difference discounted by $\prod_{m=1}^{k} \beta\left(1-s_{t+m-1}\right)$, the effect of a permanent increase in benefits would decrease the higher is $k$. Our findings in this section again reject this hypothesis.

${ }^{18}$ Except for a brief extension of benefit duration in New Jersey studied by Card and Levine (2000) and discussed in Section 4.7 below. Eliminating 1996 New Jersey data from the placebo sample has no impact on the findings.
} 
rate at the state level and specify our placebo extension of 13 weeks in any month when the preceding three month average of the state seasonally adjusted unemployment rate exceeded $5 \%$ (our substantive conclusions are not sensitive to the choice of this cut-off). We then aggregate from monthly to quarterly data, take logs and difference across border county pairs replicating exactly the procedures in our analysis of the actual UI extensions. Finally, we estimate the main specification of the paper using the interactive effects estimator and compute standard errors via block-bootstrap.

Applied to these data, our quasi-differenced estimator correctly recovers a negligible and statistically insignificant coefficient of 0.007 ( $\mathrm{p}$-value of 0.17 ) measuring the impact of placebo benefits on unemployment. ${ }^{19}$

\subsection{Testing for Endogeneity}

In this section we formalize the potential endogeneity problem as well as develop and implement a test to detect its presence. We begin, however, by outlining the origin of the problem informally using an intuitive example that imposes stronger conditions than those actually required for identification. ${ }^{20}$

Imagine a border county pair consisting of county $a$ belonging to state $A$ and county $b$ belonging to state $B$. State $A$ also has some geographic area $\mathcal{A}$ that excludes county $a$. We now consider two cases.

\section{Case 1. Continuous economic conditions at the state border.}

Suppose there is a large shock affecting the economy of $\mathcal{A}$. The economic effects of this shock might spread geographically to reach county $a$. However, there is no particular reason for these effects to stop upon reaching the state border. Thus, they will continue spreading and would affect county $b$ similarly to their effect on county $a$. If this is the case, there is no endogeneity problem in our baseline specification (14) as the difference in unemployment between counties $a$ and $b$ is due solely to the difference in benefit policies, perhaps triggered by the developments in $\mathcal{A}$. With geographically continuous economic fundamentals, shocks directly to counties $a$ and $b$ also do not create an endogeneity problem even if either one or both counties are large enough

\footnotetext{
${ }^{19}$ It is also interesting to note that extended benefits where available to those unemployed in 2001 through the extensions triggered in early 2002. The Temporary Extended Unemployment Compensation act passed in March 2002 provided extended benefits to anyone who became unemployed after March 2001. In addition, several states triggered benefit extensions in the first half of 2002 via the Extended Benefits (EB) program, which also applied to people who became unemployed in 2001. To the extent that these extensions were anticipated (e.g. because of the collapse in asset prices in the technology sector, the September 11 terrorist attacks, etc.), 2001 data is not appropriate for a placebo experiment. Nevertheless, implementing the experiment on 1996-2001 data, we find a small but now marginally statistically significant positive estimate of 0.014 on unemployment. This increase in the coefficient is expected given our theory and reinforces our other findings on the role of expectations. Its specific magnitude is not readily interpretable, however, because we do not know the correlation between the benefit durations assigned through an artificial placebo trigger with the true anticipated durations.

${ }^{20}$ In Appendix III we discuss additional informal examples.
} 
to trigger a change in policies in the corresponding states.

\section{Case 2. Discontinuous economic conditions at the state border.}

The endogeneity problem can arise only if shocks to e.g., productivity, stop when reaching a state border. In this case, a shock to $\mathcal{A}$ may affect, say, productivity in county $a$ and trigger a change in unemployment benefit policy in state $A$. In contrast, this shock stops when reaching the state border so that neither $b$ 's productivity nor $B$ 's benefit policy is affected. In this case, the difference in unemployment between counties $a$ and $b$ is driven by both the difference in productivities and the difference in benefits, with the latter at least partially induced by the difference in productivities. In this case, the estimate of the effect of benefits would be biased if the difference in state productivities is not controlled for.

We now turn to a more formal exposition. The identifying assumption of our empirical strategy is that the error term $\nu_{p, t}$ in estimation equation (14) is uncorrelated with benefits $\Delta b_{p, t}$. The variable of interest $x$ at the county level is driven by benefits $b$, the time varying factors $F$ and county-specific factors such as productivity or demand which are unobserved and are part of the term $\nu_{p, t}$. The assumption that $\nu_{p, t}$ is not correlated with benefits then means that the differences in productivity, demand, etc. across border counties are not correlated with the benefits across the same counties. Since benefits are a function of state level variables, for this assumption to be valid, the difference in county level productivity, demand, etc. has to be uncorrelated with the corresponding differences at the state level, i.e.

$$
\operatorname{Corr}\left(\nu_{p, t}, \Delta z_{p}\right)=0
$$

where $z$ is state level measure of productivity or demand and $\Delta z_{p}$ is the difference in this measure across states. Thus, our identifying assumption does not require border counties to be identical (conditional on the differences accounted for by the factor model) so that $\nu_{p, t}$ is pure measurement error. It is weaker than this as it allows counties to be different in terms of countyspecific factors and only requires that state-level factors affect the two counties symmetrically so that the difference in state-level shocks does not affect the difference of $x$ across the two counties. $^{21}$

To test this assumption, we can decompose the term $\nu_{p, t}$ into a part that depends on the state, $\Delta z_{p}$, and another part that depends on county-specific factors only, $\tilde{\nu}_{p, t}$,

$$
\nu_{p, t}=\chi \Delta z_{p}+\tilde{\nu}_{p, t}
$$

\footnotetext{
${ }^{21}$ In terms of the examples above, an endogeneity problem would not arise even in Case 2 if there are discontinuous idiosyncratic shocks to counties $a$ or $b$ as long as these shocks do not affect the state average conditions and do not trigger changes in benefit policy at the state level. This is not a very strong restriction as the median border county has only one half of one percent of its state's employment. In addition, in Column (5) of Table 1 we redo the analysis where we drop counties that have greater than $15 \%$ share of state employment and find our estimates unchanged.
} 
so that we rewrite the empirical specification as

$$
\Delta \tilde{x}_{p, t}=\alpha \Delta b_{p, t}+\lambda_{p}^{\prime} F_{t}+\chi \Delta z_{p}+\tilde{\nu}_{p, t}
$$

for a (possibly) nonzero coefficient $\chi$.

The economics behind this test is clear. Unemployment benefit extensions are determined at the state level and thus depend on a state's economic conditions such as state-level productivity or demand $z$. Thus, a negative state-level shock to $z$ can cause unemployment to increase in all the counties in the state and simultaneously lead to an extension of benefits. If state-level shocks do not affect border counties similarly, i.e., $\chi \neq 0$, the estimated coefficient $\alpha$ would be biased in our baseline specification in Equation (14). The presence of this bias would be revealed, however, by implementing specification (21). If the bias is present, we would expect the coefficient $\chi$ on $\Delta z_{p}$ to be statistically different from zero and the coefficient $\alpha$ on benefit duration to change in magnitude and perhaps lose its statistical significance.

To implement this test in the data, we use two measures of state-level conditions $z$ - the state productivity and state-level unemployment instrumented with the Bartick shock. We discuss these two tests in turn.

\section{Endogeneity test using state productivity.}

Our first implementation of this test in the data uses state productivity defined as real gross state product per worker. We obtain data on state real GDP at a quarterly frequency from the Regional Economic Accounts at the Bureau of Economic Analysis. ${ }^{22}$ We then divide quarterly state GDP by quarterly state employment. The results are provided in Column (2) of Table 1. Note that including the difference in state productivity has almost no effect on the estimate of the effect of benefit duration on unemployment. These results provide clear evidence that our findings are not driven by a mechanical relationship between the economic conditions at the state level and the duration of unemployment benefits.

In Table 3 we also report the results of performing this test in a simpler specification with pair fixed effects:

$$
\Delta \tilde{x}_{p, t}=\alpha \Delta b_{p, t}+\lambda_{p}+\tilde{\nu}_{p, t}
$$

for the baseline, and

$$
\Delta \tilde{x}_{p, t}=\alpha \Delta b_{p, t}+\lambda_{p}+\chi \Delta z_{p}+\tilde{\nu}_{p, t}
$$

when state-level productivity is added to test for endogeneity.

We find that the estimated effects of benefits on unemployment using the factor model and the simple fixed effects model are quite similar. The coefficients estimated in both specifications are not changed by adding state level productivity.

\footnotetext{
${ }^{22}$ https://www.bea.gov/newsreleases/regional/gdp_state/2015/xls/qgsp0915_real.xlsx
} 
Table 3: Endogeneity Tests using Fixed Effects Model

\begin{tabular}{|c|c|c|c|c|c|c|}
\hline VARIABLES & $(1)$ & $(2)$ & $(3)$ & (4) & $(5)$ & $(6)$ \\
\hline & \multicolumn{3}{|c|}{ Baseline Sample } & \multicolumn{3}{|c|}{ Scrambled Sample } \\
\hline $\begin{array}{l}\text { Weeks of } \\
\text { Benefits }\end{array}$ & $\begin{array}{l}\mathbf{0 . 0 4 2 1} \\
(0.000)\end{array}$ & $\begin{array}{r}\mathbf{0 . 0 4 6 4} \\
(0.000)\end{array}$ & $\begin{array}{r}\mathbf{0 . 0 4 4 2} \\
(0.048)\end{array}$ & $\begin{array}{l}\mathbf{0 . 1 0 8 2} \\
(0.000)\end{array}$ & $\begin{array}{r}\mathbf{0 . 0 9 6 0} \\
(0.000)\end{array}$ & $\begin{array}{r}-0.0074 \\
(0.811)\end{array}$ \\
\hline $\begin{array}{l}\text { State GDP } \\
\text { per Worker }\end{array}$ & & $\begin{array}{l}-0.032 \\
(0.098)\end{array}$ & & & $\begin{array}{c}-\mathbf{0 . 0 8 2 1} \\
(0.001)\end{array}$ & \\
\hline $\begin{array}{l}\text { Instrumented } \\
\text { State Unemployment }\end{array}$ & & & $\begin{array}{r}-0.0713 \\
(0.795)\end{array}$ & & & $\begin{array}{l}\mathbf{- 1 . 4 1 4} \\
(0.000)\end{array}$ \\
\hline $\begin{array}{l}\text { Observations } \\
\text { R-squared }\end{array}$ & $\begin{array}{l}37,177 \\
0.4581\end{array}$ & $\begin{array}{l}37,177 \\
0.4601\end{array}$ & $\begin{array}{c}35,205 \\
0.565\end{array}$ & $\begin{array}{c}37,177 \\
0.642\end{array}$ & $\begin{array}{c}37,177 \\
0.490\end{array}$ & $\begin{array}{c}35,205 \\
0.642\end{array}$ \\
\hline
\end{tabular}

Note - $p$-values (in parentheses) calculated via bootstrap. Bold indicates $p<0.05$. Coefficients estimated using a model with border county pair fixed effects specifications in Eqs. (22)-(24).

Column (1) - Baseline sample,

Column (2) - Baseline sample controlling for state GDP per worker,

Column (3) - Baseline sample controlling for state unemp. instrumented with Bartik shocks,

Column (4) - Scrambled border county pairs sample,

Column (5) - Scrambled border county pairs sample controlling for state GDP per worker,

Column (6) - Scrambled border county pairs sample controlling for state unemployment instrumented with Bartik shocks.

Endogeneity test using Bartik shocks and state unemployment.

Our second implementation of the endogeneity test uses state-level unemployment instrumented with Bartik shocks:

$$
\Delta \tilde{x}_{p, t}=\alpha \Delta b_{p, t}+\lambda_{p}+\chi \Delta_{t, p} u_{t, s}+\tilde{\nu}_{p, t}
$$

where $\Delta_{t, p} u_{t, s}$ is the difference of the change in unemployment across the states the counties in the pair belong to instrumented with Bartik shocks. The results of implementing this test in the data reported in Column (3) of Table 3 indicate that the instrumented difference in state unemployment is statistically insignificant and including it in the regression does not affect the coefficient on benefits, consistent with the benchmark estimate being unbiased.

We instrument state unemployment with Bartik shocks because the endogeneity test must be based on an exogenous variable reflecting state-level economic conditions. As discussed below, the empirical literature typically relies on the state-level unemployment rate for this purpose. This raises the question whether the difference in non-instrumented state-level unemployment rates can be used directly in place of $\Delta z_{p}$ when testing for endogeneity. The answer is no and the logic is very simple. State unemployment is endogenous to benefits. When benefits are raised in a state, unemployment increases in every county of the state. Moreover, unemployment is a slow moving state (in a mathematical sense) variable in response to benefits. Thus, while benefits change abruptly, county and state unemployment co-move in response to this change. As a con- 
sequence, if one regresses county unemployment on benefits and state unemployment, benefits are not relevant, as all their impact is summarized by state unemployment. In other words, state unemployment is the only variable that has a predictive power for county unemployment in such a regression while benefits - that drive both the county and state unemployment are completely wiped out. In Appendix II we illustrate this point using data simulated from the model calibrated in Section 5.4 below. The model imposes exogeneity because the county and state-level shocks are orthogonal, yet the coefficient of benefits is erroneously estimated to be zero when non-instrumented state unemployment is included in the regression. Note that the same logic applies to the evaluation of any state-level policy that affects unemployment throughout the state. The effect of any such policy change would be entirely (but erroneously) attributed to state unemployment if it is included in the regression and is not instrumented.

The fact that the endogeneity tests indicate that economic fundamentals evolve smoothly across state borders implies that the size of the border counties relative to their state's is not a relevant consideration for our analysis. Even if one of the counties is large enough so that a shock to that county triggers a policy change at the state level, both counties in the pair are affect similarly by the shock so that the difference between them depends only on the difference in benefit policies. We can also verify this implication directly. To do so we restrict the sample to border county pairs such that each county in the pair accounts for no more than $15 \%$ of employment in the state that county belongs to. The results of re-estimating the benchmark specification on this sample are reported in Column (5) of Table 1. They confirm that the estimate of the effect of benefit extensions is virtually unaffected.

\subsubsection{Scrambled Border County Pairs}

In the previous section we tested for endogeneity and found that including difference in state productivities or instrumented state unemployments has a negligible effect on the estimated effect of benefit extensions, $\alpha$, and that the effects of these state-level variables, $\chi$, are not statistically different from zero. The results lent empirical support to our identification assumption (19).

An important remaining question to answer is whether the test based on state-level productivity or instrumented unemployment has power. To verify that it does, we randomly assign counties to pairs. That is, instead of pairing neighboring counties from different states, pairs are formed by randomly matching counties from the original set of the border counties. This mechanically introduces a discontinuity in economic conditions across the constructed "border"

county pairs, so that Case 2 described in the preceding section applies with the associated endogeneity bias. Consider again the example of county $a$ from state $A$ being matched to county $b$ from state $B$. With randomly assigned pairs, however, counties $a$ and $b$ do not border each other so that shocks to, say productivity of area $\mathcal{A}$ of state $A$ affect productivity in county 
$a$ but not in county $b$. If these shocks also affect economic conditions in state $A$, they would also be correlated with the difference in policies between States $A$ and $B$. This invalidates our identification assumption (19).

Consequently, estimating our benchmark specification (14) on a scrambled border county sample would yield a biased coefficient of interest $\alpha$ because $\nu_{p, t}$ is correlated with $\Delta b_{p, t}$ since both are correlated with $\Delta z_{p}$. The empirical results of the estimation are in Column (3) of Table 1 and show that the estimate of $\alpha$ is indeed substantially upward biased on a sample of randomly paired counties.

Next, we add the difference in state-level productivities to this regression as in specification (21). We expect to find a negative $\chi$ because of the endogeneity problem induced by the random pairing of counties. Adding state level productivity, however, alleviates the endogeneity problem and diminishes the bias in estimating $\alpha$. The bias is not expected to fully disappear when we add state level productivity since we do not control for other state variables, such as state demand, which are also correlated with $\nu_{p, t}$ leading to a bias. Results in Column (4) of Table 1 confirm this logic. Importantly, state-level productivity is highly significant in this sample of scrambled county pairs, illustrating the power of the test based on this variable.

Similarly, adding the difference in state unemployment instrumented with Bartik shocks to the regression in (21) estimated on the scrambled sample of "border" counties reveals a highly significant coefficient of this variable and leads to a substantial change of the coefficient on benefits. This is consistent with this estimation being biased (as expected) but reveals the power of the test based on this variable.

\subsection{LAUS Data Quality}

A potential concern with any empirical investigation is the quality of the underlying data. In the case of the analysis in this part of the paper the concern is with the construction of the county-level unemployment data by LAUS. In particular, if a component of county-level unemployment data was somehow imputed using state-level unemployment, this could give rise to the endogeneity problem discussed above whereby both benefit duration and measured county unemployment would be driven by underlying economic conditions in the state, such as productivity or demand in the state $z_{p}$. Fortunately, the endogeneity tests in Section 4.4 revealed this to not be the case. Indeed, we find that the difference in measured unemployment across border-county pairs is uncorrelated with the difference in state-level productivity or the difference in instrumented state unemployment (more precisely, $\operatorname{Corr}\left(\nu_{p, t}, \Delta z_{p}\right)=0$ ). This reveals that county-level unemployment estimated by the BLS does not reflect state-level variables to an important degree since otherwise this correlation would not be zero reflecting the negative correlation between state level productivity or demand and state unemployment.

We now describe the data construction by LAUS and implement modifications to their 
procedures to provide an alternative check of the appropriateness of the LAUS data for the analysis in this paper. ${ }^{23}$

\subsubsection{Removing Additivity Factors}

The primary labor force survey used to measure unemployment in the US is the Current Population Survey (CPS). Unfortunately, this survey is not representative at the county level. The objective of the LAUS program is then to estimate county level employment and unemployment in a way that would match as closely as possible the estimate that would have been obtained if a representative labor force survey was conducted in each county. To do so, the LAUS program draws on a variety of data sources. In addition to the CPS, the LAUS relies on large scale surveys and quarterly censuses of payroll employment as well as the data form the universe of jobs covered by the UI laws and data on the universe of UI claims. Using these data LAUS estimates using the observed relationships in the aggregate (not state-level) data the number of unemployed workers who left a UI covered job and remain unemployed at a particular point in time (have not exited the labor force). In addition, it uses the age distribution of the population in a county from the Census Bureau to predict the number of new entrants (or re-entrants) into the labor market who are not yet covered by the UI system. Taken together, this represents the estimate of county unemployment. The estimation of county-level number of new entrants is mainly based on aggregate relationships but it does use the fiveyear average state-level estimates of the number of new entrants. Although the use of only the long-run average of state-level variables in this step minimizes the concern that it may induce the endogeneity problem, we formally verify that it does not in Section 4.5.2. Prior to doing so, we assess the last step of the procedure in which current state-level variables may indeed enter the county-level estimates. In this step, the LAUS multiplies the unemployment estimate in each county of the state by the same "additivity factor" necessary to ensure that the sum of unemployment estimates across all counties in a state adds up to the total estimate of state unemployment.

Introducing this additivity adjustment may cause a bias in our estimates if the relationship between LAUS estimate and unmeasured unemployment (the additivity error) varies across the state. The endogeneity tests performed above indicate the lack of such a bias. In contrast, if the proportionality assumption is approximately correct, then not applying the additivity factors may lead to biased estimates when comparing border counties. Fortunately, we can directly assess the consequences of using the additivity adjustment on our estimates by undoing this

\footnotetext{
${ }^{23}$ In Appendix III we perform an alternative test of LAUS data quality as proposed in Hall (2013). Specifically, Hall (2013) noted that a regression of border county unemployment on unemployment in the state it belongs to and unemployment in the adjacent out-of-state county in some year with no benefit extensions, yields a relatively large and significant coefficient on state unemployment. We show that quantitatively similar results are obtained on administrative data free of data quality issues relevant for our analysis. Moreover, we explain that such results are expected and present no evidence of an endogeneity problem.
} 
step of the LAUS procedure. ${ }^{24}$ A direct comparison of the estimates on the data before and after the additivity adjustment is performed reveals that they are very similar, as can be seen in Column (6) of Table 1.

\subsubsection{Using Administrative Unemployment Claims Data}

To enable an additional independent verification of the quality of LAUS data, the BLS has agreed to provide us with 2005-2012 administrative data from the unemployment insurance system. The data include all continuing unemployment claims in the regular state unemployment insurance benefit program (i.e., during the first 26 weeks of an unemployment spell) by county. ${ }^{25}$ In addition, the data include the number of final payments, i.e. the number of unemployed who collected their final unemployment check under the regular state system (the $26^{\text {th }}$ week). The final payment data are available to us only at the Labor Market Area (LMA) level as defined by the BLS. ${ }^{26}$ A Labor Market Area may include a single or multiple counties in one or more states. As a consequence, we restrict the sample to single county LMAs. This leaves us with a sample of 278 border county pairs and 8,896 observations. Importantly, these continuing claims and final payments data are pure counts, and are not subject to any imputation or other adjustments (in particular, these data contain neither estimation of the number of new entrants nor any adjustment for additivity - the two steps in LAUS estimation procedure that might in theory give rise to endogeneity problem).

These data allow us to measure the job-finding rate of unemployment insurance claimants in their first 26 weeks of compensated unemployment (details of the procedure are in Appendix IV). Implementing our estimation procedure using the baseline specification in Equation (14) to measure the effect of benefit extensions on this job-finding rate, we find that the coefficient $\alpha_{f}=-0.0606$, with a p-value of 0.05 . The coefficient on benefit duration in the regression for the job-finding rate multiplied by one minus the unemployment rate should approximately equal the coefficient in the regression for unemployment, i.e. $\alpha_{f}(1-u) \approx-\alpha_{u}$. Using the value for the average unemployment rate of $7.01 \%$ over the period, we get $\alpha_{u}=0.0564$. Using instead LAUS county unemployment data to re-estimate our baseline specification on unemployment on this sample we find a nearly identical coefficient on benefit duration of 0.0499 , with a p-value of 0 . Thus, the effect of unemployment benefit extensions on unemployment as measured with administrative claims data is quantitatively consistent with the effect measured with LAUS county-level unemployment data. ${ }^{27}$

In addition to confirming the appropriateness of using LAUS data for our baseline empirical

\footnotetext{
${ }^{24}$ We are very grateful to the BLS for releasing the additivity factors underlying LAUS estimates to us.

${ }^{25}$ Importantly, unemployment benefit recipients must exhaust all state benefits before being eligible for federal extensions under either EUC or EB programs.

${ }^{26}$ The LMA directory is available at http://www.bls.gov/lau/lmadir.pdf.

${ }^{27}$ Note that our results imply that the ratio of county LAUS unemployment over county claimants does not respond to changes in benefits as it would if county unemployment was imputed using state-level unemployment.
} 
strategy, this result also highlights the quantitative importance of the equilibrium impact of benefit extensions on job creation. Our baseline analysis using LAUS data measures the effects of benefit extensions on all of the unemployed, including those who are ineligible to receive benefits. That measure therefore is a combination of the macro effect (which affects all unemployed) and the differential micro effect on search behavior of unemployed who are either eligible or ineligible to receive benefits. Using claims data, however, we exclusively focus on the unemployed who are eligible. If the micro effect was quantitatively important, the estimated coefficient on the claims sample should be significantly different from the one on the LAUS sample, since even at the depths of the recession the fraction of unemployed receiving claims did not exceed half of the unemployed. Our finding of similar effects of benefit extension on all unemployed in LAUS data and on benefit recipients in claims data suggests only a small role of micro elasticity, confirming existing estimates based on the data from the CPS. ${ }^{28}$

\subsection{Sensitivity of Estimates}

\subsubsection{Border Counties with Similar Industrial Composition}

As pointed out by Holmes (1998), the density of manufacturing industry employment varies systematically across counties within border pairs that belong to states with different right-towork legislation. Manufacturing industries and thus states with a large manufacturing sector have more cyclical unemployment. They may also have a more cyclical unemployment benefit policy, potentially giving rise to the endogeneity problem. If this cyclical heterogeneity across states is sufficiently empirically important, however, our interactive effects estimator picks it up through assigning a higher loading on the cyclical aggregate factor for more cyclical states.

As an additional and more general check, we now investigate whether differences in industrial composition affect our results. To this aim, we repeat the benchmark analysis on a subset of border counties with similar industrial composition. If the industrial composition affected our results, we would expect a different result in the subsample than in the full sample. We obtain data on county employment by industry from the Bureau of Economic Analysis, Regional Economic Information System. ${ }^{29}$ Using sample average industry employment shares within each county, we construct the $l^{2}$-distance between border counties within each pair. The results, presented in Column (7) of Table 1, are based on the sample of $50 \%$ of county pairs with the most similar industrial composition out of all border county pairs. The effect of unemployment benefit extensions on unemployment on this subsample is similar to the one found in our full sample.

\footnotetext{
${ }^{28}$ This conclusion will be further confirmed in Section 5 , where we estimate the effect of unemployment benefit extensions on the overall job finding rate measured using county-level job vacancy data and find it to be the same as the effect on the job finding rate of benefit claimants documented in this Section.

${ }^{29} \mathrm{http}: / /$ www.bea.gov/regional/
} 


\subsubsection{Degree of Economic Integration between Border Counties}

The degree of economic integration varies across county border pairs. This is relevant for the following reason. If two border counties have a fully integrated labor market with perfect mobility of workers, the residence and employment decisions are separated. In other words, the decision in which of the two counties to (look for) work is independent of the decision in which of the counties to live. Thus, in response to a change in benefits, say, in one of the states, residents of both counties adopt the same strategy of which county to work in. As unemployment is measured by the place of residence, it will be the same in both counties. Thus, our estimate of the effect of unemployment benefit extensions on unemployment would be severely biased toward zero.

In Section 6 we will present evidence that workers do not change the location of employment in response to changes in benefits and that labor markets in border counties are well approximated as closed economies. Here we explore whether the potential bias is large by restricting attention to a subsets of border counties with different degrees of geographic proximity and economic integration. In Column (8) of of Table 1 we consider a subset of counties with population centers that are at most 30 miles apart (which is the median distance between population centers in our sample of border county pairs). ${ }^{30}$ In Column (9) we further restrict the sample to include only counties with most integrated labor markets. To do so, we repeat the analysis on a restricted sample of border counties that belong to the same Core Based Statistical Areas (CBSAs). CBSAs represent a geographic entity associated with at least one core of 10,000 or more population, plus adjacent counties that have a high degree of social and economic integration with the core (see Office of Management and Budget (2010) for detailed criteria). The results of both experiments imply similar effect of unemployment benefit extensions on unemployment to the one found in our full sample.

\subsubsection{Alternative Benefit Duration Measure}

Our baseline measure of weeks of benefits available corresponds to the number of weeks a newly unemployed worker can expect to receive if current policies and aggregate conditions remained in force for the duration of the unemployment spell. An alternative, albeit extreme, assumption is that individuals have perfect foresight of the future path of benefits.

To construct the perfect foresight measure of available benefits, for a worker who becomes unemployed in a given week, we compute the realized maximum number of weeks available to him during the course of his unemployment spell (this takes into account extensions that are enacted after the spell begins).

The following example illustrates the construction of the two measures of benefit duration.

\footnotetext{
${ }^{30}$ We are grateful to Bob Hall for sharing the geolocation data on county population centers with us.
} 
Consider October 2009 in California. At the time, up to 26 regular weeks were available, in addition to 20 weeks in Tier 1 and 13 weeks in Tier 2 of EUC08 and 20 weeks in EB. Thus, under our baseline specification the measure of weeks available would be $26+20+13+20=79$ weeks. In November of 2009, the weeks available were expanded up to 99 total (two additional tiers were added) and the program continued to be extended at those benefit levels through September of 2012. So the perfect foresight measure would assign 99 weeks available to a worker that became unemployed in 2009.

The results based on the perfect foresight measure of available benefit duration are reported in Columns (10) of Table 1. Similar to the results based on the baseline measure of benefit availability, they continue to imply a quantitatively large impact of unemployment benefit duration on unemployment.

\subsubsection{Controlling for Other State-Level Policies}

Clearly, not only the unemployment insurance policies, but all state policies are discontinuous at state borders. Thus, an important question to answer is whether our analysis isolates the effects of unemployment benefit policies or picks up the effects of changes in some other state policies that are correlated over the sample period with unemployment and unemployment benefit extensions. While this is an important element of the analysis, due to space constraints, it is provided in Appendix V. Specifically, we collect data on and control for numerous tax, transfer, and regulatory policies at the state and county levels. We also control for the effects of stimulus spending and variation in foreclosure laws. We find that changes in no other state policies were sufficiently correlated with unemployment benefit extensions to affect our estimates.

\subsection{Comparison to Existing Empirical Estimates}

The existing literature measuring the impact of unemployment benefit extensions on unemployment has not yet attempted to measure the joint contribution of micro and macro effects. Nevertheless, the research design underlying some strands of the literature suggests that their estimates might be interpreted as suggestive of the magnitude of the total effect. We now review this literature.

One key strand in the relevant literature is based on the seminal contributions by Moffitt (1985), Katz and Meyer (1990), and Meyer (1990). ${ }^{31}$ These authors used administrative data on unemployment benefit recipients and exploited the cross-state variation in unemployment benefit extensions to measure the effect of the extensions on the hazard rate of leaving compensated unemployment. The effects found in this literature are sizable, implying that a one week increase in potential benefit duration increases the average duration of the unemployment spells

\footnotetext{
${ }^{31}$ Krueger and Meyer (2002) provide a survey of other important contributions to this strand of the literature.
} 
of UI recipients by 0.1 to 0.2 weeks. ${ }^{32}$ These studies were based on a sample of unemployed workers who collect benefits. To assess the effect of benefit duration on overall unemployment one also needs to know the impact on those unemployed who do not collect benefits. This was studied by Hagedorn et al. (2015c) who show that the job finding rate of ineligible workers responds as much as that of the eligible ones to the specific benefit extensions studied in these seminal contributions as well as during the Great Recession.

Consider the implications of these estimates. During the Great Recession unemployment benefits were extended 73 weeks from 26 to 99 weeks. Thus, these estimates imply an increase in unemployment duration between 7.3 and 14.6 weeks, i.e. the duration approximately doubles. But a doubling of duration implies that the exit rate from unemployment falls by a factor of two. This would then imply roughly a doubling of the unemployment rate, as can be seen from, e.g., the basic steady state relationship that balances flows in and out of unemployment, $u=s /(s+f)$. This is a considerably larger effect than the one we find.

However, the interpretation of these large consensus estimates is not clear. The literature was exploiting the variation of benefit duration across US states during the recessions of the early 1980s to measure the effects of benefit duration on the probability to find a job. As the regressions were estimated on state-level data, to obtain an unbiased estimate of this effect, one needs to control for all other aggregate factors affecting the state-level job finding rate. This can be accomplished by including a state-time dummy in the regression. The effect of benefits would then be identified from cross sectional variation among unemployed in time until their benefits run out. While this approach would identify the coefficient properly, the interpretation is important. The coefficient would only reflect the micro effect, that is the effect of benefits on individuals' incentives to search. The macro effect of benefits on labor demand would be instead subsumed by the state-time dummy alongside all other aggregate shocks.

Virtually all existing studies, however, include the state unemployment rate instead of a state-time dummy in the regressions of state-level job finding rates on benefit duration. While this cannot control for all aggregate factors, the underlying assumption must be that benefits and unemployment are orthogonal to all other aggregate factors. Note that even if this assumption were correct, the coefficient on benefits would be a convolution of the micro effect and some part of unknown magnitude and sign of the macro effect. However, this assumption is clearly erroneous because state unemployment and/or benefits are endogenous. This is easy to see. Consider some aggregate shock that affects the job finding rate in period $t-1$. By definition, this shock also affects unemployment (at the end of) period $t-1$. If the shock is persistent (and most aggregate shocks are), this shock also affects the job finding rate in period $t$. Thus, the right-hand-side variable unemployment is correlated with the error of the regression in which the job finding rate is the dependent variable. A biased regressor contaminates the

\footnotetext{
${ }^{32}$ Many influential studies find even larger effects, e.g. Ham and Rea (1987).
} 
whole regression. Similarly, past shocks to the labor market affect current benefits, rendering the estimated coefficient on benefits biased as well. Thus, the interpretation of coefficients in a regression of state-level job finding rate on benefits and state unemployment is very unclear, especially given that state-level benefits and unemployment are highly correlated.

Thus, at least in theory, the methodology in this literature can yield an estimate of the micro effect at the cost of ignoring the effect of benefit extensions on labor demand (by differencing it out or capturing it together with all other shocks in the state-time dummy). What the literature lacks is an identification strategy that accounts for the effect of unemployment benefit extensions on labor demand by forward looking job creators - the macro effect. The development of the necessary methodology is a contribution of this paper.

Another strand in the literature that might be suggestive of the magnitude of the total effect of unemployment benefit extensions is based on a quasi-experimental research design. In a seminal study following this research strategy, Card and Levine (2000) consider the experience of New Jersey that awarded 13 extra weeks of benefits to those whose regular 26 weeks of benefits expired between June and November of 1996. This unemployment benefit extension was a "side-effect" of a political process and was not driven by underlying economic conditions, minimizing the need to control for other aggregate shocks and the endogeneity of policy. The authors estimate that this policy lead to a $16.6 \%$ decline in the exit rate from unemployment, which implies a slightly smaller effect of policy than what is implied by the literature studying the effects of 1980 s extensions discussed above. ${ }^{33}$ The authors suggest that this might be driven by the fact that their experiment took place during a relatively prosperous period while earlier studies considered the effects of benefit extensions in recessions. What might be also important, however, is that neither of the two literatures has controlled for the effects of expectations regarding future policy changes. It is plausible that job creators where correctly expecting the 1980's benefit extensions to be more persistent, explaining a quantitatively larger response. Taking this into account, the magnitude of the effect found in Card and Levine (2000) is much larger than what our estimates would imply for such a small and transitory extension.

The fact that our estimates imply significantly smaller effects of unemployment benefit extensions relative to most earlier studies might also be consistent with a secular decline in the responsiveness of the labor market to this policy. Katz (2010) proposes that this might be due to a declining reliance by firms and industries on using temporary layoffs with recall dates tailored to benefit durations. We find some indirect support for this hypothesis. Specifically, we repeated the analysis in this paper using the data on benefit extensions during the earlier 2001 recession (using the 1996-2004 sample). We found the coefficient on benefit duration of 0.058 with a p-value of 0 . While this estimate still suggests smaller effects of benefit extensions than

\footnotetext{
${ }^{33}$ Specifically, Card and Levine (2000) find that a one week increase in potential benefit duration increases the average duration of unemployment spells of UI recipients by 0.08 weeks.
} 
Figure 4: The Macro Effect of the Cut in Potential Benefit Duration in Missouri in April 2011.

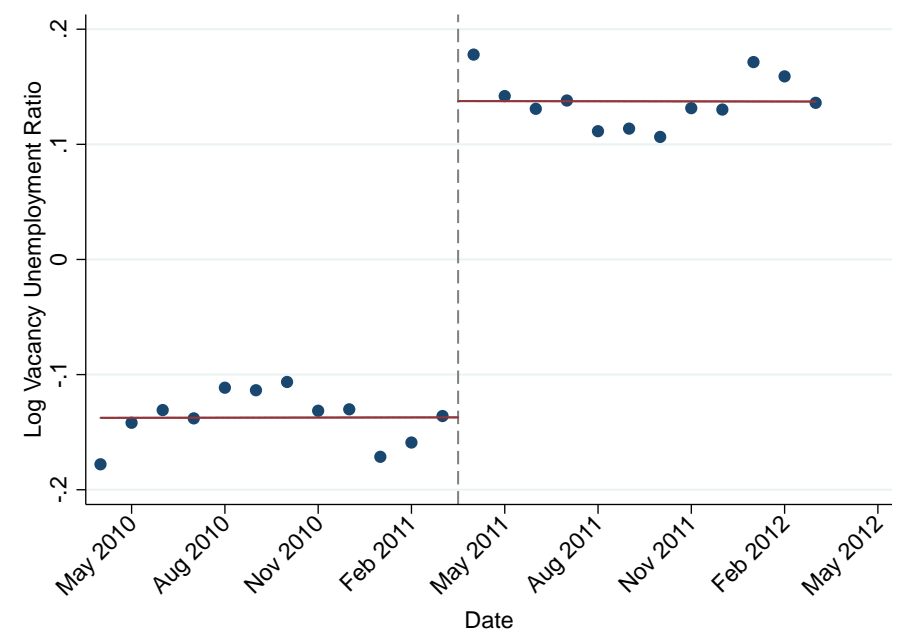

Note - The figure plots the difference in the log vacancy-unemployment ratio between border counties in Missouri and adjacent border counties across Missouri state borders. The dashed vertical line indicates the date when potential benefit duration was cut by 16 weeks in Missouri. Seasonal effects removed through a regression on a full set of month dummies.

found in the earlier literature using the 1908s and 1990s data, it is larger than our estimate of 0.049 using the later data from the Great Recession period.

A recent quasi-experimental study by Johnston and Mas (2015) assessed the impact of the sudden and unanticipated cut in potential benefit duration by 16 weeks in Missouri in April 2011. The cut applied only to new claimants while those who claimed benefits prior to the reform were grandfathered into the old potential benefit duration schedule. Comparing the hazards out of unemployment for these two samples the authors find a large micro effect, the magnitude of which is quite surprising given the estimates in the existing literature. Their experiment is, however, consistent with the presence of a very large macro effect on job creation which is evident in Figure 4. Specifically, we plot the seasonally adjusted monthly difference in the log vacancy-unemployment ratio between border counties in Missouri and their paired counties from bordering states during a year before and a year after the reform. We observe a sharp and discontinuous $28 \%$ rise in the vacancy-unemployment ratio in Missouri at the time of the reform. As predicted by the standard equilibrium search model, the jump was due to a sharp increase in job vacancy creation as unemployment declined only very gradually. Note that at least on impact, the jump in vacancy creation cannot be in response to higher search effort of new claimants eligible for fewer weeks of benefits following the reform simply because they represent a tiny fraction of all unemployed (only about a third of all unemployed were claiming benefits in Missouri at the time of the reform and it took a number of months for the claimants under the new rules to account for a meaningful share of all claimants).

While the implied macro effect appears very large, interpreting its magnitude is difficult for two reasons. First, this simple experiment does not control for job creators' expectations. 
Indeed, this experiment is likely to yield a lower bound on the true macro effect if job creators in Missouri assigned, prior to the reform, some probability to a future cut in benefit duration but were surprised by the specific timing of when the reform was implemented. Similarly, there is a downward bias if, upon observing the policy change in Missouri, job creators in neighboring states assigned a higher probability to similar benefit duration cuts taking place in their states. Second, it is difficult to draw econometrically sound conclusions robust to the influence of sampling uncertainty from essentially one data point provided by this reform. Consequently, in the next section we apply the methodology we developed to control for the effects of expectations in measuring the macro effects and expand the scope of the analysis to include all changes in benefit duration in all states in the contiguous US following the Great Recession. This analysis yields the estimate of the macro effects that is one third smaller than what the estimate based on the Missouri reform, taken at face value, suggests.

\section{The Role of Macro Effects}

In equilibrium labor market search models, the dynamics of unemployment over the business cycle and the response of unemployment to changes in policies are primarily driven by employers' vacancy creation decisions. Consider, for example, an increase in unemployment benefit duration. Having access to longer spells of benefits improves the outside option of workers and leads to an increase in the equilibrium wage. This lowers the accounting profits of firms and reduces vacancy posting to restore the equilibrium relationship between the cost of firm entry and the expected profits. Lower vacancy creation leads to a decline in labor market tightness, defined as the ratio of vacancies to unemployment. This lowers the job finding rate of workers and results in an increase in unemployment.

In this section, we present evidence on the empirical relevance of these macro effects. In particular, we document the effect of unemployment benefit extensions on vacancy creation, employment, and wages in the data. We also compare the magnitude of these empirical findings to those in a calibrated equilibrium search model.

\subsection{Unemployment Benefit Extensions and Vacancy Creation}

We begin by considering the effect of unemployment benefit extensions on vacancy posting by employers and on labor market tightness using HWOL data and the basic specification in Equation (14). The results are reported in Columns (1) and (2) of Table 4. We find that changes in unemployment benefits have a large and statistically significant short-run effect on vacancy creation: a $1 \%$ rise in benefit duration for only one quarter lowers the number of vacancies by $0.042 \log$ points and labor market tightness by $0.086 \log$ points. ${ }^{34}$

\footnotetext{
${ }^{34}$ In theory there should be an exact mapping between our results in Tables 1 and 4 for (log) unemployment, vacancies and tightness, since $\log (\theta)=\log (V)-\log (U)$. The very minor discrepancy in our estimates arises
} 
Table 4: Unemployment Benefit Extensions and Job Creation

\begin{tabular}{lccccc}
\hline VARIABLES & Vacancies & Tightness & QCEW Emp & QWI Emp & Wages \\
& $(1)$ & $(2)$ & $(3)$ & $(4)$ & $(5)$ \\
\hline Weeks of Benefits & $\mathbf{- 0 . 0 4 2}$ & $\mathbf{- 0 . 0 8 6}$ & $\mathbf{- 0 . 0 0 3 0}$ & $\mathbf{- 0 . 0 0 3 8}$ & $\mathbf{0 . 0 0 9 9}$ \\
& $(0.020)$ & $(0.000)$ & $(0.035)$ & $(0.000)$ & $(0.070)$ \\
N. factors & 1 & 1 & 4 & 3 & 2 \\
Observations & 34,617 & 34,617 & 36,971 & 36,962 & 36,962 \\
R-squared & 0.104 & 0.102 & 0.959 & 0.930 & 0.550 \\
\hline
\end{tabular}

Note - $p$-values (in parentheses) calculated via bootstrap. Bold indicates $p<0.1$.

In the standard equilibrium search model, the matching function implies a tight relationship between changes in unemployment, vacancies, and tightness. As we have obtained independent estimates of the effects of benefit extensions on these variables, it is of interest whether their magnitudes are mutually consistent. The following calculation establishes that this is indeed the case.

Assuming that the matching function is of the commonly used Cobb-Douglas type,

$$
M(u, v)=\mu v^{1-\gamma} u^{\gamma},
$$

allows us to relate the change in tightness to the change in unemployment. Since the job finding rate is given by

$$
f=\mu \theta^{1-\gamma},
$$

the implied change in $f$ induced by a change in benefits equals $-(1-\gamma) \times 0.086$. Since the elasticity of the steady-state unemployment rate $u$ with respect to $f$ equals $1-u$, the implied change in $u$ (due to the change in tightness induced by the change in benefits) equals

$$
(1-u)(1-\gamma) \times 0.086
$$

Given the best available estimate in Brügemann (2008) of $\gamma=0.4$, and assuming $u=0.05$, the implied change equals 0.049 . This value is the same as the actual change in unemployment reported in Table 1.

Note that this result also points toward only a small effect of benefit extensions on search effort and job acceptance decisions by the unemployed. Changes in these decisions by the unemployed would translate into changes in the parameter $\mu$ of the matching function (i.e., a decline in the job finding rate for a given vacancy-unemployment ratio). We find very lim-

because (1) we have unemployment data for more county pairs than we do for vacancy data so that the estimates are obtained on slightly different samples, and (2) benefit duration is not the only regressor as we use an interactive-effects estimator (Bai, 2009) which adds an estimated number of factors to the regression. The estimation procedure is unlikely to select exactly the same aggregate factors for the three data series (even simply including time and county-pair fixed effects would not guarantee an exact mapping of the two tables' results). The coefficients do add up exactly, of course, if we use an OLS on the same samples and with benefits as the only regressor. 
ited evidence of such changes being induced by unemployment benefit extensions given the conventional estimates of the matching function elasticity. ${ }^{35}$

\subsection{Unemployment Benefit Extensions and Employment}

In Columns (3) and (4) of Table 4 we report the effect of unemployment benefit extensions on employment using QCEW and QWI data, respectively. We find a large negative effect implying that a rise in unemployment associated with an extension of unemployment benefits is similar in magnitude to the decline in employment. This finding challenges the wisdom of relying on unemployment benefit extensions as a policy to stimulate aggregate demand. The large decline in employment associated with such policies is likely to substantially dampen any potential stimulative effects. Note that the effect of unemployment benefit extensions on employment that we find is quantitatively similar to the one measured in Hagedorn et al. (2015b) who used a different source of variation for identification and relied on a different empirical methodology.

A hypothesis often mentioned in the literature following Solon (1979) is that the rise in unemployment in response to unemployment benefit extensions might be driven by measurement issues. In particular, workers who collect benefits claim to be actively searching for a job in response to surveys used to determine the unemployment rate, while in reality they are not. In other words, had benefits not been extended, these workers would have reported themselves as being out of the labor force. The decline in the vacancy rates and employment documented here provides evidence against the quantitative importance this hypothesis. In fact, using Equation (12), we can compute the effect of permanently extending benefits to 99 weeks on employment:

$$
\frac{-0.003}{1-\beta(1-s)} \times(\log (99)-\log (26))=-0.037
$$

Thus, the long-run average employment rate would decrease from 95\% to 91.3\%. This 3.7 percentage point decrease is of a comparable magnitude to the 4.1 percentage point increase in the unemployment rate found in the corresponding experiment in Section 4.1.

Assuming perfect foresight of future benefits, in Section 4.1 we found that benefit extensions increased unemployment by 2 percentage points in 2011. The same calculation implies that employment in 2011 was lower by 2 percentage points due to benefit extensions. Thus, benefit extensions led to a decline in employment and an increase in unemployment of the same magnitude.

Note that our estimate of the effect of unemployment benefit extensions on employment is

\footnotetext{
${ }^{35}$ Note that the corollary of this argument, at least in standard empirically relevant models, is that the effect of unemployment insurance generosity on the unemployment entry rate, conditional on the vacancy-unemployment ratio, cannot be large either. This is because job acceptance and separation decisions are symmetric: Work if the surplus is nonnegative and enter/rejoin the unemployment pool otherwise. Thus, if unemployment benefit extensions do not have a quantitatively large impact on job acceptance decisions, they are also unlikely to have a significant impact on the (equivalent) quit decisions.
} 
based on the difference across border counties. We then use the resulting coefficient to predict the effect of a nation-wide extension. A potential concern with such a procedure is that when some states extend benefits more than others, economic activity and, thus, employment may reallocate to states with lower benefits. This reallocation is picked up by our estimates but would be absent if the policy was changed nation-wide. We find no empirical justification for such a concern. In particular, we apply our empirical methodology to measure the change in employment in sectors producing output that is plausibly non-tradable across states, such as retail or food services. If the change in employment is driven to an important degree by reallocation, we would not expect benefit extensions to have a large effect on these sectors. Instead, we find that a $1 \%$ rise in benefit duration for one quarter leads to a decline of employment by 0.011 and $0.010 \log$ points in retail and food services sectors, respectively. Both effects are statistically significant at 1\%. In addition, Hagedorn et al. (2015a) use the Nielsen Consumer Panel Data to measure the responsiveness of cross state border shopping to changes in unemployment benefit generosity. Their results indicate that this effect is negligible.

\subsection{Unemployment Benefit Extensions and Wages}

We have established that extensions of unemployment benefits lead to a decline in job creation by employers. In a standard equilibrium search model such a response is induced by the fact that longer expected benefit eligibility improves the outside option of workers and

leads to an increase in the equilibrium wage. We now assess whether this equilibrium effect is consistent with the data.

Consider the wage of a worker $i$ in county $a$ in pair $p$ which depends on county productivity $z^{a}$, county market tightness $\theta^{a}$, benefits $b^{a}$ and idiosyncratic productivity $\phi^{i}$ :

$$
\log \left(w_{t}^{i}\right)=\beta_{0}+\beta_{z} \log \left(z_{t}^{a}\right)+\beta_{\theta} \log \left(\theta_{t}^{a}\right)+\beta_{b} \log \left(b_{t}^{a}\right)+\log \left(\phi_{t}^{i}\right)+\eta_{t}^{i}
$$

where $\eta$ is a measurement error. Theory predicts that the equilibrium wage, conditional on county productivity, demand, etc, increases when UI becomes more generous. It is important to emphasize that we are referring to the response of the equilibrium wage, which is also negatively affected by a drop in market tightness caused by a negative response of job creation to the policy change. The fact that the equilibrium wage combines the positive direct effect of benefit extensions and the negative effect induced by the equilibrium response of job creation, makes the identification of the net equilibrium effect on wages more demanding on the data.

The crucial issue in studying the dynamics of wages is selection. The idiosyncratic productivity of workers moving from non-employment to employment or from job to job depend on business cycle conditions (Gertler and Trigari (2009), Hagedorn and Manovskii (2013)). Idiosyncratic productivity can be decomposed into permanent ability $\mu^{i}$, job specific productivity 
$\kappa^{i}$ and a stochastic component $\epsilon^{i}$ :

$$
\log \left(\phi_{t}^{i}\right)=\log \left(\mu_{t}^{i}\right)+\log \left(\kappa_{t}^{i}\right)+\log \left(\epsilon_{t}^{i}\right) .
$$

The decision of a non-employed to accept a job depends on $z_{t}, \mu_{t}^{i}$, the job-specific productivity $\hat{\kappa}$ as well as on benefits $b$. The decision of a worker to switch jobs depends on the worker's current job specific productivity $\kappa_{t}^{i}$ and the job-specific productivity in the new job $\hat{\kappa}$. Productivity $\hat{\kappa}$ is a random draw from a distribution $F$. A worker who has received $N$ offers during a period accepts the highest draw $\kappa$, which is distributed according to $F^{N}$. Since the $F^{N}$ are ordered by first-order stochastic dominance, the expected value of $\kappa$ is increasing in $N$ and is thus increasing in the number of vacancies. A more generous unemployment insurance system leads to a drop in vacancy posting and therefore to fewer offers and a lower expected value of $\kappa$. By the Law of Large Numbers, workers starting a new job in a recession or when benefits are high then have a lower average value of $\kappa$ than workers starting a job when many offers are available such as in a boom or when benefits are low. Thus, if we regress wages on benefits we also pick up the impact of benefits on the average value of $\kappa .^{36}$ To deal with this issue, we follow Hagedorn and Manovskii (2013) and consider job stayers, defined as workers who have the same job in periods $t$ and $t+1$ and thus also the same value of $\kappa$. Taking differences across time for a job stayer yields

$$
\begin{aligned}
& \log \left(w_{t+1}^{i}\right)-\log \left(w_{t}^{i}\right) \\
= & \beta_{z}\left(\log \left(z_{t+1}^{a}\right)-\log \left(z_{t}^{a}\right)\right)+\beta_{\theta}\left(\log \left(\theta_{t+1}^{a}\right)-\log \left(\theta_{t}^{a}\right)\right)+\beta_{b}\left(\log \left(b_{t+1}^{a}\right)-\log \left(b_{t}^{a}\right)\right) \\
+ & \log \left(\epsilon_{t+1}^{i}\right)-\log \left(\epsilon_{t}^{i}\right)+\eta_{t+1}^{i}-\eta_{t}^{i},
\end{aligned}
$$

that is the terms $\mu^{i}$ and $\kappa^{i}$ drop out. We therefore consider a group of workers who worked in period $t$ and $t+1$ for the same employer with average wages $w_{t, t}^{a}$ in period $t$ and $w_{t, t+1}^{a}$ in period $t+1$. Theory then predicts that regressing the difference in wages $\log \left(w_{t, t+1}^{a}\right)-\log \left(w_{t, t}^{a}\right)$ on the difference in benefits, $\log \left(b_{t+1}^{a}\right)-\log \left(b_{t}^{a}\right)$, yields a positive coefficient. We again have to control for the endogeneity of policy and to this end we again invoke assumption (19) and consider the difference across paired border counties. Taking differences across counties $a$ and $b$ in the same pair $p$ of $\log \left(w_{t, t+1}^{a}\right)-\log \left(w_{t, t}^{a}\right)$ and $\log \left(w_{t, t+1}^{b}\right)-\log \left(w_{t, t}^{b}\right)$ yields

$$
\begin{aligned}
& \left(\log \left(w_{t, t+1}^{a}\right)-\log \left(w_{t, t}^{a}\right)\right)-\left(\log \left(w_{t, t+1}^{b}\right)-\log \left(w_{t, t}^{b}\right)\right) \\
= & \beta_{\theta}\left(\left(\log \left(\theta_{t+1}^{a}\right)-\log \left(\theta_{t}^{a}\right)\right)-\left(\log \left(\theta_{t+1}^{b}\right)-\log \left(\theta_{t}^{b}\right)\right)\right) \\
+ & \beta_{b}\left(\left(\log \left(b_{t+1}^{a}\right)-\log \left(b_{t}^{a}\right)\right)-\left(\log \left(b_{t+1}^{b}\right)-\log \left(b_{t}^{b}\right)\right)\right)+\vartheta_{t},
\end{aligned}
$$

where $\vartheta_{t}$ collects all error terms and stochastic components unrelated to policy. We then regress

\footnotetext{
${ }^{36}$ Benefits may also affect $\kappa$ by making liquidity constrained workers more selective in the jobs they accept.
} 
this double difference of wages on the double difference in benefits:

$$
\begin{aligned}
& \left(\log \left(w_{t, t+1}^{a}\right)-\log \left(w_{t, t}^{a}\right)\right)-\left(\log \left(w_{t, t+1}^{b}\right)-\log \left(w_{t, t}^{b}\right)\right) \\
= & \tilde{\beta}_{b}\left(\left(\log \left(b_{t+1}^{a}\right)-\log \left(b_{t}^{a}\right)\right)-\left(\log \left(b_{t+1}^{b}\right)-\log \left(b_{t}^{b}\right)\right)\right)+\tilde{\vartheta}_{t} .
\end{aligned}
$$

The coefficient $\tilde{\beta}_{b}$ captures the equilibrium wage response which, using (29), combines the direct effect of benefits on wages, $\beta_{b}$, and the indirect effect of benefits on market tightness $\theta, \beta_{\theta} \beta_{\theta, b}$, where $\beta_{\theta, b}$ is the regression coefficient of market tightness on benefits,

$$
\tilde{\beta}_{b}=\tilde{\beta}_{b}+\beta_{\theta} \beta_{\theta, b} .
$$

We therefore obtain instead of the potentially large direct effect $\beta_{b}$ the smaller equilibrium response $\tilde{\beta}_{b}$ which takes into account the benefit induced change in market tightness and its effect on wages. It is the latter, the equilibrium response, $\tilde{\beta}_{b}$, which theory predicts to be positive.

To implement this procedure, we obtain wage data from the QWI that allows us to measure wages of job stayers. The QWI provides a measure of full quarter employment - workers who remained employed at the same firm for the entire quarter - and average wage earnings of full quarter employees. However, in quarter $t$ the measure of full quarter employment also includes workers who will separate in $t+1$, and in quarter $t$ the measure includes new hires from quarter $t$. Thus, to isolate the wages of stayers we difference out the average wages of $t+1$ separators (also available from QWI) from the average wages in $t$ and difference out the average $t$ new hire wages from the average wages in $t+1$. This yields the true average wages of stayers in quarters $t$ and $t+1$.

Column (5) of Table 4 shows the result. We find that wages statistically significantly increase in response to an increase in benefits. ${ }^{37}$ As we explain in Appendix VI, the increase in wages of job stayers indicates that benefit extensions increase the outside option available to these workers when they bargain on the job, consistent with the existing US laws and UI system regulations. Note that the increase in wages that we document provides strong evidence for the general equilibrium effects. Indeed, if higher unemployment was not caused by unemployment benefit extensions, one would expect wages to be lower in counties with higher unemployment.

\subsection{Validation using Model-Generated Data}

In this Section we evaluate the performance of our empirical method on data generated by a calibrated equilibrium search model. The model is an extension of Mortensen and Pissarides (1994) to allow for unemployment benefit expiration.

To address the border county design, the model features a nested state-county structure. In

\footnotetext{
${ }^{37}$ To assess the quantitative magnitude of this estimate consider a typical county pair in the Great Recession. The estimate implies that a county with 70 weeks of benefits has a $0.33 \%$ higher level of wages than a county with 50 weeks of benefits, everything else equal.
} 
particular, there is a stochastic process for state's productivity. The unemployment benefit policy depends on the endogenous unemployment level in the state economy. The county economy takes the endogenously induced joint stochastic process for state unemployment, productivity and benefits as exogenous. The assumption is that counties are "small" relative to the state of which they are apart.

Preferences, technology and frictions are the same across the state and county economies.

Agents. In any given period, a worker can be either employed (matched with a firm) or unemployed. Risk-neutral workers maximize expected lifetime utility

$$
U=\mathbb{E}_{0} \sum_{t=0}^{\infty} \beta^{t} c_{t},
$$

where $\mathbb{E}_{0}$ is the period-0 expectation operator, $\beta \in(0,1)$ is the discount factor, $c_{t}$ denotes consumption in period $t$. An unemployed worker produces $h$, which stands for the combined value of leisure and home production. In addition, unemployed workers may be eligible for benefits $b$. Unemployed workers who are eligible for benefits lose eligibility stochastically at rate $e_{t}(\cdot)$, which depends on the state unemployment rate as specified below.

Firms are risk-neutral and maximize profits. Workers and firms have the same discount factor $\beta$. A firm can be either matched to a worker or vacant. A firm posting a vacancy incurs a flow cost $k$.

Matching. The number of new matches in period $t$ is given by $M\left(u_{t}, v_{t}\right)$, where $u_{t}$ is the number of unemployed in period $t$, and $v_{t}$ is the number of vacancies. The matching function is assumed to be constant returns to scale, and strictly increasing and strictly concave in both arguments. We define $\theta_{t}=v_{t} / u_{t}$ as the market tightness in period $t$. We then define the jobfinding probability as $f\left(\theta_{t}\right)=M\left(u_{t}, v_{t}\right) / u_{t}=M\left(1, \theta_{t}\right)$ and the probability of filling a vacancy as $q\left(\theta_{t}\right)=M\left(u_{t}, v_{t}\right) / v_{t}=M\left(1 / \theta_{t}, 1\right)$. By the assumptions on $M$ made above, the function $f\left(\theta_{t}\right)$ is increasing in $\theta_{t}$ and $q\left(\theta_{t}\right)$ is decreasing in $\theta_{t}$. Existing matches are destroyed with exogenous job separation probability $\delta$.

Production. A matched worker-firm pair produces output $z_{t}$, which follows a first order Markov process. Firms pay workers a wage $w_{t}$, determined through Nash bargaining with workers' bargaining power $\xi$. Thus, the period profit of a matched firm is given by $\pi_{t}=z_{t}-w_{t}$.

\subsubsection{State Economy}

In the state economy the benefit expiration policy depends on the state unemployment rate, $e_{t}\left(u_{t}^{S}\right)$. We assume ineligible workers regain eligibility as soon as they are matched with a firm. The relevant state variables for the state economy are thus the exogenous state productivity $z_{t}^{S}$ and the endogenous unemployment rate $u_{t}^{S}$. Let $\Omega_{t}^{S}=\left(z_{t}^{S}, u_{t}^{S}\right)$. The state law of motion for 
employment is therefore:

$$
L_{t+1}^{S}\left(\Omega_{t}^{S}\right)=(1-\delta) L_{t}^{S}+f\left(\theta_{t}^{S}\right)\left(1-L_{t}^{S}\right)
$$

and $u_{t}^{S}=1-L_{t}^{S}$.

Value Functions. The flow value for a firm employing a worker is

$$
J_{t}^{S}\left(\Omega_{t}^{S}\right)=z_{t}^{S}-w_{t}^{S}+\beta(1-\delta) \mathbb{E} J_{t+1}\left(\Omega_{t+1}^{S}\right)
$$

and the flow value of a vacant firm is:

$$
V_{t}^{S}\left(\Omega_{t}^{S}\right)=-k+\beta q\left(\theta_{t}^{S}\right) \mathbb{E} J_{t+1}\left(\Omega_{t+1}^{S}\right),
$$

where $k$ is the flow cost of maintaining a vacancy. The surplus for a firm employing a worker is thus $J_{t}^{S}-V_{t}^{S}$.

The value functions for workers can be written as:

$$
\begin{aligned}
W_{t}^{S}\left(\Omega_{t}^{S}\right)= & w_{t}^{S}+\beta(1-\delta) \mathbb{E} W_{t+1}^{S}+\beta \delta\left(1-e_{t}\left(\Omega_{t}^{S}\right)\right) \mathbb{E} U_{t+1}^{S, E}\left(\Omega_{t+1}^{S}\right) \\
& +\beta \delta e_{t}\left(\Omega_{t}^{S}\right) \mathbb{E} U_{t+1}^{S, I}\left(\Omega_{t+1}^{S}\right) \\
U_{t}^{S, E}\left(\Omega_{t}^{S}\right)= & h+b+\beta f\left(\theta_{t}^{S}\right) \mathbb{E} W_{t+1}^{S}\left(\Omega_{t+1}^{S}\right)+\beta\left(1-f\left(\theta_{t}^{S}\right)\right)\left(1-e_{t}\left(\Omega_{t}^{S}\right)\right) \mathbb{E} U_{t+1}^{S, E}\left(\Omega_{t+1}^{S}\right) \\
& +\beta\left(1-f\left(\theta_{t}^{S}\right)\right) e_{t}\left(\Omega_{t}^{S}\right) \mathbb{E} U_{t+1}^{S, I}\left(\Omega_{t+1}^{S}\right) \\
U_{t}^{S, I}\left(\Omega_{t}^{S}\right)= & h+\beta f\left(\theta_{t}^{S}\right) \mathbb{E} W_{t+1}\left(\Omega_{t+1}^{S}\right)+\beta\left(1-f\left(\theta_{t}^{S}\right)\right) \mathbb{E} U_{t+1}^{S, I}\left(\Omega_{t+1}^{S}\right)
\end{aligned}
$$

where $W_{t}^{S}$ s the value of a job for a worker, $U_{t}^{S, E}$ is the value of unemployment for an agent eligible for benefits and $U^{S, I}$ is the value of unemployment for a non-eligible agent. Define the surplus of being employed as $\Delta_{t}^{S, E}=W_{t}^{S}-U_{t}^{S, E}$. Also define the surplus for an unemployed worker of being eligible: $\Phi_{t}^{S}=U_{t}^{S, E}-U_{t}^{S, I}$. The laws of motion for these quantities are:

$$
\begin{aligned}
\Delta_{t}^{S, E}\left(\Omega_{t}^{S}\right)= & w_{t}^{S}-h-b+\beta\left(1-\delta-f\left(\theta_{t}^{S}\right)\right) \mathbb{E} \Delta_{t+1}^{S, E}\left(\Omega_{t+1}^{S}\right) \\
& +\beta\left(1-\delta-f\left(\theta_{t}^{S}\right)\right) e_{t}\left(\Omega_{t}^{S}\right) \mathbb{E} \Phi_{t+1}^{S}\left(\Omega_{t+1}^{S}\right), \\
\Phi_{t}^{S}\left(\Omega_{t}^{S}\right)= & b+\beta\left(1-f\left(\theta_{t}^{S}\right)\right)\left(1-e_{t}\left(\Omega_{t}^{S}\right)\right) \Phi_{t+1}^{S}\left(\Omega_{t+1}^{S}\right) .
\end{aligned}
$$

The wage is chosen to maximize:

$$
\left(\Delta_{t}^{S, E}\left(\Omega_{t}^{S}\right)\right)^{\xi}\left(J_{t}^{S}\left(\Omega_{t}^{S}\right)-V_{t}^{S}\left(\Omega_{t}^{S}\right)\right)^{1-\xi} .
$$

State Equilibrium Definition. Given a policy $\left(b, e_{t}(\cdot)\right)$ and an initial condition $\Omega_{0}^{S}$ an equilibrium is a sequence of $\Omega_{t}^{S}$-measurable functions for wages $w_{t}$, market tightness $\theta_{t}^{S}$, employment $L_{t}^{S}$, and value functions $\left\{W_{t}^{S}, U_{t}^{S, E}, U_{t}^{S, I}, J_{t}^{S}, V_{t}^{S}, \Delta_{t}^{S}\right\}$ such that:

1. The value functions satisfy the worker and firm Bellman equations (30), (31), (32), (33), (34);

2. Free entry: The value $V_{t}^{S}$ of a vacant firm is zero for all $\Omega_{t}^{S}$; 
Table 5: Internally Calibrated Parameters

\begin{tabular}{llclcc}
\hline \hline & Parameter & Value & Target & Data & Model \\
$h$ & Value of non-market activity & 0.6124 & Regression Coefficient & 0.049 & 0.049 \\
$\xi$ & Bargaining power & 0.0982 & Mean tightness & 0.634 & 0.634 \\
$\gamma$ & Matching function parameter & 0.4012 & Mean job finding rate & 0.139 & 0.139 \\
\hline
\end{tabular}

3. Nash bargaining: The wage satisfies equation (37);

4. Law of motion for employment: The employment process satisfies (29).

\subsubsection{County Economy}

The county is assumed to be small with respect to the state of which it is a member. That is, the county unemployment rate is not assumed to affect the state unemployment rate and the county productivity process is orthogonal to the state one. The benefit expiration policy for the county, however, depends on the state unemployment rate. Thus, in addition to exogenous county productivity, $z^{C}$, the state productivity and the state unemployment rate will be state variables (since they are jointly sufficient to forecast benefit policy). Thus, denote the vector of states for the county $\Omega_{t}^{C}=\left(z_{t}^{C} ; z_{t}^{S}, u_{t}^{S}\right)$. All of the equations governing workers and firms are the same as in the state's economy with the appropriately adjusted state vector. The definition of equilibrium is modified to add an additional condition, namely that the joint process for $\left(z_{t}^{S}, u_{t}^{S}\right)$ is consistent with the state equilibrium. The full equations and definition of the county equilibrium can be found in Appendix VII.

\subsubsection{Calibration}

The calibration strategy we employ is to require the state economy to be consistent with key labor market statistics and to match the effect of unemployment benefit extensions on unemployment estimated in Section 4.1. The model period is taken to be one week. We match the average labor market tightness, the average job finding rate, and the regression coefficient of quasi-differenced unemployment on benefit duration. The calibrated parameters are summarized in Table 5. In order to be consistent with the existing EB program, in the calibration we set benefit expiration policy at 26 weeks when state unemployment is less than $6.5 \%, 39$ weeks when unemployment is between $6.5 \%$ and $8 \%$ and 46 weeks when greater than $8 \%$. The remainder of the parameters are calibrated externally, using the same values and parametric forms for the matching function as Hagedorn and Manovskii (2008).

\subsubsection{Quantitative Evaluation}

The goal of the simulation exercise is to generate synthetic data at the county level comparable to the actual data. We simulate two states and one county in each of them. The two 
Table 6: Estimated Permanent Effect of a 10 Week Benefit Extension from Regressions Coefficients in Model Generated Data

\begin{tabular}{lccc}
\hline VARIABLES & $\begin{array}{c}\text { Unemp. } \\
(1)\end{array}$ & $\begin{array}{c}\text { Vacancies } \\
(2)\end{array}$ & $\begin{array}{c}\text { Tightness } \\
(3)\end{array}$ \\
\hline Data & 0.146 & -0.126 & -0.258 \\
Model & 0.151 & -0.135 & -0.287 \\
\hline
\end{tabular}

states and the two counties each have the same process for productivity. The counties, consistent with our border county assumption, have the same realized sequence of shocks. The two states, however, have different realized sequences of productivity shocks. Consequently, the realized endogenous sequences of state unemployment will be different. Thus, the two counties will have a different time series of unemployment benefits.

We simulate the two states and the two counties for 100 years and throw out the first 15 years of data as "burn-in." We then estimate the same regression (with quasi-differenced unemployment on the left-hand side) as we do on the data from the Great Recession. Recall that our calibration strategy ensures that coefficient on the difference in benefits in this regression is the same in the data and in the simulations of the model. Then, we calculate the effect of a permanent 10-week increase in benefits on unemployment, vacancies and tightness. We then compare these true permanent effects from the model to the calculated permanent effects from the data. The results and relevant comparisons are displayed in Table 6. The model generated data confirms the empirical validity of our specification, as our model, calibrated to generate the same regression coefficient on unemployment benefit duration from the data delivers right permanent effects on unemployment, vacancies and tightness. These effects are induced by changes of wages in the model that are also of the right magnitude. Replicating the regression of wages on benefit duration described in Section 5.3 on model generated data yields a coefficient of 0.0078 , similar to its empirical counterpart reported in Table 4.

\section{Change in Location of Employment in Response to Changes in Benefits}

A potential concern arises from the observation that households may live in different states than where they work. This would bias our estimates if the households systematically change their job search behavior in response to changes in unemployment benefits. For example, if households search in states with less generous benefits to take advantage of a higher jobfinding rate, our estimate of the effect of benefit extensions on unemployment would be biased downwards, since those households would face a higher job-finding rate, which would translate into a lower unemployment rate in that county. In this section, we use two different methods to show that our analysis is not affected by such a bias. First, we develop an imputation procedure 
that allows to estimate the effects of unemployment benefit extensions while fully accounting for mobility. Second, we provide direct empirical evidence of job search behavior. Both approaches confirm that search behavior does not vary systematically with changes in benefits, validating our use of a simple and transparent specification that ignores mobility decisions.

Because integrated labor markets generally contain multiple neighboring counties, instead of focusing on the county pair as the unit of analysis for search behavior we aggregate all counties on both sides of a border segment and perform the imputation on that "border segment" pair. To impute what fraction of workers search in the state where they live, consider the following model. We consider the local economy to consist of a pair of state border segments $A, B$. The segments are populated by labor forces of size $n_{t}^{A}$ and $n_{t}^{B}$ (taken as the sum of all the border county labor forces in each state on the respective side of the border) and populations $p_{t}^{A}$ and $p_{t}^{B}$.

In any given period, a worker can be either employed (matched with a firm), unemployed or not in the labor force. In period $t$, firms in state $A$ post vacancies in state $A, v_{t}^{A}$. An unemployed worker in state $A$ searches either in state $A$ or in state $B$. We assume that a fraction $\zeta$ of nonlabor force participants (observed in the LAUS data) enter the labor force and search for jobs. The number of new matches in state $\mathrm{A}$ in period $t$ equals

$$
M\left(\tilde{u}_{t}^{A}, v_{t}^{A}\right),
$$

where $\tilde{u}_{t}^{A}$ is the measure of individuals in period $t$ searching in state $A$. The number of matches is the same for state $B$ mutatis mutandis. $M(\cdot, \cdot)$ exhibits constant returns to scale and is strictly increasing and strictly concave in both arguments. We define

$$
\tilde{\theta}_{t}^{A}=\frac{v_{t}^{A}}{\tilde{u}_{t}^{A}}
$$

to be the market tightness in state $A$ in period $t$. We define the job-finding and vacancy-filling probabilities as in Section 5.4.

We can thus write for the number of unemployed searching in state A and B, resp.:

$$
\begin{aligned}
& \tilde{u}_{t}^{A}=\left(u_{t}^{A}+\zeta\left(p_{t}^{A}-n_{t}^{A}\right)\right) x_{t}^{A}+\left(1-x_{t}^{B}\right)\left(u_{t}^{B}+\zeta\left(p_{t}^{B}-n_{t}^{B}\right)\right), \\
& \tilde{u}_{t}^{B}=\left(u_{t}^{B}+\zeta\left(p_{t}^{B}-n_{t}^{B}\right)\right) x_{t}^{B}+\left(1-x_{t}^{A}\right)\left(u_{t}^{A}+\zeta\left(p_{t}^{A}-n_{t}^{A}\right)\right),
\end{aligned}
$$

where $u_{t}^{i}$ is the number of unemployed who live in state $i, x_{t}^{i}$ is the fraction of the unemployed in state $i$ that searches in state $i$, and $\delta_{t}$ is the separation probability into unemployment, calculated from the Current Population Survey (CPS) following Shimer (2007). We follow Hall (2013) and set $\zeta$ to $5 / 27$ to match the ratio of the job-finding rates of non-participants to the unemployed in the CPS.

We can measure the probabilities for an unemployed worker from states A and B to find a 
job, $\phi_{t}^{A}$ and $\phi_{t}^{B}$, in the data:

$$
\begin{aligned}
\phi_{t}^{A} & =\frac{u_{t}^{A}-u_{t+1}^{A}+\delta_{t}\left(n_{t}^{A}-u_{t}^{A}\right)}{u_{t}^{A}}, \\
\phi_{t}^{B} & =\frac{u_{t}^{B}-u_{t+1}^{B}+\delta_{t}\left(n_{t}^{B}-u_{t}^{B}\right)}{u_{t}^{B}},
\end{aligned}
$$

as all right-hand variables are observed in the data. We can relate the measurable $\phi_{t}^{A}$ and $\phi_{t}^{B}$ to the unobservable variables $x_{t}^{A}, x_{t}^{B}, f\left(\theta_{t}^{A}\right), f\left(\theta_{t}^{B}\right)$ :

$$
\begin{aligned}
\phi_{t}^{A} & =x_{t}^{A} f\left(\theta_{t}^{A}\right)-\left(1-x_{t}^{A}\right) f\left(\theta_{t}^{B}\right), \\
\phi_{t}^{B} & =x_{t}^{B} f\left(\theta_{t}^{B}\right)-\left(1-x_{t}^{B}\right) f\left(\theta_{t}^{A}\right) .
\end{aligned}
$$

The four equations (38), (39), (42) and (43) have 4 unknowns, $x_{t}^{A}, x_{t}^{B}, f\left(\theta_{t}^{A}\right), f\left(\theta_{t}^{B}\right) .{ }^{38}$ These equations are not linearly independent and thus do not allow us to recover these 4 unknowns. Instead they give us a set of solutions $S$.

In order to proceed to identify $x_{t}^{A}, x_{t}^{B}$, we assume that the matching function is CobbDouglas, $\mu u^{\gamma} v^{1-\gamma}$. Note, however, that we do not necessarily see the true level of vacancies. However, if we assume that we see the same fraction, $\psi$, of total vacancies for both counties in a pair, we can still estimate the effective matching function given our observed vacancies. If we observe $\tilde{v}=\psi v$, then the total number of matches is $\tilde{\mu} u^{\gamma} \tilde{v}^{1-\gamma}$, where $\tilde{\mu}=\psi^{\gamma-1} \mu$. Thus, we propose to identify $\tilde{\mu}$ and $\gamma$ in addition to the $x$ 's.

We allow $\tilde{\mu}$ to change over time, to capture any possible time trends in the adoption of online vacancies. The algorithm consists of selecting $\alpha,\left\{\mu_{t}, x_{t}^{A}, x_{t}^{B}\right\}_{t=1}^{T}$ to minimize the error in the equations (42), (43) and:

$$
\frac{q\left(\theta_{t}^{A}\right)}{q\left(\theta_{t}^{B}\right)}=\left(\frac{\theta_{t}^{B}}{\theta_{t}^{A}}\right)^{\alpha}
$$

where we observe all left hand side variables for all $t .^{39}$

We measure the effect of benefits on search behavior by examining the difference between the imputed fraction of workers searching away from their home states $\left(1-x_{t}^{A}\right)-\left(1-x_{t}^{B}\right)$. Further, we construct imputed tightness by dividing county level vacancies by the imputed measure of unemployed workers searching in that county $\left(v_{t}^{A} / \tilde{u}_{t}^{A}\right)$, corrected for the search behavior along that border segment (we impose the same $x$ 's for all counties within a state for each border segment). Then, the job finding rate is constructed using the imputed tightness and the estimated parameters of the matching function. Table 7 Column (1) shows, using the differencein-difference estimator, that there is only a very small and statistically insignificant response of

\footnotetext{
${ }^{38}$ We do not directly observe $x_{t}^{A}$, and thus we don't observe $\tilde{u}_{t}^{A}$ and $\theta_{t}^{A}$, nor the matching function.

${ }^{39}$ The probability to fill a vacancy $q_{t}=1-\frac{v_{t+1}-v_{t+1}^{\text {new }}}{v_{t}}$, where $v_{t}$ is the stock of vacancies at $t$ and $v_{t}^{\text {new }}$ are newly posted vacancies at $t$, so that $v_{t+1}-v_{t+1}^{\text {new }}$ are not filled vacancies from period $t$. Both $v_{t}$ and $v_{t}^{\text {new }}$ are observable in the data.
} 
Table 7: Effect of UI Benefits on Imputed Labor Market Variables

\begin{tabular}{lccc}
\hline VARIABLES & Out of State Search & Imputed Tightness & Imputed Job-finding \\
\hline Weeks of Benefits & 0.0002 & $\mathbf{- 0 . 1 1 5 4}$ & $\mathbf{- 0 . 0 5 2 4}$ \\
& $(0.510)$ & $(0.000)$ & $(0.000)$ \\
Factors & 2 & 2 & 2 \\
Observations & 29,492 & 29,492 & 29,492 \\
R-squared & 0.066 & 0.2816 & 0.2996 \\
\hline Note - $p$-values (in parentheses) calculated via bootstrap. Bold indicates $p<0.01$.
\end{tabular}

search behavior, to changes in benefits, so that mobility does not bias our estimates. Further, the effect on imputed tightness, which now fully accounts for changes in mobility in response to changes in benefits, is not statistically significantly different from the baseline estimate.

Next, we look for direct empirical evidence on where people work relative to where they live. We use data from the American Community Survey (ACS) from 2005-2013. The ACS is an annual $1 \%$ survey of households in the United States conducted by the Census Bureau. The survey contains information on the county of residence of households and the state of employment. The survey is representative at the Public Use Micro Area level - a statistical area that has roughly 100,000 residents (and thus also for counties with more than 100,000 residents). We compute the share of households in border counties who work in the neighboring state. We can then examine how this share of border state workers responds to changes in benefits across states. We perform our analysis using the same difference-in-difference estimator as with the imputed search behavior. We find a statistically insignificant coefficient on weeks of benefits available of .0117 (se .0323). This direct evidence once again implies that worker search behavior does not respond significantly to changes in unemployment benefits.

\section{Conclusion}

We developed an empirical methodology to measure the effect of unemployment benefit extensions on unemployment that includes the effect of benefit extensions on job creation neglected in the existing empirical literature. In particular, we exploited the discontinuity of unemployment insurance policies at state borders to identify their impact. Our estimator controls for the effect of expectations of future changes in benefits and has a simple economic interpretation. It is also robust to the heterogeneous impacts of aggregate shocks on local labor markets.

We found that unemployment benefit extensions have a large effect on total unemployment and that they can potentially account for a significant share of the persistently high unemployment following the Great Recession. The analysis of administrative claims data reveals that unemployment benefit extensions have a significant negative impact on labor demand. We found further support for this conclusion by documenting direct evidence of a significant negative impact of unemployment benefit extensions on vacancy creation and employment through 
their effect on wages. These results indicate the importance of taking the impact of benefit extension on job creation into account for a more complete evaluation of this policy tool. They also illustrate the need for the new methodology required to measure the response of forward looking job creators that we develop.

One motivation for increasing unemployment benefit durations during the Great Recession, in addition to helping unemployed workers smooth their consumption, is to increase employment through its stimulative effect on local demand. Although we cannot do full justice to evaluating this effect given the methodology on which our analysis relies, our results nevertheless offer some insights. To the extent that the unemployed spend a significant fraction of their income in their home counties (in a form of e.g., rent payments or service purchases), the corresponding part of the stimulative effect is fully captured by our analysis. Indeed, we find that border counties with longer benefit durations have much higher unemployment, despite the potential beneficial effects of spending. If, on the other hand, spending by the unemployed was spread uniformly on goods and services provided in all counties, this aggregate component is not captured, as it is differenced out by our estimator. We find, however, that an increase in unemployment due to benefit extensions is similar in magnitude to the decline of employment. Thus, the total effect on spending is ambiguous as extending benefits increases spending by the unemployed but at the same time decreases spending as fewer people are employed. The potential offsetting effect of lower employment due to higher benefits was also recognized by policymakers but it was believed to be quantitatively very small. Our results of a sizable macro effect leads us to expect that the stimulative effect of higher spending by the unemployed is largely offset by the dramatic negative effect on employment from the effect of benefit expansion on vacancy creation. 


\section{References}

Andrews, D. W. K. (2005): "Cross-Section Regression with Common Shocks," Econometrica, $73,1551-1585$.

BAI, J. (2009): "Panel Data Models with Interactive Fixed Effects," Econometrica, 77, 12291279.

BAI, J. AND S. NG (2002): "Determining the Number of Factors in Approximate Factor Models," Econometrica, 70, 191-221.

BArro, R. (2010): "The Folly of Subsidizing Unemployment," Wall Street Journal.

Bartik, T. J. (1991): Who Benefits from State and Local Economic Development Policies?, Kalamazoo, MI: W.E. Upjohn Institute for Employment Research.

Bertrand, M., E. Duflo, and S. Mullainathan (2004): "How Much Should We Trust Differences-In-Differences Estimates?" Quarterly Journal of Economics, 119, 249-275.

Brügemann, B. (2008): "What Elasticity of the Matching Function is Consistent with U.S. Aggregate Labor Market Data?" mimeo, Yale University.

Card, D. And P. B. Levine (2000): "Extended Benefits and the Duration of UI Spells: Evidence from the New Jersey Extended Benefit Program," Journal of Public Economics, 78, 107-138.

Cordell, L., L. Geng, L. Goodman, and L. Yang (2013): "The Cost of Delay," Working Paper 13-15, Federal Resrve Bank of Philadelphia.

Costain, J. S. And M. Reiter (2008): "Business Cycles, Unemployment Insurance, and the Calibration of Matching Models," Journal of Economic Dynamics and Control, 32, 11201155.

Diamond, P. A. (2013): "Cyclical Unemployment, Structural Unemployment," National Bureau of Economic Research Working Paper 18761.

Dube, A., W. Lester, And M. Reich (2010): "Minimum Wage Effects Across State Borders: Estimates Using Contiguous Counties," Review of Economics and Statistics, 92, 945 - 964.

Gertler, M. And A. Trigari (2009): "Unemployment Fluctuations with Staggered Nash Bargaining," Journal of Political Economy, 117, 38-86.

Gobillon, L. And T. Magnac (2015): "Regional Policy Evaluation: Interactive Fixed Effects and Synthetic Controls," Review of Economics and Statistics, Forthcoming.

Hagedorn, M., J. Handbury, and I. Manovskit (2015a): "Demand Stimulus and Inflation: Empirical Evidence," mimeo, University of Pennsylvania.

Hagedorn, M. And I. Manovskit (2008): "The Cyclical Behavior of Equilibrium Unemployment and Vacancies Revisited," American Economic Review, 98, 1692-1706. 
(2013): "Job Selection and Wages over the Business Cycle," American Economic Review, $103,771-803$.

Hagedorn, M., I. Manovskit, and K. Mitman (2015b): "The Impact of Unemployment Benefit Extensions on Employment: The 2014 Employment Miracle?" National Bureau of Economic Research Working Paper 20884.

(2015c): "Unemployment Benefits and Unemployment in the Great Recession: The Role of Micro Effects," mimeo, University of Pennsylvania.

HALL, R. E. (2005): "Employment Fluctuations with Equilibrium Wage Stickiness," American Economic Review, 95, 50-65.

(2013): "Some Observations on Hagedorn, Karahan, Manovskii, and Mitman, "Unemployment Benefits and Unemployment in the Great Recession: The Role of Macro Effects"," mimeo, Nov. 6, Stanford University.

Hall, R. E. AND P. Milgrom (2008): "The Limited Influence of Unemployment on the Wage Bargain," American Economic Review, 98, 1653-74.

Ham, J. C. And S. A. REA, JR (1987): "Unemployment Insurance and Male Unemployment Duration in Canada," Journal of Labor Economics, 5, 325-353.

Herkenhoff, K. F. And L. E. Ohanian (2013): "Foreclosure Delay and U.S. Unemployment," mimeo, UCLA.

Holmes, T. J. (1998): "The Effect of State Policies on the Location of Manufacturing: Evidence from State Borders," Journal of Political Economy, 106, 667-705.

Johnston, A. C. And A. MAs (2015): "Potential Unemployment Insurance Duration and Labor Supply: The Individual and Market-Level Response to a Benefit Cut," mimeo, Princeton University.

Katz, L. F. (2010): "Long-Term Unemployment in the Great Recessions," Testimony for the Joint Economic Committee U.S. Congress.

Katz, L. F. And B. D. Meyer (1990): "The Impact of the Potential Duration of Unemployment Benefits on the Duration of Unemployment," Journal of Public Economics, 41, $45-72$.

Kolko, J., D. Neumark, and M. C. Mejia (2013): "What Do Business Climate Indexes Teach Us About State Policy And Economic Growth?" Journal of Regional Science, 53, $220-255$.

Krause, M. U. And H. Uhlig (2012): "Transitions in the German Labor Market: Structure and Crisis," Journal of Monetary Economics, 59, 64-79.

Krueger, A. And B. Meyer (2002): "Labor Supply Effects of Social Insurance," Handbook of Public Economics, 4, 2327-2392. 
Ljungqvist, L. And T. J. Sargent (2015): "The Fundaments Surplus in Matching Models," mimeo, New York University.

MeYer, B. D. (1990): "Unemployment Insurance and Unemployment Spells," Econometrica, $58,757-82$.

Millard, S. P. And D. T. Mortensen (1997): "The Unemployment and Welfare Effects of Labor Market Policy: A Comparison of the U.S. and the U.K," in Unemployment Policy: Government Options for the Labour Market, ed. by D. J. Snower and G. de la Dehesa, Cambridge: Cambridge University Press.

Mitman, K. AND S. Rabinovich (2013): "Do Changes in Unemployment Insurance Explain the Emergence of Jobless Recoveries?" mimeo, University of Pennsylvania.

Moffitt, R. (1985): "Unemployment Insurance and the Distribution of Unemployment Spells," Journal of Econometrics, 28, 85-101.

Mortensen, D. T. And C. Pissarides (1994): "Job Creation and Job Destruction in the Theory of Unemployment," Review of Economic Studies, 61, 397-415.

Mulligan, C. B. (2008): "A Depressing Scenario: Mortgage Debt Becomes Unemployment Insurance," National Bureau of Economic Research Working Paper 14514.

(2009): "Means-Tested Mortgage Modification: Homes Saved of Income Destroyed?" National Bureau of Economic Research Working Paper 15281.

- (2010): "Foreclosures, Enforcement, and Collections under the Federal Mortgage Modification Guidlines," National Bureau of Economic Research Working Paper 15777.

(2012): The Redistribution Recession: How Labor Market Distortions Contracted the Economy, Oxford University Press.

Office of Management and Budget (2010): "2010 Standards for Delineating Metropolitan and Micropolitan Statistical Areas; Notice," Federal Register, 75, 37245-37252.

Pissarides, C. (2000): Equilibrium Unemployment Theory, Cambridge, MA: MIT Press.

Sahin, A., J. Song, G. Topa, And G. L. Violante (2014): "Mismatch Unemployment," American Economic Review, 104, 3529-64.

Shi, S. And Q. Wen (1999): "Labor Market Search and the Dynamic Effects of Taxes and Subsidies," Journal of Monetary Economics, 43, 457-495.

Shimer, R. (2007): "Reassesing the Ins and Outs of Unemployment," mimeo, University of Chicago.

Solon, G. (1979): "Labor Supply Effects of Extended Unemployment Benefits," Journal of Human Resources, 14, 247-255. 


\section{APPENDICES}

\section{Implementation of Iterative Two-Stage Estimator}

The following is a brief description of the algorithm implementing our iterative two-stage estimator.

1. Start with a guess for $\alpha$, say $\alpha_{1}$.

2. At each iteration $\xi$, do the following:

(a) given $\alpha_{\xi}$, for each $p$, construct $v_{p, t}=\Delta x_{p, t}-\beta\left(1-s_{t}\right) \Delta x_{p, t+1}-\alpha_{j} \Delta b_{p, t}$. Then, $v_{p, t}=\lambda_{p}^{\prime} F_{t}$ is a pure factor model and can be estimated consistently using principal components. $^{40}$

(b) Given the estimates for $\lambda_{p}$ and $F_{t}$, estimate equation (14) via OLS and update the guess to obtain $\alpha_{\xi+1}$.

3. Repeat 2 until $\alpha_{\xi}$ converges. $^{41}$

\section{Inadmissibility of Uninstrumented State Unemploy- ment Differences in Testing for Endogeneity}

In this section we illustrate why controlling for the difference in state unemployment (without instrumenting with Bartik shocks) does not constitute a valid exogeneity test. To do so, we simulate data from our calibrated model where we impose exogeneity - i.e. we assume the productivity processes at the county and state level are independent. In Figure A-1 we plot the time series for state unemployment, county unemployment and weeks of benefits available. Notice that both state and county level unemployment are smooth moving variables, whereas the weeks of benefits jumps when a benefit extension is triggered on. The correlation between state and county unemployment is significantly higher than between county unemployment and benefits, and controlling for state unemployment completely takes out the effect of benefits. However, it is important to note that the only channel through which the state economy affects the county economy is through the benefit policy (because in this example the productivity processes are orthogonal). Thus, controlling for state unemployment, which is endogenous to benefits, is not a valid test for exogeneity.

\section{Additional Discussion of Endogeneity}

\section{III.1 Some Informal Examples}

The key identification problem that our methodology was designed to overcome is the positive feedback from state unemployment to benefit extensions. This is guaranteed in our setting

\footnotetext{
${ }^{40}$ The exposition of the estimator assumes that there are no missing observations. We use the generalized procedure described in Bai (2009) and allow for missing observations.

${ }^{41}$ We have conducted a number of Monte Carlo simulations with sample sizes similar to our sample. The estimator described here is found to converge to the true parameter. Results are available upon request.
} 


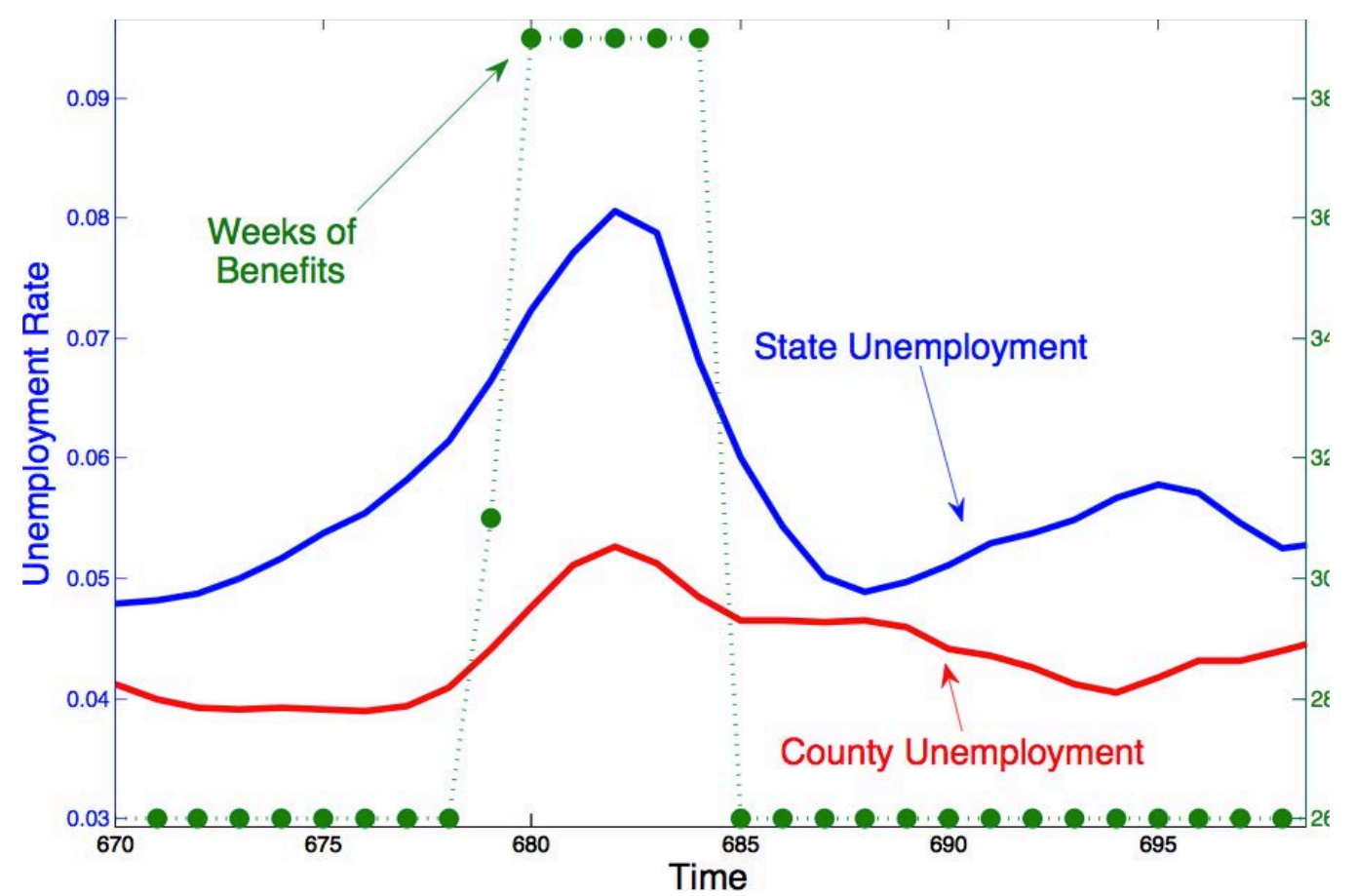

Figure A-1: County and State Unemployment: Model.

if shocks that affect state unemployment (and consequently benefits) impact symmetrically the two counties on the two sides of the state border. In this case, when we difference the variables between these two counties, the shock is differenced out so the only remaining difference between counties is the difference in benefits (that was induced by that shock).

To make things concrete, consider the following stylized (and not necessarily factually correct) examples. The discovery of hydraulic fracking was a big positive shock to the economy of Pittsburgh, PA during the Great Recession. This shock raised productivity and lowered unemployment in Pennsylvania relative to New Jersey. The border counties of Philadelphia, PA and Camden, NJ benefited equally from the availability of now cheaper natural gas. Faced with the same negative aggregate shock during the Great Recession, due to the feedback effect from unemployment to benefits, New Jersey raised unemployment benefits while Pennsylvania did not. Now consider the difference between Philadelphia and Camden Counties. They are affected by the same aggregate shock and have the same positive effect from the access to natural gas from Pittsburgh. These effects cancel out so that the difference in unemployment between them comes only from the fact that one has higher benefits than the other. Similarly, consider the effects of Hurricane Sandy that was a much bigger shock for New Jersey than Pennsylvania. The fact that this makes it more likely that benefits would be changed in NJ is not relevant because the storm had a similar impact on Philadelphia and Camden. Note that for this argument it is quite irrelevant whether Philadelphia is large or small relative to Camden or relative to Pennsylvania.

Alternatively, imagine a more idiosyncratic shock to counties. Suppose the Interstate Highway I-95 that is a major route connecting Philadelphia and Camden to other states is temporarily closed down for mechanical reasons. This will be a major shock to both counties. However, this shock is more likely to trigger benefit extensions in Pennsylvania since Philadelphia is much 
larger and important to Pennsylvania's economy than Camden is relative to New Jersey. Does this present a challenge to our identification strategy? No. The difference between the Philadelphia and Camden counties still arises only because of benefits and not because of underlying economic conditions.

The identification tests developed in the main body of the paper formally verify that shocks to economic conditions of the two states indeed have a symmetric impact on the two border counties, except through their effect on benefits.

\section{III.2 Alternative "Endogeneity Test"}

Hall (2013) proposed trying to detect the presence of contamination on county-level LAUS unemployment data with state level variable by studying the correlation between the county unemployment rate measured in LAUS and state unemployment rate (relative to the correlation with the adjacent county's unemployment rate). To implement this suggestion, as proposed by Hall (2013), we use LAUS data and regress county unemployment on state unemployment and adjacent county unemployment in 2007. The estimated coefficient on the state is 0.908 with a standard error of 0.039 and the coefficient on the adjacent out-of-state county is 0.350 with a standard error of 0.023 .

To test whether the large estimate on the state-level variable implies the presence of contamination we perform the same analysis with administrative unemployment insurance claims data (that are not subject to any imputation). Specifically, we perform the same regression with continuing claims divided by population. The estimated coefficient on the state is 1.121 with a standard error of 0.045 and the coefficient on the adjacent out-of-state county is 0.415 with a standard error of 0.024 . Thus, the results of these experiments do not provide support for the hypothesis that LAUS county-level unemployment contains an imputed state-level component.

The fact that state unemployment is an important predictor of county unemployment is also not very surprising and does not indicate shortcomings of our methodology. To see this, consider a purposefully simplified example that describes an ideal scenario with no endogeneity problem but where state unemployment is nevertheless a significant predictor. Suppose the shocks to the state, including the border county in that state and its adjacent out-of-state county have a common component. Each county is also subject to independent idiosyncratic shocks and measurement error in local unemployment. When we difference between the two border counties, the common component of the shock is differenced out implying no endogeneity concern. But consider now the regression of border county unemployment on unemployment in the state and adjacent out-of-state county. As a state consists of many counties, idiosyncratic shocks and measurement error are largely eliminated. Thus, the regression includes two regressors that have the same informational content for the dependent variable, but one of the regressors (state unemployment) is measured with little error while the other (out-of-state county unemployment) with lots of error. Clearly, the regressor measured with little error will be a significant predictor. Thus, such a regression cannot be interpreted as a test of endogeneity. It only provides evidence of the importance of common components and the distribution of errors at various levels of aggregation. 
Table A-1: County unemployment and employment as a function of pair county and state

\begin{tabular}{|c|c|c|}
\hline VARIABLES & $\begin{array}{c}\text { (1) } \\
\text { county unemployment }\end{array}$ & $\begin{array}{c}(2) \\
\text { county employment }\end{array}$ \\
\hline other county unemployment & $\begin{array}{c}\mathbf{0 . 4 0 4 0} \\
(0.017)\end{array}$ & \\
\hline state unemployment & $\begin{array}{r}\mathbf{0 . 4 8 4 2} \\
(0.026)\end{array}$ & \\
\hline other county employment & & $\begin{array}{c}\mathbf{0 . 3 7 4 6} \\
(0.019)\end{array}$ \\
\hline state employment & & $\begin{array}{c}\mathbf{0 . 4 1 7 3} \\
(0.037)\end{array}$ \\
\hline Observations & 2,356 & 2,312 \\
\hline R-squared & 0.331 & 0.239 \\
\hline
\end{tabular}

In addition, states differ with respect to many policies, e.g., taxes, regulations, UI and other benefit policies that apply to all locations within a state. Thus, it is expected that there is a difference in unemployment between border counties even when benefit durations are the same in both of them. Our estimation is based on a panel with large variation over time and these differences are accounted for by controlling for pair fixed effects (the factor model) and explicitly controlling for changes in these policies.

Further, since we know that county-level QWI employment data is also not subject to any imputation using state-level variables, we now repeat the same experiment using 2007 LAUS unemployment and QWI employment data. In order to make the regressions comparable, we run them in logs of the level of unemployment and employment, as opposed to rates (because the calculation of employment rate would involve a potentially imputed county labor force variable which is only available in LAUS data the quality of which we aim to ascertain). The results of the regressions are displayed in the Table A-1. Both for county employment and unemployment we find large, positive significant coefficients on both the other county and on the state-level variables, and that the coefficient on the state is larger than that of the adjacent county. ${ }^{42}$ Both pairs of coefficient estimates have overlapping $95 \%$ confidence intervals. This experiment once again reinforces the conclusion that the large coefficient on the state variables is not evidence of an imputation problem. Instead, it is likely picking up a relationship between county and state variables driven by real economic factors and the fact that county-level variables are noisier than the state-level ones.

While the results of these test support the conclusion that LAUS county-level unemployment data are not inappropriately imputed using state-level variables, we find the analysis of

\footnotetext{
${ }^{42}$ To understand the relationship between these estimates in levels of unemployment to the estimates in rates reported above, note that since the level of a state variable is about two orders of magnitude larger than the county, in logs this would translate into roughly a factor of two difference on the state variable, which is what we observe.
} 
endogeneity in the main text of the paper to provide a more direct and powerful verification of the lack of an endogeneity problem in our analysis. Moreover the fact that the results using county-level LAUS unemployment data are quantitatively consistent with the results based on independent datasets on vacancies, employment, and unemployment insurance claims strongly points to the same conclusion. This is comforting not only from the point of view of our research design but also because LAUS estimates are the basis for determining local spending under many State and Federal programs.

\section{Measuring the Job-finding Rate in Administrative State UI Data}

In this section we describe the measurement of the job-finding rates of unemployment benefit recipients in the regular state UI programs using administrative data on the count of continuing claims and final payments.

The counts of continued claims are provided monthly. The claims are a count of the total number of continued claimants in the reference week of that month (the week including the 12 th, as with the CPS). The final payments data are at a weekly frequency and represent the count of claimants who receive their $26^{\text {th }}$ benefit check, i.e., the final payment from the regular state UI system. The continued claims data, therefore include the number of final payments from the reference week of that month. We can write the number of continued claimants in month $t$ as:

$$
u_{t}^{C C}=u_{t, 2}^{F P}+\sum_{k=0}^{4} \frac{\bar{u}_{t+k}^{F P}}{\prod_{j=0}^{k}\left(1-f_{t+j}\right)},
$$

where $u_{t}^{C C}$ is the number of continuing claims at month $t, f_{t}$ is the probability to find a job in month $t,{ }^{43} u_{t, \tau}^{F P}$ is the number of those who received the final payment in week $\tau$ of month $t$, and $\bar{u}_{t}^{F P}$ is the total number of those who received their final payments after the reference week in month $t$ but not later than the reference week in month $t+1$. For example, in a month with five weeks, the measure would include final payments in weeks 3-5 of that month, and then the final payments in the first two weeks of the subsequent month, i.e.

$$
\bar{u}_{t}^{F P}=\sum_{\tau=3}^{5} u_{t, \tau}^{F P}+\sum_{\tau=1}^{2} u_{t+1, \tau}^{F P} .
$$

Rearranging Equation (A1) we can express the job-finding rate as

$$
f_{t}=1-\frac{\bar{u}_{t}^{F P}+\sum_{k=1}^{4} \frac{\bar{u}_{t+k}^{F P}}{\prod_{j=1}^{k}\left(1-f_{t+j}\right)}}{u_{t}^{C C}-u_{t, 2}^{F P}},
$$

yielding a system of equations with four more unknowns than equations. Setting terminal conditions for the final four measures of the job-finding rate we can solve backwards and calculate

\footnotetext{
${ }^{43}$ We assume that during the first 26 weeks that an individual is receiving benefits the only reason why the claimant stops receiving benefits is because of a transition to employment. Alternatively, the claimant could stop collecting benefits without finding a job. We do not expect this to be quantitatively important.
} 
Table A-2: Controlling for State SNAP and Foreclosure Policies

\begin{tabular}{lcccc}
\hline VARIABLES & $(1)$ & $(2)$ & $(3)$ & $(4)$ \\
\hline Weeks of Benefits & $\mathbf{0 . 0 4 9}$ & $\mathbf{0 . 0 4 0 7}$ & $\mathbf{0 . 0 4 6 3}$ & $\mathbf{0 . 0 4 8 6}$ \\
& $(0.000)$ & $(0.000)$ & $(0.000)$ & $(0.000)$ \\
SNAP Broad Eligibility & & $\mathbf{0 . 0 1 1 5}$ & & \\
& & $(0.000)$ & & \\
SNAP Spending & & $\mathbf{0 . 0 0 6 9}$ & $(0.040)$ \\
& & & & 0.0007 \\
Foreclosure Policy & & & & $(0.385)$ \\
& 2 & 2 & 2 & 2 \\
Number of Factors & 37,177 & 32636 & 32636 & 37,177 \\
Observations & 0.458 & 0.460 & 0.458 & 0.461 \\
R-squared & & \multicolumn{3}{c}{. } \\
Note - $p$-values (in parentheses) calculated via bootstrap. Bold indicates $p<0.01$.
\end{tabular}

all of the preceding job-finding rates. We use the national job-finding rate from the CPS for the first four months of 2013 as our terminal conditions. ${ }^{44}$ We then perform our analysis through 2012:Q3, dropping the observations with the terminal conditions.

\section{Unemployment Benefit Extensions and Unemploy- ment: Controlling for Other State-Level Policies}

In this section we control for tax and transfer policies that might be correlated with unemployment and unemployment benefit extensions at the county or state levels.

\section{V.1 Controlling for the Expansion of Food-Stamps Programs}

Mulligan (2012) has argued that in addition to unemployment benefit extensions, the Department of Agriculture's food-stamp program, now known as the Supplemental Nutrition Assistance Program, or SNAP, was also expanded considerably following the Great Recession. It is possible that the expansion of this program at the state level was correlated with unemployment benefit extensions so that the results reported above combine the effects of these programs. We now isolate their impacts.

Food-stamps were originally designed as a means-tested program for the poor. During the Great Recession the Federal government has allowed states to adopt broad eligibility criteria that effectively eliminated the asset test and states received waivers from work requirements for the participants in the program. As a result, the participation in the program increased dramatically so that by 2010 half of non-elderly households with an unemployed head or spouse were receiving food stamps, with large variation across states.

To asses the extent to which the effects of unemployment benefit extensions documented above are affected by the expansion of food-stamps program eligibility, we obtained USDA's

\footnotetext{
${ }^{44}$ Alternatively, we could back out the job-finding rate from the LAUS unemployment data. Doing so does not affect our results.
} 
SNAP Policy Database which documents policy choices of each state at monthly frequency. ${ }^{45}$ We construct a dummy variable equal to one during all periods when states use broad-based categorical eligibility to increase or eliminate the asset test and/or to increase the gross income limit for virtually all SNAP applicants. The variable is zero otherwise. We include this variable in our baseline regression and report the results in Column (2) of Table A-2. The results confirm the argument in Mulligan (2012) that the expansion of food-stamps eligibility represents a marginal tax on working and thus leads to an increase in unemployment. It is, however, only weakly correlated with unemployment benefit extensions and thus does not significantly affect our estimate of their impact.

In addition, we control for the actual state-level spending on SNAP benefits that we obtained from the Regional accounts of the BEA. The results reported in Column (3) of Table A-2 confirm our findings in Column (2) which were based on statutory rule changes.

\section{V.2 Controlling for Variation in State Foreclosure Policies}

The Great Recession has began with a sharp but heterogeneous across states decline in house prices. The government has responded by introducing various mortgage modification programs with the objective of helping underwater mortgagors. Various of these programs were either asset-tested or designed to write down mortgage principle to ensure that housing costs did not exceed a certain proportion of household income. In a series of papers, Mulligan (2008, 2009, 2010) has noted that this represents an implicit subsidy to unemployed workers. Moreover, Herkenhoff and Ohanian (2013) have argued that the duration of the foreclosure process has been extended considerably following the Great Recession and that unemployed mortgagors use their ability to skip payments without being foreclosed upon as an implicit loan subsidy negatively affecting their job search and acceptance decisions.

Cordell et al. (2013) use proprietary data to measure the heterogeneity in foreclosure delay following the Great Recession across states. They find that in judicial states, in which state law requires a court action to foreclose, the delay is much larger than in statutory foreclosure states that do not require judicial intervention. Our use of the interactive effects estimator was specifically motivated by the concerns that aggregate shocks, such as shocks to house prices, may have heterogeneous impacts across border-county pairs depending, in part, on their state foreclosure law. To verify the performance of the estimator, we define a dummy variable taking the value of one for border counties belonging to states with judicial foreclosure laws and zero otherwise. We then include in the benchmark specification the difference of the value of this dummy between border counties $i$ and $j$ in pair $p$. The results reported in Column (4) of Table A-2 indicate that this variable (the difference of the two dummies) is not statistically significant and does not affect the estimate of the effect of unemployment benefit extensions. This finding does not imply that foreclosure delay was not an important determinant of unemployment. It only means that our interactive effects estimator accounted for some of this aspect of heterogeneity across states and it did not impart a bias on our estimate of the effect of unemployment benefit extensions.

\footnotetext{
${ }^{45}$ http://www.ers.usda.gov/data-products/snap-policy-database.aspx
} 
Table A-3: Controlling for State Tax and Spending Policies

\begin{tabular}{|c|c|c|c|c|c|c|c|c|c|}
\hline VARIABLE & (1) & (2) & (3) & (4) & $(5)$ & (6) & (7) & (8) & (9) \\
\hline \multirow[t]{2}{*}{$\begin{array}{l}\text { Weeks of } \\
\text { Benefits }\end{array}$} & $\begin{array}{c}\mathbf{0 . 0 4 9} \\
(0.000)\end{array}$ & $\begin{array}{c}\mathbf{0 . 0 4 8 1} \\
(0.000)\end{array}$ & $\begin{array}{c}\mathbf{0 . 0 4 2 8} \\
(0.000)\end{array}$ & $\begin{array}{l}\mathbf{0 . 0 4 4 1} \\
(0.000)\end{array}$ & $\begin{array}{c}\mathbf{0 . 0 4 8 0} \\
(0.000)\end{array}$ & $\begin{array}{r}\mathbf{0 . 0 4 7 8} \\
(0.000)\end{array}$ & $\begin{array}{r}\mathbf{0 . 0 4 8 7} \\
(0.000)\end{array}$ & $\begin{array}{r}\mathbf{0 . 0 4 7 2} \\
(0.000)\end{array}$ & $\begin{array}{l}\mathbf{0 . 0 4 6 1} \\
(0.000)\end{array}$ \\
\hline & & & \multicolumn{3}{|c|}{ Variable in Levels } & \multicolumn{4}{|c|}{ Variable Relative to GDP } \\
\hline $\begin{array}{l}\text { Stimulus } \\
\text { Spending }\end{array}$ & & $\begin{array}{c}0.0000 \\
(0.595)\end{array}$ & & & & $\begin{array}{c}-\mathbf{0 . 0 0 0 2} \\
(0.035)\end{array}$ & & & \\
\hline $\begin{array}{l}\text { Total Tax } \\
\text { Revenue }\end{array}$ & & & $\begin{array}{c}\mathbf{0 . 0 0 2 9} \\
(0.000)\end{array}$ & & & & $\begin{array}{c}-0.0032 \\
(0.145)\end{array}$ & & \\
\hline $\begin{array}{l}\text { Sales Tax } \\
\text { Revenue }\end{array}$ & & & & $\begin{array}{c}\mathbf{0 . 0 0 1 9} \\
(0.000)\end{array}$ & & & & $\begin{array}{c}\mathbf{0 . 0 0 1 6} \\
(0.003)\end{array}$ & \\
\hline $\begin{array}{l}\text { Income Tax } \\
\text { Revenue }\end{array}$ & & & & & $\begin{array}{c}-\mathbf{0 . 0 0 0 9} \\
(0.000)\end{array}$ & & & & $\begin{array}{c}-\mathbf{0 . 0 0 1 2} \\
(0.000)\end{array}$ \\
\hline \# Factors & 2 & 2 & 2 & 2 & 2 & 2 & 2 & 2 & 2 \\
\hline Obs. & 37,177 & 37,177 & 37,177 & 37,177 & 37,177 & 37,177 & 37,177 & 37,177 & 37,177 \\
\hline R-squared & 0.458 & 0.460 & 0.461 & 0.461 & 0.461 & 0.461 & 0.461 & 0.461 & 0.461 \\
\hline
\end{tabular}

\section{V.3 Controlling for the Effect of Stimulus Spending}

In the specification of Column (2) of Table A-3 we control for the effects of stimulus spending. We use data on actual county level spending arising from the American Recovery and Reinvestment Act (ARRA) - commonly referred to as the "stimulus package." We obtain an accounting of all stimulus spending at the zip code level under the ARRA. ${ }^{46}$ We then match counties to zip codes. We run our specification both in levels and by dividing the spending by the population in the county, obtained from the Census. We find that that controlling for ARRA spending does not affect our estimate of the effect of unemployment benefit extensions. ${ }^{47}$

\section{V.4 Controlling for State Tax Policies}

To control for the variation in state-level tax policies we obtained detailed Census Bureau data on quarterly tax revenues for each state. ${ }^{48}$ We consider whether effective total or sales tax rates have co-moved systematically with unemployment benefit durations. We find no support for this hypothesis. The results reported in Table A-3 imply that directly controlling for these effective tax rates has virtually no impact on our estimates of the effect of unemployment benefit extensions on unemployment.

Our analysis was based on effective tax rates for two reasons. First, the statutory rates have

\footnotetext{
${ }^{46}$ www.recovery.gov.

${ }^{47}$ The coefficient on spending however has to be interpreted with caution. It is conceivable, in contrast to unemployment benefits which depend on economic conditions at the state level, that spending at the county level depends on the economic conditions at the county level. In this case the coefficient on spending will be biased.

${ }^{48} \mathrm{http}: / /$ www.census.gov/govs/qtax/
} 
Table A-4: Controlling for Other State Policies

\begin{tabular}{lcccc}
\hline VARIABLES & $(1)$ & $(2)$ & $(3)$ & $(4)$ \\
\hline Weeks of Benefits & $\mathbf{0 . 0 4 9 0}$ & $\mathbf{0 . 0 4 8 9}$ & $\mathbf{0 . 0 4 8 9}$ & $\mathbf{0 . 0 4 8 4}$ \\
& $(0.000)$ & $(0.000)$ & $(0.000)$ & $(0.000)$ \\
SBSI & & -0.0002 & & \\
SBTCI & & $(0.600)$ & & \\
& & & 0.0012 & \\
BHI & & & $(0.455)$ & \\
& & & & 0.0007 \\
Number of Factors & 2 & 2 & 2 & 2 \\
Observations & 37,177 & 37,177 & 37,177 & 37,177 \\
R-squared & 0.458 & 0.461 & 0.464 & 0.461 \\
\hline \multicolumn{2}{l}{ Note - $p$-values (in parentheses) calculated via bootstrap. } \\
Bold indicates $p<0.01$.
\end{tabular}

not changed systematically over our sample period. Despite many states having balanced budget laws, expansions of unemployment benefits have not required changes in tax rates as extensions were mostly federally financed. Second, there are numerous state programs targeted to attract businesses that offer tax deductions to individual firms. For competitive reasons details of such policies are rarely disclosed. We can effectively measure them, however, by focusing on actual tax receipts.

\section{V.5 Controlling for Other State Policies}

While we found no evidence that the effects of unemployment benefit extensions on unemployment are a proxy for changes in other tax policies, we now consider whether they could be driven by other state policies, such as changes in regulatory or litigation environment. For this purpose we obtain data from three prominent indexes of state policies - U.S. State Business Policy Index (SBSI), State Business Tax Climate Index (SBTCI), and BHI State Competitiveness Index (BHI). ${ }^{49}$ The construction of these indexes is based on a well-documented methodology, the data is available annually over our sample period, and can be made consistent over time. A description of these indexes, the analysis of their predictive performance for state economic outcomes, and references to other academic evaluations can be found in Kolko et al. (2013).

The motivation for using these broad policy indexes was provided in Holmes (1998), who found that controlling for a similar (but no longer available) index of state policies accounted for the positive relationship between right-to-work laws and manufacturing employment. This suggests that the conclusion about the effects of one policy may be misleading without taking into account other state policies reflected in a broad index. In contrast, the results reported in Table A-4 imply that controlling for such indexes does not affect the measured impact of unemployment benefit extensions on unemployment.

\footnotetext{
${ }^{49}$ www.sbecouncil.org, www.taxfoundation.org, www.beaconhill.org, respectively.
} 


\section{Additional Comments on the Wage Channel}

It is clear that unemployment benefit extensions directly affect wages of newly hired workers by raising the value of the outside option of declining a job (there is, of course, the offsetting equilibrium effect that with lower job availability newly hired workers might be hired into lower quality jobs). For the incumbent workers this effect might be less clear because to exercise their outside option they must quit the job and in theory quitters are not eligible for unemployment benefits. This potentially raises two questions. First, if the wage channel does not operate for the incumbent workers, is there a need for our methodology based on quasi-differencing the variables of interest. Second, how to interpret our empirical finding that wages of incumbent workers respond positively to benefit extensions. We address these questions in this Appendix.

First, we explain that the issue of whether unemployment benefit extensions affect wages of incumbent workers is irrelevant for our methodology and findings. We assume that the wage of a new hire will respond to future determinants, including expected changes in unemployment benefits, productivity, demand, etc. This assumption is clearly not controversial. It is the expected productivity, the expected wages and the expected workers' value of unemployment which matter for the firm's decision to post a vacancy. These expected values depend on both current and future values.

Consider two neighboring counties $A$ and $B$ with the same unemployment benefits and the same worker productivity in the current period but where productivity is known to increase in county $A$ next period and to remain unchanged in county $B$. Benefits remain unchanged in both counties. Obviously, the current period incentives to post vacancies (create jobs) are higher in county $A$ than in county $B$ although current period values of benefits and productivity are identical. Our quasi-difference estimator accounts for this formation of expectations.

The same argument applies to benefits. Suppose it is expected that next period productivity remains the same but UI benefits increase in county $A$. This future increase in benefits negatively affects vacancy posting in county $A$ in the current period. This happens because the workers' value of remaining unemployed increases today. In Hall and Milgrom (2008) this also increases the (newly hired) worker's payoff while bargaining. ${ }^{50}$ This increases the wage and lowers profits and thus fewer vacancies are posted in county $A$ in the current period. Our quasi-difference estimator accounts for this effect of expectations. ${ }^{51}$

Note that these arguments do not invoke the assumption that an outside option continues to be available when the incumbent worker bargains on the job. The need for the quasi-difference estimator is independent of that assumption. The presence of continuous bargaining (where the outside option remains available) may make the dependence on future values quantitatively stronger. No matter how strong the expectation effect is, however, it has to be accounted for by the estimation strategy.

\footnotetext{
${ }^{50} \mathrm{~A}$ worker and a firm who start bargaining but do not reach an agreement in period $t$, continue bargaining in period $t+1$ and are in a bargaining situation similar to the one of a worker and a firm who meet and start bargaining in period $t+1$.

${ }^{51}$ To put it differently, dropping the quasi-difference estimator would yield a coefficient which is an uninterpretable convolution of the current and future county-differences in UI benefits.
} 
Furthermore, our findings indicate that wages of job stayers (in the same firm in consecutive periods) do increase when benefits are extended. This is an empirical fact that the empirical strategy to estimate the contemporaneous effects of benefits on unemployment, vacancies, tightness and employment should also be consistent with, and our quasi-differenced specification is.

We now turn to the second question of whether our finding that wages of incumbent workers respond to unemployment benefit extension are consistent with economic theory and its interpretation.

The result that unemployment benefit extensions affect wages of incumbent workers is clearly and firmly rooted in economic theory. Consider, for example, the efficiency wage models that have been the workhorse model of wage setting for a number of recent decades. The central element of these models is that the effort of an employee is not fully observable and is not verifiable by a court. Thus, if workers are dismissed, they will certainly be entitled to unemployment benefits. When the outside option of (incumbent) workers improves, they have to be paid more to exert effort. Thus, any such model has the implication that an increase in the outside option leads to a wage increase. Whether the employer pays a higher piece rate, a larger bonus or just increases the wage is irrelevant for our methodology and our results.

The bargaining models have the same implication. Viewed through the lens of these models, our empirical finding that wages of stayers respond to benefits implies that the outside option continues to be available when the worker bargains on the job. This model of wages is certainly widely accepted as it is used not only in the standard Pissarides (2000) textbook but also in prominent papers on the subject, e.g., Hall and Milgrom (2008) and even Hall (2005). One may question the assumption underlying this literature by arguing that to exercise the outside option, the worker would need to quit, and quitters do not receive UI benefits. However, this assertion does not fully reflect reality in the U.S. labor market. In particular, it is hard to tell apart quits and layoffs and the burden of proof is on the employer. We will provide some examples below, but it is clear that many employers will not be able or willing to contest UI claims of employees. Contesting is costly even in normal times but especially during the Great Recession employers' incentives to engage in providing such evidence have been presumably negligible when benefit extensions are paid by the federal government. Our empirical findings suggest that quitters receive, at least with some probability, UI benefits. This conclusion is supported by our analysis of the legal features of the UI system summarized below.

\section{VI.1 Elements of California Unemployment Insurance Law}

We now discuss some legal details on the eligibility of workers for benefits in the State of California. UI policies and procedures are state-dependent but the general principles are similar. Much of the discussion is copied verbatim from the State of California Benefit Determination Guide, an eight-volume compendium, designed to present definitive discussions on points of unemployment insurance law for the field office determination interviewer.

The basic line of argument in this section is as follows.

1. As a general rule, voluntary quitters are not entitled to benefits. In Section VI.1.1 we provide examples illustrating the difficulties in establishing whether a voluntary quit has 
occurred.

2. In Section VI.1.2 we explain that even if the quit is voluntary in the sense that the employer had the job available for the worker and had no intention of firing the employee, the quit may not be considered voluntary from the point of view of the Unemployment Insurance laws and regulations. If employee can argue that he had a good reason for leaving the employer, he will be entitled to benefits. We provide a small subset of such reasons that illustrate the potential for uncertainty on the part of the employer as to whether the separating employee will be able to collect benefits. This is sufficient to explain why employers accede to wage demands of incumbent workers when the generosity of the UI system increases.

3. In Section VI.1.3 we argue that an improvement in the generosity of the UI system strengthens workers' hand in bargaining with the employer through an additional channel. Instead of the threat of outright quitting, the worker can implicitly threaten the employer to induce a firing. While workers fired for misconduct are not eligible for benefits, establishing misconduct is very difficult, in part due to the necessity of proving that misconduct was willful, and the burden of proof is on the employer. It seems likely that many employers would have little ability, resources, or economic motivation, to contest such cases in the courts. It may well be cheaper to accept workers' wage demands instead.

\section{VI.1.1 Was the Separation a Quit?}

This is not very straightforward to establish. For example, if separation is due to mutual agreement or mutual misunderstanding the worker is eligible for benefits. In particular, when both parties have a reasonable but mistaken belief of the others understanding of the separation, the claimant is not subject to disqualification. In addition, there may be a separation by mutual agreement if the employer and the employee have mutually agreed to separate, either at the time of the termination, or initially, at the time of hire. In such cases the termination is neither a discharge nor a leaving and thus a disqualification cannot arise under Section 1256.

The following Precedent Decisions illustrate: ${ }^{52}$

In P-B-253, the claimant's attendance became irregular because of poor health. Her union contract provided for a leave of absence for a maximum of two years. The claimant was carried on the employer's "absent-sick service payroll" from January to March. In March the claimant contacted her supervisor, saying she was still ill and didn't know when she would be able to return. During the course of the interview, she and the employer agreed that the claimant's separation "might be the best thing to do." Neither suggested the leave continue. In its decision, the Board said:

\footnotetext{
${ }^{52}$ Precedent decisions refer to the body of case law that is developed through the adjudicatory process at the California Unemployment Insurance Appeals Board (CUIAB) and contains the Appeals Board's definitive expression on unemployment matters. The Unemployment Insurance Code specifically authorizes CUIAB Board Members to consider, decide and designate as precedent decisions those cases that contain a significant legal or policy determination of general application that is likely to recur. CUIAB, its administrative law judges, and the Employment Development Department Director are controlled by these precedents, except as modified by judicial review.
} 
...[T]he evidence before us justifies a conclusion that the conversation ... resulted in a mutual agreement between the claimant and her employer that under the circumstances no useful purpose would be served by the indefinite extension of her then existing leave of absence. Under these facts, we hold that the claimant's abandonment of the employer-employee relationship ... was with good cause... .

Some separations appear insolvable from the standpoint of a misunderstanding between the claimant and the employer, in which each thinks the other has been the moving party in the separation. In cases such as the following, the Board has considered the separation to be neither a quit nor a discharge.

In P-B-458, the claimant had been counseled concerning his job performance some five weeks prior to the separation. On the last day of his employment, he was called to a meeting with the president and general manager. At the meeting, the claimant remarked that if he were in charge he would place the blame for slow business upon himself. The president felt the claimant had not been working to capacity, and the claimant specifically recalled that the president told him they "should part company." Shortly after that, the claimant announced that he would be leaving. The claimant cleaned out his desk and left. The employer interpreted the conversation and events as a resignation, while the claimant felt he had been discharged. In its decision, the Board stated:

The record does not sufficiently reflect that either the claimant or the employer was the moving party. We hold that where the claimant and the employer are mutually but reasonable mistaken about the other party's understanding of the separation, the claimant is not subject to disqualification under Section 1256 of the Code.

Important Caveat. In fairness, we must admit, however, that we could not find a precedent decision clarifying how a separation upon an exogenous separation shock after $78^{\text {th }}$ round of Hall-Milgrom bargaining would be treated... Separation by mutual agreement or mutual misunderstanding?

\section{VI.1.2 Can Voluntary Quitters Be Eligible for Benefits?}

As a general rule, voluntary quitters are not entitled to benefits. There are many exceptions, though, to which a worker voluntary leaving his or her job may appeal in order to receive benefits. In this section we mention some of many such reasons. The point of this discussion is that there is at least a chance, and perhaps a sizable one, that a worker might be able to collect

benefits even in the event of quitting. Even on its own, this is sufficient to explain why a more generous UI system induces a higher equilibrium wage even for incumbent workers.

1. Section VQ90 A: Conscientious objection.

When directly related to working conditions, a conscientious objection is considered to be a compelling reason for restricting availability for work or for voluntarily leaving work. Conscientious objection means an objection by an individual to performing an act that 
individual sincerely believes is wrong. The objection may be based on ethical, moral, religious, or philosophical grounds.

Title 22, Section 1256-6 (b), provides:

... If an individual has, or after working a time newly acquires a conscientious objection to the work condition or assigned work based on religious beliefs founded on the tenets or beliefs of a church, sect, denomination, or other religious group, or on ethical or philosophical grounds, an individual's voluntary leaving of the most recent work based on religious beliefs or other grounds is with good cause...

The degree to which the claimant's beliefs are commonly held or considered reasonable by others is immaterial.

2. Section 1256, VQ150:

\section{AA. All Reasonable Transportation Alternatives Exhausted}

The claimant quit your employment because of a lack of transportation. There is no adequate public transportation available and the claimant had exhausted all alternatives before quitting. Available information shows that the claimant had good cause for leaving work.

BB. Commute Time Excessive

The claimant quit your employment because of the commute time required. Available information shows that the claimant had good cause for leaving work.

CC. Moved - No Transfer Available

The claimant quit your employment to move. He/she could not have transferred to a job site nearer to the new home. Available information shows that the claimant had good cause for leaving work.

EE. Transportation Costs Too High

The claimant quit your employment because the transportation costs were too high. Available information shows the claimant had good cause for leaving work.

3. Section 1256, VQ 155

\section{AA. Compelling Domestic Obligations}

The claimant quit your employment because of domestic reasons. Available information shows that the claimant had good cause for leaving work.

BB. Moving After Marriage - Outside Normal Commute Area

The claimant quit your employment to move with his/her spouse to a place outside the normal commute area. Available information shows that the claimant had good cause for leaving work. 


\section{Moving After Marriage - No Transfer Available}

The claimant quit your employment to move with his/her spouse. He/she was unable to transfer to another worksite nearer the new home. Available information shows that the claimant had good cause for leaving work.

DD. Family Illness or Death - No Leave Available

The claimant quit your employment because of a family illness/death. Available information shows that the claimant had good cause for leaving work

EE. Unemancipated Minor

The claimant quit your employment at the insistence of his/her parents. The claimant is a minor, subject to parental control. Available information shows that the claimant had good cause for leaving work.

FF. Domestic Violence Abuse - No Reasonable Alternative

4. Section 1256, VQ235

\section{AA. Medical Advice to Quit}

The claimant quit your employment on his/her doctor's advice. A leave of absence was not available or would not have resolved the problem. Available information shows that the claimant had good cause for leaving work.

BB. Reasonable Concern for Health or Safety

The claimant quit your employment because of a reasonable concern for his/her health or safety. Available information shows that the claimant had good cause for leaving work.

CC. Failure to Take Drug Test - Employer Request Unreasonable

The claimant quit your employment because he/she was asked to take a drug test. The claimant had not previously consented to the test and there was no reasonable suspicion that he/she was under the influence of drugs. Available information shows that the claimant had good cause for leaving work.

There are many, many other reasons the worker can establish that a voluntary leave was for a good cause, including arguing that the workplace represented an intimidating, hostile or offensive working environment as illustrated by the following two Precedent Decisions.

In P-B-300, the claimant did establish real and compelling cause for her action. The claimant worked as a bookkeeper for a small insurance firm. She quit that employment because the employer repeatedly criticized her in a sarcastic manner in front of customers; some of the criticism was caused by errors made by the claimant in her work, but some criticism concerned matters not attributable to the claimant and some concerned matters wholly unrelated to the claimant's work. Occasionally, the claimant left the employer's office in tears. Three witnesses testified on behalf of the claimant. In finding the claimant eligible for benefits, the Board stated: 
... the record established that the conduct of the claimant's employer in the instant case was abusive and hostile, moreover, this conduct was repeated on numerous occasions. Under the circumstances this constituted a compelling reason for the claimant to leave her employment...

Thus, if undue embarrassment, or harassment is caused by continual criticism, in contrast to a single instance of criticism, good cause for leaving does exist. In P-B-475 the Board ruled that offensive (to the worker) behavior of sexual nature also constitutes a valid reason to leave employment because of offensive working environment.

\section{VI.1.3 Was the Discharge for Misconduct?}

As a general rule, employees discharged for misconduct are not eligible for benefits. Only those who were discharged not through the fault of their own are. The question we are interested in here is whether an employee can implicitly threaten the employer with misconduct during the wage bargaining. It appears that the answer is at least to some degree affirmative.

\section{What Constitutes Misconduct?}

For an employee to be discharged for misconduct, it has to be proven by the employer that misconduct was willful. Where the element of willfulness is missing, the claimant's actions would generally not be misconduct. For example, according to Section 1256-30(b)(3) of Title 22 , misconduct generally does not exist, because willfulness is missing, if the claimant:

- Has been merely inefficient.

- Has failed to perform well due to inability or incapacity.

- Has been inadvertent.

- Has been ordinarily negligent in isolated instances.

- Has made good faith errors in judgment or discretion.

The following sequence of examples illustrates.

1. Example - Inefficiency 1:

In P-B-222, the claimant was a pasteurizer for a large creamery. Prior to the claimant's discharge, there had been several discussions between the superintendent and the claimant in connection with the quality of the claimant's services. Although the claimant testified that his work improved after those discussions, his superintendent believed that the claimant had failed to improve sufficiently to warrant keeping the claimant. The principal complaint against the claimant appears to be a failure to pasteurize milk on occasions at proper temperatures and that the claimant at times held milk in the vats an excessive time, resulting in the milk acquiring an undesirable flavor. In one instance, about 
three hundred gallons of milk were spoiled due to improper pasteurization, resulting in a considerable financial loss to the employer. In finding the claimant eligible, the Board said:

A careful review of the entire evidence in the instant matter does not disclose, in our opinion, more than inefficiency or unsatisfactory performance on the part of the claimant... The record does not establish that the claimant wilfully or intentionally disregarded the employer's interest or that the occurrences forming the basis for the discharge were deliberate violations of standard good behavior...

2. Example - Inefficiency 2:

In P-B-184, the employer hired the claimant as a production worker after the claimant indicated that he had operated drill presses, lathes, punch presses, reamers, and similar equipment. He was assigned to work a drill press and found to be unsatisfactory. He was next assigned to a lathe and was moved from that job when he incorrectly loaded a part and wrecked a fixture which required several hours to rebuild. He was, thereafter, tried on several other jobs but failed to meet the employer's standards on any of them and was discharged about three weeks after being hired. The Board found him eligible and stated:

The record does not establish that the claimant wilfully or intentionally disregarded the employer's interests, or that the occurrences forming the basis for the discharge were deliberate violations of standards of good behavior which the employer had a right to expect of his employee.

3. Example - Inability to Perform to Employer's Standard:

In P-B-224, the claimant was employed for four weeks as a bookkeeper, and let go because the employer considered that her work was not "up to par." The Board found her eligible and stated:

We find that the efficient cause of the claimant's discharge was her inability to satisfy the employer's standards in relation to the quality of her work ... mere ineptitude is not misconduct...

4. Example - Incapable of Meeting Standard:

The claimant, a tube-bender and assembler for an aircraft manufacturer, was discharged after six years' employment because of his inability to produce an acceptable amount of work on a swaging machine. He had been assigned to this new task for only four hours when he was given a "correction interview." At this interview, he was informed that his production was 50 percent below standard and that he would be discharged unless he showed immediate improvement.

The employer contended that the claimant had deliberately "stalled" but was unable to substantiate such a statement. The claimant had performed satisfactorily on other 
operations, had even been graded "excellent" in production on other tasks. When the claimant was again assigned to the swaging machine the next workday, he refused the assignment as he knew that if he did not make the quota he would be fired. He was discharged as a result.

The claimant complied with the employer's orders when he was initially assigned to a new machine and according to the record he made every effort to become proficient in its operation. Because of his age and slight physical stature the claimant could foresee that he would not be able to operate the new machine to the satisfaction of the employer and felt justified in refusing the assignment.

In this case the discharge would not be for misconduct. The claimant was unable to meet the employer's standards because of his age and slight physical stature. It should also be noted that the employer did not give the claimant a sufficient amount of time to meet the standards (only four hours). Likewise, if an employer should fail to provide adequate equipment for doing the work or should set quantity standards so high that only the exceptional few could meet them, a failure to produce the required quantity of work would not be misconduct.

5. Example - Error in Judgment:

In P-B-195 the claimant, a cab driver, was discharged because of a traffic accident. At the time the claimant was hired, he received a course of instructions covering the company's rules and the motor vehicle laws with which he was expected to comply. Shortly after the end of the course, the claimant was involved in a minor accident when he backed into a parked car. He was warned that he would be discharged if involved in one more accident within a year. Several months later, the claimant was en route to pick up a passenger. He was driving approximately 40 feet behind another car, when he was hailed by someone on the left side of the street and glanced toward the person hailing him. He heard the screech of brakes, immediately looked to the front and applied his own brakes when he saw that the traffic in front of him had stopped. He was unable to stop before colliding with the car in front of him. The collision was observed by two police officers and the claimant was cited under Section 22350 of the California Vehicle Code. The Board found the claimant eligible and stated:

In this case, the claimant was cited under Section 22350 of the California Vehicle Code. We do not consider the fact of citation controlling in this case, but only one of the factors which we must consider in arriving at our conclusion. The quoted section of the Vehicle Code is so phrased as to allow the driver of a vehicle to exercise judgment in the operation of such vehicle. Assuming that the claimant was careless as found by the traffic officers involved, his carelessness was, at most, an error of judgment. Admittedly, it was his fault that the collision occurred. However, he was following the vehicle preceding him at a reasonable distance and erred only when he withdrew his attention from the road when he was hailed by a person on the sidewalk. It appears 
to us that the claimant's action could readily be defined as a reflex action in response to the call, especially since it was the practice of the taxi drivers to seek to identify such a person so that the company could be informed of a possible customer.

6. Example - Isolated Incident of Ordinary Negligence 1:

In Silva v. CUIAB (First Appellate Court, 1973), the claimant was being trained for new and unfamiliar work; he became nervous and frustrated and either "blew up" or felt he was going to blow up. He left work without permission in midafternoon. The employer was aware of some emotional problems the claimant was having. The employer spoke to the claimant the next morning about his unauthorized departure. The claimant's reply was sarcastic and, when told if such action was repeated he would be discharged, he responded with a vulgar remark. He was told if that was the way he felt, he could leave, whereupon he left. He would have been discharged for his attitude and language that morning had he not left. The court held:

Given the tests of fault and wilful or wanton behavior as essential elements of 'misconduct', the single instance of an offensive remark ... uttered in the circumstances disclosed falls within the category of a mere mistake or error in judgment, a 'minor pecadillo' and is not misconduct disqualifying appellant from unemployment insurance benefits.

\section{Example - Isolated Instance of Ordinary Negligence 2:}

The claimant was hired to drive his employer's new cars from a freight depot to the company's storage warehouse. The automobiles were shipped directly from the factory and were serviced as they were unloaded. The employer testified that oral warnings had been given all employees to check oil and water levels before driving the cars and that any driver who subsequently caused damage to a car would be discharged.

One of the automobiles the claimant was driving incurred engine damage because the car was driven with no oil in it. The claimant denied that he had been warned to check the oil and water levels before driving the vehicles. Additionally, there was dispute as to whether the oil gage was operating correctly.

The claimant's contented that this was an "isolated" incident and that he had acted unknowingly and without evil design or intent. Because of the dispute as to the employer's warning to check oil and water levels and the working condition of the oil gage, it cannot be shown that there was wilful negligence. The discharge would not be for misconduct.

8. Example - Action Not Willful:

In Maywood Glass Co. v. Stewart (1959), the claimant was discharged because she packed defective glassware on several occasions. The employer testified that she had been warned several times she would be discharged if she persisted. 
The claimant denied such warnings were given. The claimant stated she packed bad glassware because of the rapidity in which they were working. She also had a headache. The court held her discharge was not for misconduct and stated:

Moreover, even if the claimant had been warned, the evidence does not compel a finding that she was guilty of 'misconduct' within the meaning of the statute. Although (claimant) admitted packing defective bottles, she denied that she had intentionally done so. (Claimant) worked the 'graveyard shift' from midnight to 8 o'clock in the morning. She testified that on the night in question she was suffering from a headache and that there was a high percentage of defective glassware coming down the line. In these circumstances the trier of fact could reasonably conclude that her conduct did not constitute 'misconduct' within the meaning of the statute...

\section{Burden of Proof and Presumption of Eligibility}

Section 1256 of the UI Code provides in part:

An individual is presumed to have been discharged for reasons other than misconduct in connection with his or her work and not to have voluntarily left his or her work without good cause unless his or her employer has given written notice to the contrary to the department as provided in Section 1327, setting forth facts sufficient to overcome the presumption. The presumption provided by this section is rebuttable.

In Perales v. California Department of Human Resources Development (1973), the Appellate court held that because the presumption in Section 1256 was established to implement the public policy of prompt payment of benefits to the unemployed so as to reduce the suffering caused thereby (Section 100 of the UI Code), the presumption affects the burden of proof. To overcome the presumption the employer and the Department must prove that the claimant was discharged for misconduct in connection with his or her work by a preponderance of the evidence.

This is also the position in the following court decisions:

- In Maywood Glass Co. v. Stewart (1959), the Court stated that the employer has the burden of establishing "misconduct" to protect its reserve fund.

- In Prescod v. California Unemployment Insurance Appeals Board (1976), the Court held that the burden of disqualification is on the employer or the Department, and not the claimant.

The punch line: Proving misconduct is costly for the employer. And the employee can probably make it not worthwhile for many employers by threatening to drag the process out through multiple appeal procedures involving testimony and provision of documentation and witnesses by the employer. 


\section{County Economy, Detailed Specification}

The law of motion for county employment is:

$$
L_{t+1}^{C}\left(\Omega_{t}^{C}\right)=(1-\delta) L_{t}^{C}+f\left(\theta_{t}^{C}\right)\left(1-L_{t}^{C}\right) .
$$

and $u_{t}^{C}=1-L_{t}^{C}$.

Value Functions. The flow value for a firm employing a worker is

$$
J_{t}^{C}\left(\Omega_{t}^{C}\right)=z_{t}^{C}-w_{t}^{C}+\beta(1-\delta) \mathbb{E} J_{t+1}\left(\Omega_{t+1}^{C}\right),
$$

and the flow value of a vacant firm is:

$$
V_{t}^{C}\left(\Omega_{t}^{C}\right)=-k+\beta q\left(\theta_{t}^{C}\right) \mathbb{E} J_{t+1}^{C}\left(\Omega_{t+1}^{C}\right) .
$$

The surplus for a firm employing a worker is thus $J_{t}^{C}-V_{t}^{C}$.

The value functions for workers can be written as:

$$
\begin{aligned}
W_{t}^{C}\left(\Omega_{t}^{C}\right)= & w_{t}^{C}+\beta(1-\delta) \mathbb{E} W_{t+1}^{C}+\beta \delta\left(1-e_{t}\left(\Omega_{t}^{C}\right)\right) \mathbb{E} U_{t+1}^{C, E}\left(\Omega_{t+1}^{C}\right) \\
& +\beta \delta e_{t}\left(\Omega_{t}^{C}\right) \mathbb{E} U_{t+1}^{C, I}\left(\Omega_{t+1}^{C}\right), \\
U_{t}^{C, E}\left(\Omega_{t}^{C}\right)= & h+b+\beta f\left(\theta_{t}^{C}\right) \mathbb{E} W_{t+1}^{C}\left(\Omega_{t+1}^{C}\right)+\beta\left(1-f\left(\theta_{t}^{C}\right)\right)\left(1-e_{t}\left(\Omega_{t}^{C}\right)\right) \mathbb{E} U_{t+1}^{C, E}\left(\Omega_{t+1}^{C}\right) \\
& +\beta\left(1-f\left(\theta_{t}^{C}\right)\right) e_{t}\left(\Omega_{t}^{C}\right) \mathbb{E} U_{t+1}^{C, I}\left(\Omega_{t+1}^{C}\right), \\
U_{t}^{C, I}\left(\Omega_{t}^{C}\right)= & h+\beta f\left(\theta_{t}^{C}\right) \mathbb{E} W_{t+1}\left(\Omega_{t+1}^{C}\right)+\beta\left(1-f\left(\theta_{t}^{C}\right)\right) \mathbb{E} U_{t+1}^{C, I}\left(\Omega_{t+1}^{C}\right) .
\end{aligned}
$$

Define the surplus of being employed as $\Delta_{t}^{C, E}=W_{t}^{C}-U_{t}^{C, E}$. Also define the surplus for an unemployed worker of being eligible: $\Phi_{t}^{C}=U_{t}^{C, E}-U_{t}^{C, I}$. The laws of motion for these quantities are:

$$
\begin{aligned}
\Delta_{t}^{C, E}\left(\Omega_{t}^{C}\right)= & w_{t}^{C}-h-b+\beta\left(1-\delta-f\left(\theta_{t}^{C}\right)\right) \mathbb{E} \Delta_{t+1}^{C, E}\left(\Omega_{t+1}^{C}\right) \\
& +\beta\left(1-\delta-f\left(\theta_{t}^{C}\right)\right) e_{t}\left(\Omega_{t}^{C}\right) \mathbb{E} \Phi_{t+1}^{C}\left(\Omega_{t+1}^{C}\right), \\
\Phi_{t}^{C}\left(\Omega_{t}^{C}\right)= & b+\beta\left(1-f\left(\theta_{t}^{C}\right)\right)\left(1-e_{t}\left(\Omega_{t}^{C}\right)\right) \Phi_{t+1}^{C}\left(\Omega_{t+1}^{C}\right) .
\end{aligned}
$$

The wage is chosen to maximize:

$$
\left(\Delta_{t}^{C, E}\left(\Omega_{t}^{S}\right)\right)^{\xi}\left(J_{t}^{C}\left(\Omega_{t}^{S}\right)-V_{t}^{C}\left(\Omega_{t}^{S}\right)\right)^{1-\xi} .
$$

County Equilibrium Definition. Taking as given an initial condition $\Omega_{0}^{C}$, benefit expiration policy, and the joint stochastic process for state productivity and unemployment, we define an equilibrium given policy:

Definition Given a policy $\left(b, e_{t}(\cdot)\right)$ and an initial condition $\Omega_{0}^{C}$ an equilibrium is a sequence of $\Omega_{t}^{C}$-measurable functions for wages $w_{t}$, market tightness $\theta_{t}^{C}$, employment $L_{t}^{C}$, and value functions

$$
\left\{W_{t}^{C}, U_{t}^{C, E}, U_{t}^{C, I}, J_{t}^{C}, V_{t}^{C}, \Delta_{t}^{C}\right\}
$$

such that: 


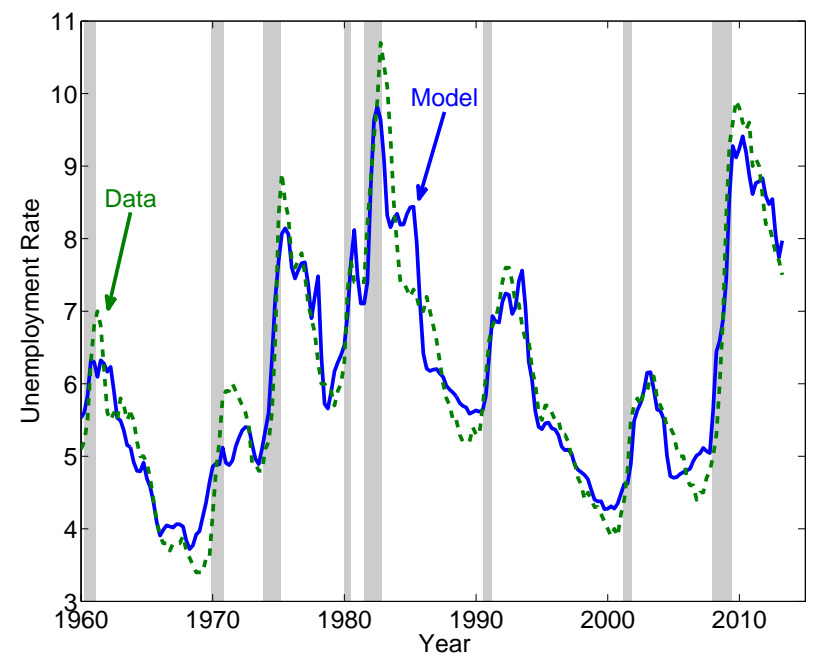

(a) The evolution of the U.S. unemployment rate

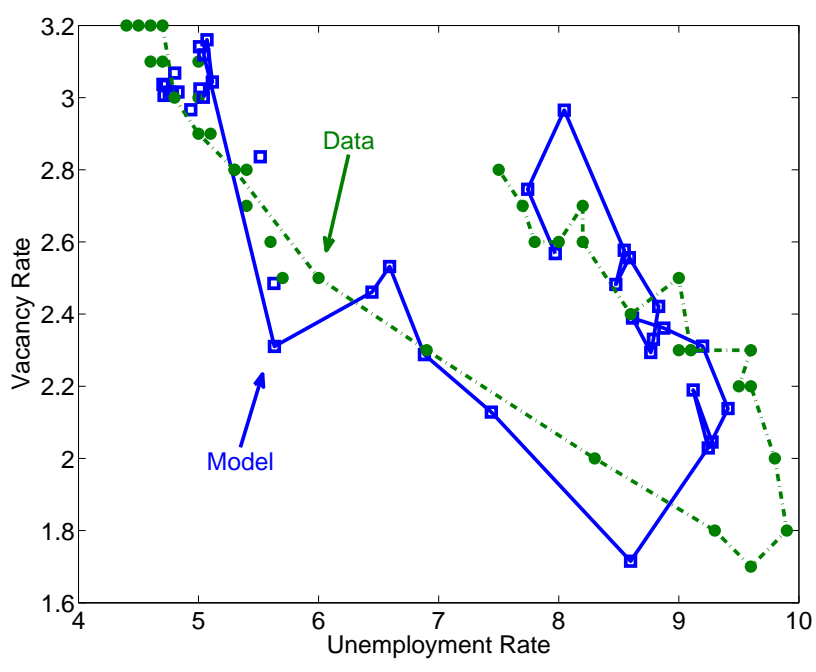

(b) The Beveridge Curve in the Great Recession

Figure A-2: Data and the prediction of the search model with unemployment benefit extensions in Mitman and Rabinovich (2013).

1. The value functions satisfy the worker and firm Bellman equations (A4), (A5), (A6), (A7), (A8);

2. Free entry: The value $V_{t}^{C}$ of a vacant firm is zero for all $\Omega_{t}^{C}$;

3. Nash bargaining: The wage satisfies equation (A11);

4. Law of motion for employment: The employment process satisfies (A3);

5. The joint process for $\left(z_{t}^{S}, u_{t}^{S}\right)$ is consistent with the state equilibrium.

\section{Implications for Macro Models}

Throughout the paper our analysis was motivated by equilibrium search models, such as Mortensen and Pissarides (1994). We found empirical support for the key mechanisms in the model. In particular, extending unemployment benefits puts an upward pressure on equilibrium wages, which induces lower vacancy posting by firms and consequently an increase in unemployment. Using a simple calibrated version of the model we found that these effects are quantitatively consistent with the data.

In this Appendix we briefly comment on the implications of our findings for the business cycle analysis using this class of models. We draw on Mitman and Rabinovich (2013), who used a version of the model in Section 5.4, calibrated to match the effect of unemployment benefit extensions on unemployment documented in this paper. They carefully model the history of unemployment benefit extensions in the US. In addition to changing unemployment benefit eligibility over time, the dynamics are driven by fluctuations in aggregate productivity. The endogenously determined dynamics of the unemployment rate in the model together with its evolution in the data are plotted in Figure A-2(a). 
The results indicate that the effect of unemployment benefit extensions on unemployment, vacancies, and wages documented in this paper is consistent with the effect of business cycle movements in aggregate productivity on these variables. Interestingly, Mitman and Rabinovich (2013) find that the automatic and discretionary benefit extensions in the recent recessions have substantially amplified the response of unemployment and served as the root cause of the widely documented phenomenon of jobless recoveries (benefit extensions are triggered when unemployment reached a sufficiently high level so that they effectively kick in after productivity is already recovering, inducing a delayed recovery of employment). This is evident in Figure A-2(a).

An important line of research, reviewed in Diamond (2013), that also aims to explain the persistently high unemployment following the great recession focused on the behavior of the Beveridge curve. As the dotted green line in Figure A-2(b) illustrates, the curve appears to have shifted out following the Great Recession. This was interpreted as implying an increase in the "structural" or "mismatch" unemployment because of the apparently high level of vacancies coexisting with high unemployment. As the solid blue line illustrates, this behavior of the Beveridge curve arises naturally in the productivity-driven equilibrium search model with the extensions of unemployment benefits as observed in the data during the Great Recession.

\section{Appendix Figures}

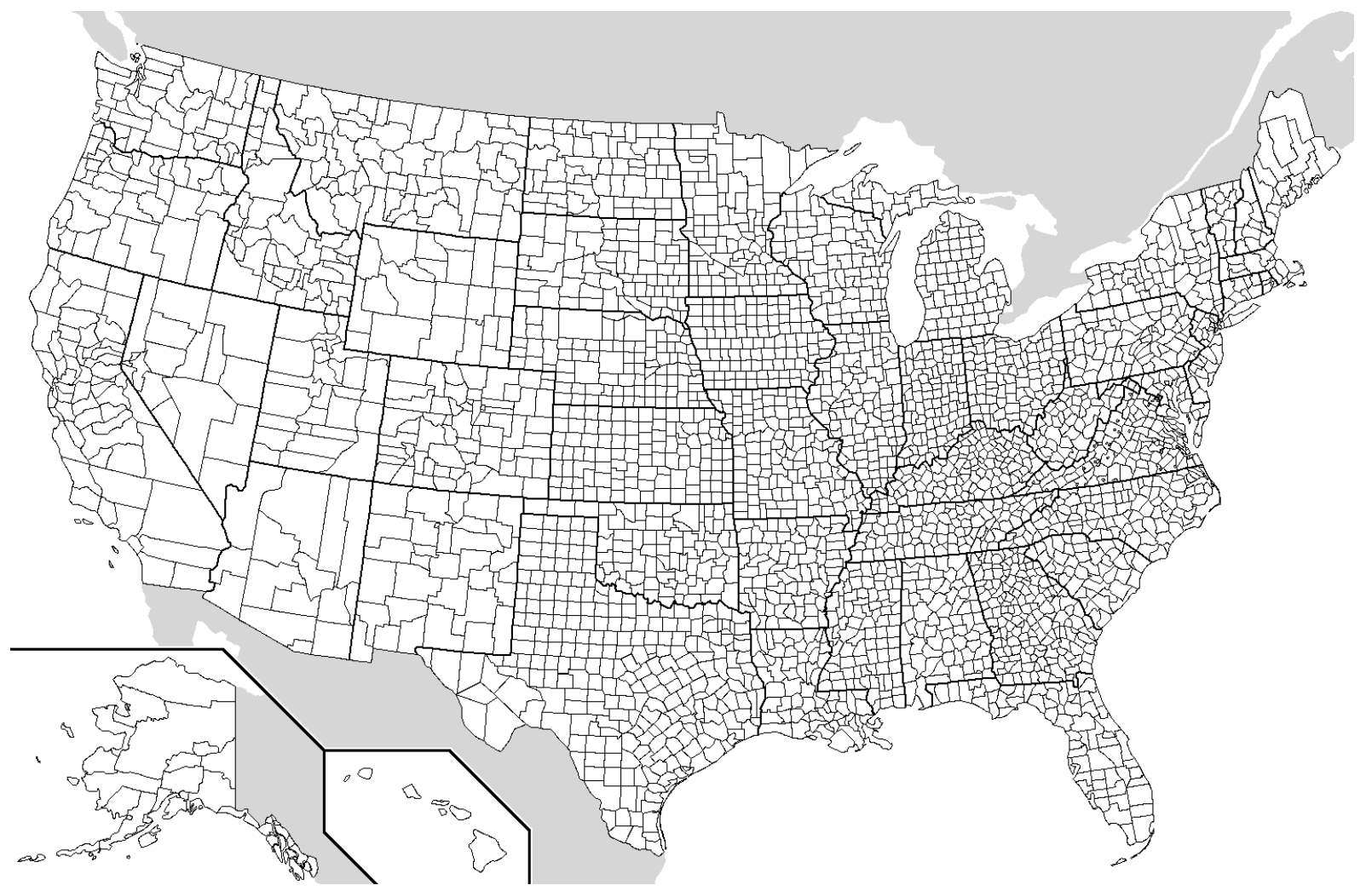

Figure A-3: Map of U.S.A. with state and county outlines. 


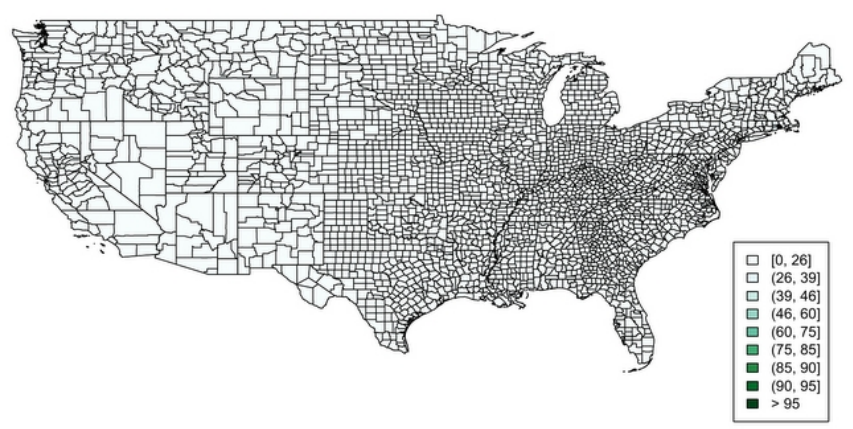

(a) June 2008

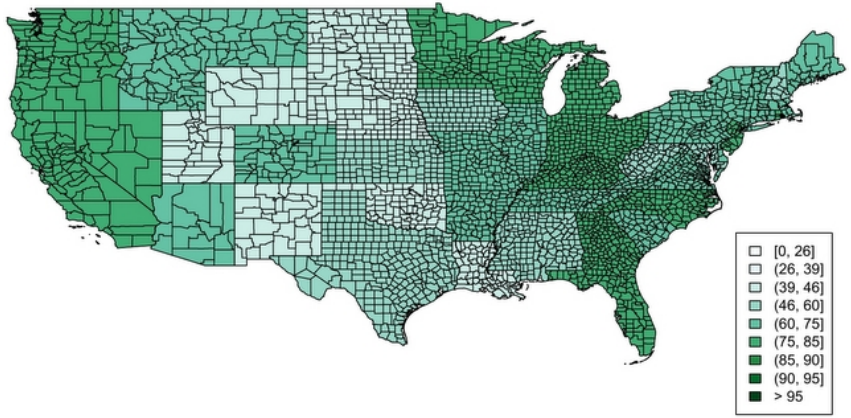

(c) June 2009 .

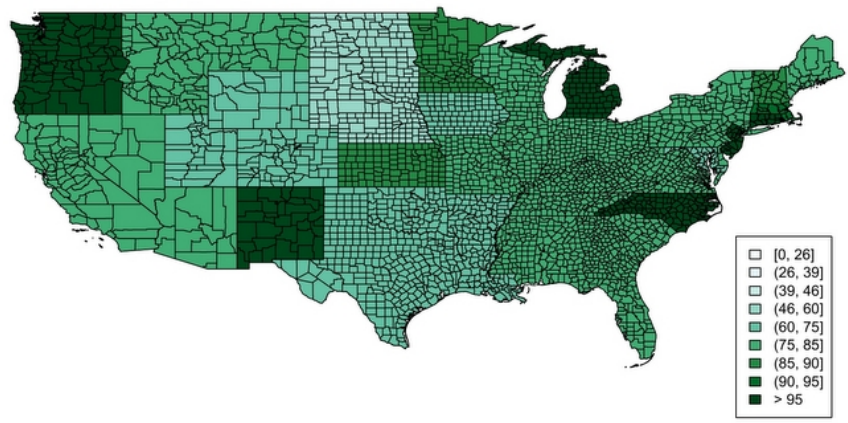

(e) June 2010 .

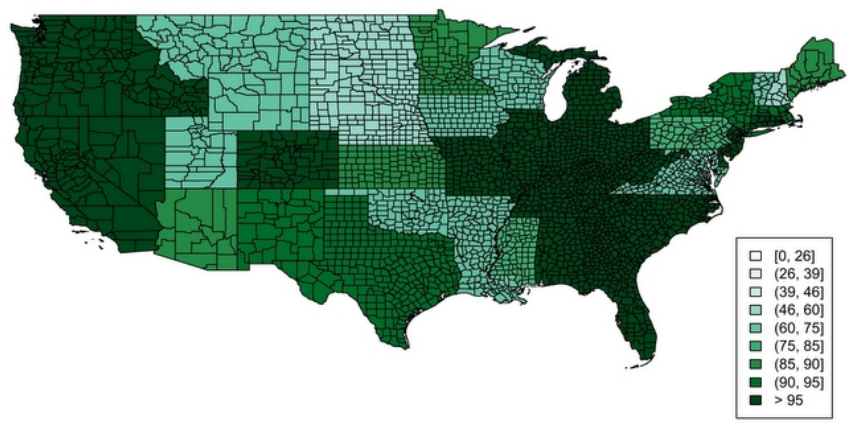

(g) June 2011.

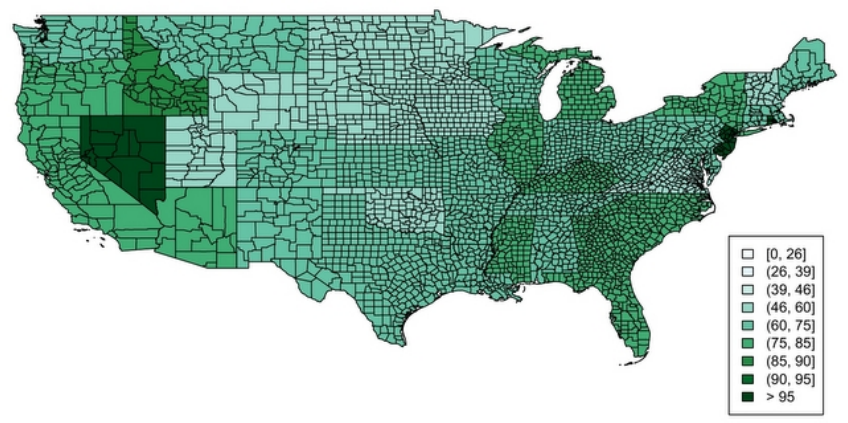

(i) June 2012 .

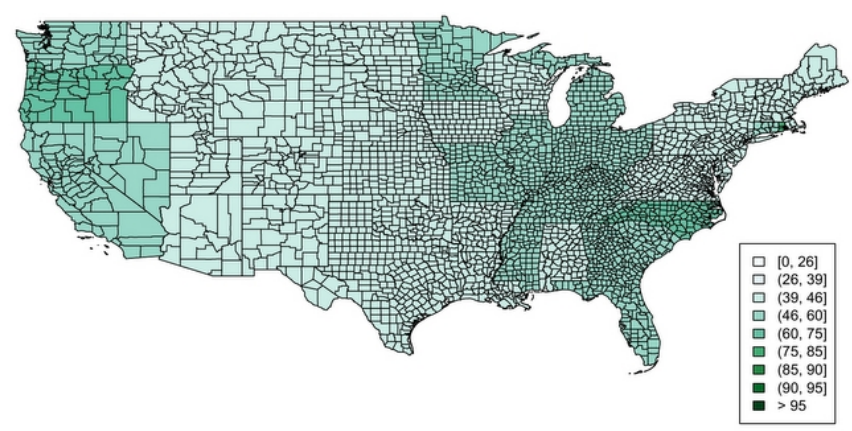

(b) December 2008.

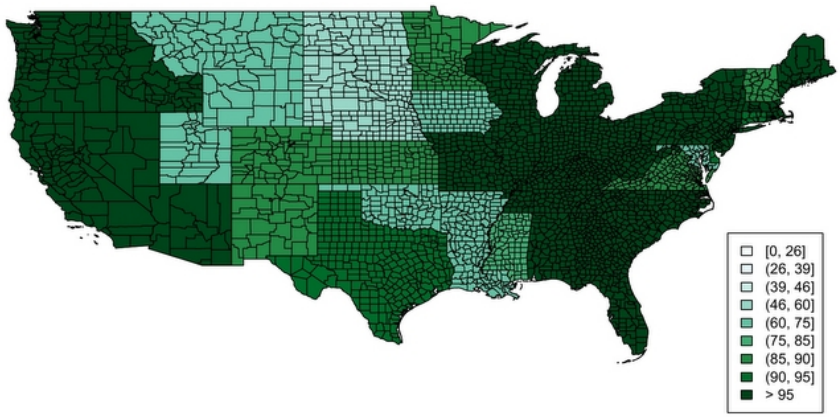

(d) December 2009.

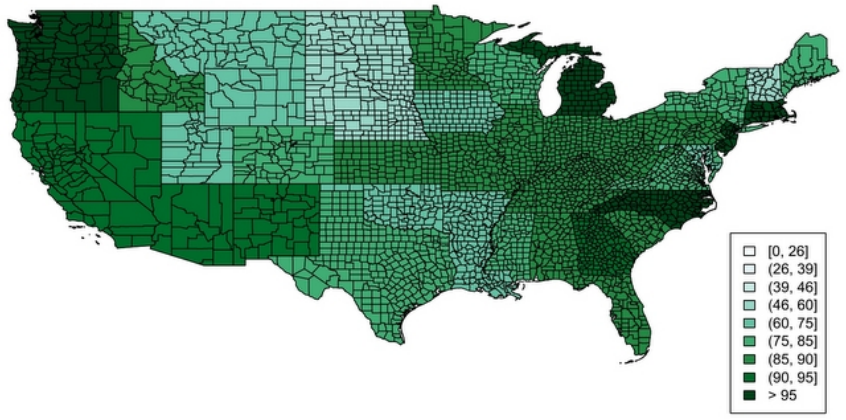

(f) December 2010 .

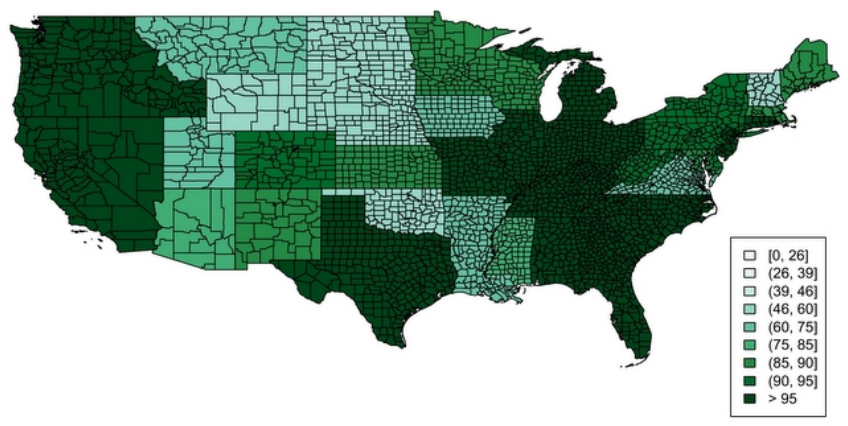

(h) December 2011.

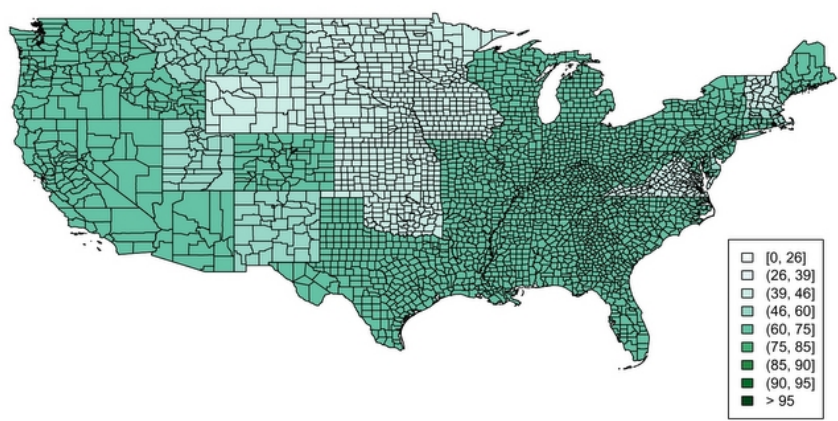

(j) December 2012 .

Figure A-4: Unemployment benefit duration across U.S. states during the Great Recession. Selected months. 